University of Louisville

ThinkIR: The University of Louisville's Institutional Repository

Electronic Theses and Dissertations

8-2011

\title{
The barriers and enabling factors to public health advocacy skills in Kentucky local health departments.
}

Joan Buchar

University of Louisville

Follow this and additional works at: https://ir.library.louisville.edu/etd

\section{Recommended Citation}

Buchar, Joan, "The barriers and enabling factors to public health advocacy skills in Kentucky local health departments." (2011). Electronic Theses and Dissertations. Paper 172.

https://doi.org/10.18297/etd/172

This Doctoral Dissertation is brought to you for free and open access by ThinkIR: The University of Louisville's Institutional Repository. It has been accepted for inclusion in Electronic Theses and Dissertations by an authorized administrator of ThinkIR: The University of Louisville's Institutional Repository. This title appears here courtesy of the author, who has retained all other copyrights. For more information, please contact thinkir@louisville.edu. 


\title{
THE BARRIERS AND ENABLING FACTORS TO PUBLIC HEALTH ADVOCACY SKILLS IN KENTUCKY LOCAL HEALTH DEPARTMENTS
}

\author{
By \\ Joan Buchar \\ B.A., Southern Illinois University, 1975 \\ M.S.Ed., Southern Illinois University, 1977 \\ M.P.H., Western Kentucky University, 2004

\begin{abstract}
A Dissertation
Submitted to the Faculty of the

School of Public Health and Information Sciences

in Partial Fulfillment of the Requirement

for the Degree of
\end{abstract} \\ Doctor of Philosophy \\ Health Promotion and Behavioral Sciences Department \\ School of Public Health and Information Sciences \\ University of Louisville \\ Louisville, Kentucky
}

August, 2011 
Copyright 2011 by Joan Buchar

All rights reserved 

THE BARRIERS AND ENABLING FACTORS TO PUBLIC HEALTH ADVOCACY SKILLS IN KENTUCKY LOCAL HEALTH DEPARTMENTS

\section{By}

Joan Buchar

B.A. Southern Illinois University, 1975

M.S. Ed Southern Illinois University, 1977

M.P.H. Western Kentucky University, 2004

Dissertation Approved on

July 26, 2011

By the following Dissertation Committee:

Richard W. Wilson

Dissertation Director

Melissa Evans Andris

James W. Holsinger, Jr.

Sheila A. Schuster 


\section{ACKNOWLEDGEMENTS}

Many people supported me through the writing of this dissertation. First, l'd like to express my appreciation to the members of my committee who gave their time and expertise generously. My committee chairman, Dr. Richard Wilson of the University of Louisville, offered calm guidance and assurance that all would be well when I had great doubts. His suggestions and patience have helped me tremendously. I am grateful that he agreed to chair both my Masters of Public Health committee and my PhD committee.

l'd like to thank Dr. Melissa Evans Andris who, despite her dual roles as professor and associate dean, agreed to be on my committee. She gave me sound advice and direction about the path to a study of which I could be proud. Her suggestions added greatly to my library and my knowledge.

I am forever grateful to Dr. James Holsinger, who started me on the path to this degree by allowing me to register for his class in the fall of 2006 . Through my relationship with him, I learned not only subject matter but how to be a mentor. He sets a wonderful example, and I am honored he is on my committee.

I would especially like to thank Dr. Sheila Schuster for her friendship, mentorship, editing and emotional and nutritional sustenance during my journey. She is an excellent editor however; her real profession is advocate extraordinaire. I've learned volumes by watching her speak for the most vulnerable populations.

I would also like to thank all the advocates, policymakers and health department practitioners who agreed to be part of my study. Their gifts of time, information, opinions and advice made this study possible.

My neighborhood family, Natalie, Jim, Pam, Jim Smith, Kathryn, Pat, Dana, Jayne and Christos kept me going with meals and encouragement. I hope to reciprocate after graduation. The cohort of students who supported me during classes, qualifying exams and dissertation writing made most of this fun.

I want to thank my parents who always supported my educational endeavors. Their sacrifice to send all of their children to parochial schools laid the foundation for our achievements. My sisters, Leanne and Marylynn 
encouraged me and cheered me on. I regret that Marylynn, who boasted that her sister would soon have her $\mathrm{PhD}$, wasn't able to live to see me finish. Thanks, Mim. Thanks, too, to Andy, Brian, Chance and soon-to-be Babyland.

My biggest thank you goes to my children. Jessica, Erin and Benjamin are my greatest cheerleaders no matter what I attempt. This achievement is theirs as well as mine. They never doubted I would finish (even though I did). They gave their love, their assistance, and most importantly, their faith in me. I hope they know that you are never too old to learn. Love of learning is one of the gifts I bequeath to them. I hope they will accept it. You know I love each of you best. 


\section{ABSTRACT \\ THE BARRIERS AND ENABLING FACTORS TO PUBLIC HEALTH ADVOCACY SKILLS IN KENTUCKY LOCAL HEALTH DEPARTMENTS}

By

Joan Buchar

July 26,2011

Background: One of the core functions of public health is to develop policies that support community and individual health. There are many historic examples in which public health practitioners have advocated successfully for policies that ultimately protected and improved populations' health. Prior research suggests that local health departments are not fully engaged in health policy advocacy, thereby missing opportunities to more effectively solve public health problems. Objective: To identify the barriers and enabling factors to advocacy in Kentucky local health departments.

Methods: Kentucky health policymakers and advocates were interviewed to determine which advocacy skills were effective and appropriate for use by local health department directors. Interviews were then conducted with 18 directors representing a diversity of health deparments from across the Commonwealth. The interviews identified which advocacy skills local health departments employed and the conditions that assisted or inhibited these skills. 
Results: The advocacy skills identified by policymakers were: research and analysis, coalition building, educating policymakers and solutions identification. Advocates agreed that research and analysis, coalitions and educating policymakers were effective. Additionally, they added lobbying and educating the public as important skills. The directors reported that the most often-used skills were: public education, research and analysis, coalition building, stakeholder engagement and educating policymakers. Based on analysis of the transcripts, the enabling factors for this advocacy were: a supportive governing body, a director with vision for the community and the organization, public health member organizations that advocated for specific policies and community partners and adequate funding for advocacy. Barriers were: a lack of support from a governing body, community attitudes regarding the role of public health, a director's lack of clarity about lobbying and advocacy, as well as the director's personality and priorities for the organization. Community partners opposed to certain public health issues also posed barriers.

Conclusions: Advocacy skills are employed in Kentucky local health departments, however barriers and enabling factors appear to exist. Steps can be taken to attempt to overcome the barriers, and the enabling factors can be communicated as models. Additional research can be conducted to verify these findings. 


\section{TABLE OF CONTENTS}

ACKNOWLEDGEMENTS ....................................................................................... iii

ABSTRACT ....................................................................................................... V

LIST OF TABLES ................................................................................................ viii

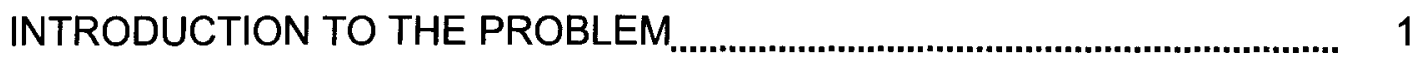

REVIEW OF LITERATURE

METHODOLOGY ........................................................................................ 52

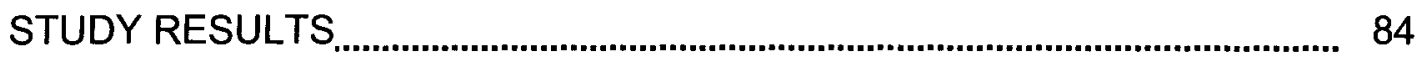

DISCUSSION, LIMITATIONS, STRENGTHS AND RECOMMENDATIONS.... 133

REFERENCES

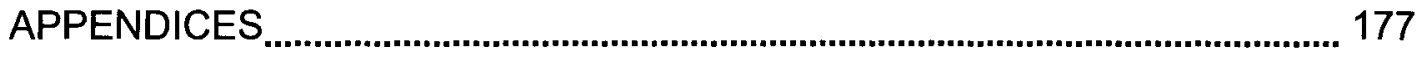

CURRICULUM VITAE ........................................................................................ 188 


\section{LIST OF TABLES}

1 Advocacy Activities by Health Educators.

2 Barriers to Advocacy by Health Educators......................................................40

3 Benefits to Advocacy by Health Educators

4 Advocacy Skills...

5 Description of Health Departments

6 Advocacy Skills Employed in Local Health Departments... 101 


\section{CHAPTER 1}

\section{INTRODUCTION TO THE PROBLEM}

\section{Introduction}

This opening chapter provides an introduction to the study. The chapter is divided into eight sections. The first section presents the framework of the study. The second section identifies the research problem the study intends to address. The third section offers the theoretical basis for the research and the objectives I aim to achieve. The fourth section presents the questions guiding the study. The fifth section presents the significance or relevance of the study. The sixth section briefly describes the methods to be employed. The seventh section delineates the limitations of the study and how this researcher plans to address each. The eighth and final section offers definitions of terms to assist the reader.

\section{Conceptual Framework}

For much of 2009 and the beginning of 2010 , the American people have been involved in or interested spectators of discussions about how to solve the escalating problems of the increasing costs of health care and the decreasing health status of our population. Although it has not been a prominent part of the discussion and debate, public health is considered a part of the solution due to its emphasis on prevention. Several of the provisions of the Patient Protection and Affordable Care Act (2010) provide funding for prevention and screening 
activities that in many communities are provided by local public health departments.

Public health is a vital part of the healthcare system and will be a health reform partner with federal and state governments, insurance companies, hospitals, private providers and the consumers of health services in solving the problems of declining health status and rising costs. This role as a health partner is not new to public health; there are precedents for this work of developing health solutions in difficult times. Public health has historically been responsible for presenting solutions to some of the world's most significant health problems such as cholera, polio and HIVIAIDS (Scutchfield \& Keck, 1997) and has "work[ed] with policymakers to translate science into practical policies" (Institute of Medicine, 2003, p. 30). In fact, public health competencies have been developed by various organizations such as National Commission for Health Education Credentialing (NCHEC), the Society of Public Health Education (SOPHE), and the American Public Health Association (APHA); and each list of competencies includes developing policies to improve the public's well being.

Several public health experts and commentators have observed that public health practitioners must be an integral part of health policy work and must make their voices heard by policymakers, (Institute of Medicine, 1988, 2003; Mail, 2006a; Northridge, 2003). This call to action can be translated to mean that public health practitioners should advocate for these health policies. If, indeed, public health practitioners should advocate for better heath policies as part of their commitment to the essential public health functions, it must be determined if 
and how this advocacy can be most effectively accomplished. The factors that enable this work can be identified so that the practice can be a model for others engaged with public health issues. Conversely, if advocacy does not occur in public health agencies, the barriers to this function can be identified in order to be overcome or avoided.

With this in mind, three issues related to public health advocacy should be investigated. First, the skills or techniques that public health practitioners can acquire and use successfully in their advocacy efforts should be identified by asking successful advocates and policymakers which skills are most effective and appropriate in effecting policy or system change that will positively impact or improve the health of the communities. Second, if advocacy skills are in use in public health departments, the attributes that enable such work should be determined. Third, if advocacy skills are not being acquired and used, the barriers to such work should be identified. The second and third issues can be identified through communication with policymakers and public health officials. My study addresses these three issues.

\section{Topic and Research Problem}

\section{Public health system.}

In its broadest sense, the American public health system consists of the public agencies that protect, monitor and provide for the public's health, as well as the private sector providers and institutions that support this effort (Badovinac, 1997; Bassett, 2003; Partnership for the Public's Health, 2007). However, most commonly, the public, and indeed some public health practitioners, focus the 
definition narrowly on only those public servants that work for state and local health departments. This study concerns advocacy in favor of policies that will protect and promote the public's health; and, according to Scutchfield, (1997) "health departments are the only entities statutorily responsible for the health of their constituent populations" (p. 4). Also, there are limitations imposed upon health departments' advocacy efforts that do not apply to private providers and others in the broader public health system. Because governmental public health practitioners' advocacy experiences differ from those of other advocates, I will limit this discussion of public health advocacy to that done by those practitioners working in Kentucky health departments.

\section{Functions of public health.}

The public health service has a long history, dating back to the health needs of ocean- and river-traveling seamen. However, in the past two and a half decades, several documents have created a new approach to the work of public health. The 1988 Institute of Medicine (IOM) report, The Future of Public Health sounded the alarm regarding the need for a more robust and organized public health system. In 2003 , the IOM directed schools of public health to prepare new practitioners with the skills needed for the future (Institute of Medicine, 2003). As a result of the 1988 IOM report and during the time between it and the 2003 IOM report, several organizations of public health practitioners developed a comprehensive list of activities all public health departments must provide for their communities. This list, the Ten Essential Public Health Services, is the foundation of the National Public Health Performance Standards used by state 
and local health departments across the nation (Centers for Disease Control and Prevention, 1994). Three of the Ten Essential Public Health Services state that a major role of public health officials is establishing or affecting public policies that protect or promote the health of local, state, national and global communities.

The Essential Public Health Services project had the support and participation of the American Public Health Association (APHA), the Centers for Disease Control and Prevention (CDC), the Association of State and Territorial Health Officials (ASTHO), the National Association of County and City Health Officials (NACCHO), the National Association of Local Boards of Health (NALBOH), the Public Health Foundation (PHF) and the National Network of Public Health Institutes (NNPHI). The ten services, collectively, elucidate the functions of public health. Services 3,4 and 5 relate to skills that lay the groundwork for system transformation through policy change or development. They are, respectively:

- Inform, educate, and empower people about health issues.

- Mobilize community partnerships to identify and solve health problems.

- Develop policies and plans that support individual and community health efforts (Butterfoss \& Cohen, 2009).

\section{Mission of public health.}

These directives are aligned with the mission of public health, which is "fulfilling society's interest in assuring conditions in which people can be healthy" (Institute of Medicine, 1988, p. 7). However, the 1988 IOM report indicated that the public health infrastructure in the United States is lagging in its ability to 
influence health policy. According to the report's authors, the state public health department should "serve the public interest in the development of comprehensive... policies by promoting use of the scientific knowledge base in decision-making about public health and by leading in developing public health policy" (p. 8).

The public health community is not the only institution charged with changing health systems. According to Caira et al (2003) "... [health] policy may sometimes be developed without input from the public health community or from the constituents it serves" but, she emphasized, "improving health by making changes in the environment requires participation in the policy process..." ( $p$. 303). Regardless of who participates in this policy work, it is commonly referred to as advocacy.

\section{Kentucky public health powers.}

The structure of the Kentucky public health system is such that each county either has its own health department or it is a member county of a multicounty district. Whether the county is part of a district, or it has a single county health department, the Kentucky Department for Public Health, located in the Frankfort, Kentucky is responsible for, "monitoring and oversight of local health department operations [and] maintaining a strong partnership with LHDs to assure a successful delivery of the "Ten Essential Public Health Services" to the residents of Kentucky" (Administrative Reference for Local Health Departments, 2011, p. 3). 
Additionally, the local departments' duties are to, "With the advice of the district board of health and the Cabinet, formulate, promote, establish, and execute policies, plans, and programs to safeguard the health of the people" ("Duties of Local Health Departments," 2005). There are currently 55 local health departments in Kentucky. Each has a governing body that must advise and supervise a director.

According to Kentucky Revised Statute 212.230 , the governing bodies have powers to, "Adopt...administrative regulations...necessary to protect the health of the people...[and] Act in a general advisory capacity to the health officer on all matters relating to the local department of health" ("Powers and Duties of County, city-county, and district health boards," 2005, p. 1). It is the duty of local health departments to promote the health of the community by establishing and executing policies as well as adopting regulations.

\section{Definition of advocacy.}

Advocacy, as defined by the technical assistance provider for non-profits, Alliance for Justice, includes "efforts to influence public policy" ("Build your advocacy grantmaking - Advocacy evaluation tool," 2005). Non-profit organizations such as public charities have used advocacy for years and clearly see the value of it as a tool to change systems. Brian O'Connell (1994) a past director of the American Heart Association and founder of Independent Sector, a leadership forum for charities and philanthropies, believes that "it is through effective advocacy [that] power is secured and used" (p. 42). The public health Essential Service 3 is to inform, educate and empower, and O'Connell states that 
"empowerment [is] to use and transfer power so that the groups in need of services secure enough political and economic power to represent themselves effectively" (p. 42).

Advocacy is also a means of connecting with others. "Defining our problems as being connected to other issues (and people) helps us to see the many ways in which we are linked together..." Advocacy can include "researching, organizing and building communications strategies" as well as "lobbying, networking and educating voters (American Heart Association, 2009).

There is no shortage of advocacy definitions. Grantmakers in Health(2005), a membership organization of philanthropies that regularly fund national and international health projects, defines advocacy efforts as including 1) research and analysis; 2) evaluation and comment on administrative and regulatory proposals; 3 ) community organizing; 4) issue framing and messaging; 5) convenings; 6) public education and information campaigns; 7) stakeholder engagement - building advocacy capacity of diverse stakeholders; 8 ) solutions identification; 9) coalition building; and 10) media advocacy (p. 2). So, advocacy skills can take many forms, but all of them contribute to speaking out for a cause, and the cause, in the case of the public health community, is the health of the population.

\section{Advocacy in curricula.}

Several professional groups such as social workers, psychologists, physicians and nurses have emphasized the importance of these advocacy skills and have developed robust training programs to improve the skills of their 
members. For instance, a Canadian Medical resident training program designed its curriculum to include skills necessary for the new physicians to be prepared to advocate for better patient policies (Flynn \& Verma, 2008). In another example, Hoefer (2005) recognized that "although social workers are experts in their jobs, few are expert in the political process" (p. 219) and recommended that social workers hone their advocacy skills in order to better serve their clients. Nurses, according to the PhD program described by Bull and Miller (2008) "develop leadership by building skills in advocacy" (p. 156). There is justification in the IOM report and surveys of other preparation programs to suggest that all public health practitioners, not just social workers, physicians and nurses, should be equipped with advocacy skills (Hearne, 2008).

\section{Advocacy in public health training.}

Indeed, in the past several years, schools of public health have explicitly detailed the competencies needed in order to achieve the goals set out by the IOM reports and the Ten Essential Public Health Services. For example, the National Health Educator Competencies Update Project (CUP) was developed during 1998 - 2004 as a monitoring tool (Gilmore, Olsen, Taub, \& Connell, 2005). Through surveying practicing public health professionals, it "addressed what health educators currently do in practice, the degree to which the role definition of the entry-level health educator is still up-to-date, and the validation of advanced-level competencies" (p. 1).

Additionally, the Association of Schools of Public Health (ASPH) (n.d.-a) has developed competencies for the Master's of Public Health (MPH) and the 
Doctor of Public Health (DrPH) degrees. Included in the competencies are several related to advancing community health policies through advocacy.

Deimers and Mamary (2008), when comparing alumni-reported skills that are needed in the public health master's program at San Jose State University with those competencies developed by the Competencies Update Project, determined that communication and advocacy for health and health education were two essential skills needed.

The Public Health Performance Standards project (Butterfoss \& Cohen, 2009) has set criteria for local health departments to meet in order to reach an optimal level of performance and continuous quality improvement. The standards are based on the Ten Essential Public Health Services and include policy and advocacy skills.

However, the Institute of Medicine, in its 1988 call to action, The Future of Public Health and then in Who Will Protect the Public's Health in 1994 identifies a discrepancy between the policy and advocacy roles public health should play and what practitioners are prepared to and actually do. With the help of health advocates and state health policymakers, I will identify the advocacy skills appropriate for and useful to the work of state and local public health practitioners, and with responses from public health directors, I will identify the barriers and enabling factors associated with the use of these advocacy skills.

\section{Rationale and Purpose of the Study}

Many experts believe that training public health practitioners in advocacy skills is desirable (Badovinac, 1997; Gebbie \& Hwang, 2000; Hearne, 2008), and 
the need for public health practitioners to be proficient in a variety of advocacy skills has been identified by a multiplicity of authors and organizations (Degutis, 2008; Demers \& Mamary, 2008; Institute of Medicine, 2003; Vernick, 1999). However, in reality advocating for good public health practice or policy can be a political endeavor with public health practitioners sometimes at odds with other stakeholders. According to the IOM report, The Future of Public Health (1988) oftentimes, public health administrators are political appointees, and this may alter the advocacy efforts of those most knowledgeable about what policy changes will make a community healthier.

Understanding what attitudes and knowledge those working in the public health system need to have in order to confidently and effectively speak out about the policies and conditions that affect the public's health is important. To achieve this outcome, it is necessary to identify effective advocacy skills necessary to advance policy changes in health, especially in public health issues. It is likewise necessary to determine which factors facilitate or enable the advocacy skills to be practiced in the field by state and local public health practitioners. Finally, in cases where these advocacy skills are not being utilized, the barriers must be identified.

\section{Guiding Questions}

There are three questions that guide this study. Each question builds upon the previous one and the sources of information needed to answer each vary. Question 1: What advocacy skills are effective and appropriate for use by public health practitioners in order to advance effective public health policies? I will ask 
experienced health advocates as well as current and former health policymakers. Question 2: What are the enabling factors that allow and assist effective advocacy by public health practitioners? And Question 3: What are the barriers that inhibit or impede effective advocacy by public health practitioners? will be identified through interviews with health department directors.

\section{Significance of the Study}

The purpose of the study is threefold. First, this study will identify, with the help of expert health advocates and policymakers, what advocacy skills can be effectively used by public health officials. Second, after identifying the necessary skills, the study seeks to identify the enabling factors that lead to advocacy by public health practitioners. Just as important, the study seeks to identify the barriers that public health practitioners most often encounter that inhibit the application of advocacy skills. By identifying these barriers, public health leaders, educators and policymakers may be able to find ways to overcome, decrease or eliminate them.

Depending on the results, this study may lead to identifying adjustment to local health department policies or education of current and future public health practitioners. By recognizing the enabling factors, these same leaders and educators can assure that all public health students, trainees and current practitioners have the competencies and motivation to enter the policy arena.

\section{Methods}

Interviews with advocates and policymakers.

In order to answer Question 1 by identifying the advocacy skills public 
health organizations can use most effectively to impact the health of their communities, two knowledgeable groups - experienced health advocates and policymakers who have served in the Kentucky legislature or Executive branch administration will be identified. In choosing the former group, I plan to select a cross section of individuals who have been involved in various advocacy activities not limited to focus on the state legislature. In choosing the latter group, every effort will be made to select past or present legislative members of the Health and Welfare Committees, past or present Cabinet for Health and Family Services staff or others that are known to be knowledgeable about matters that influence the health of Kentuckians.

I plan to conduct interviews with these individuals to identify the advocacy skills that they believe are most appropriate for local public health department practitioners to use in their work of protecting and improving the health of Kentucky communities. Utilizing the results of the interviews, I plan to develop a list of questions to be used in semi-structured interviews of health department directors or administrators from around the Commonwealth. These interviews will be conducted with the goal of answering Questions 2 and 3.

The interview questions will be designed to determine if those advocacy skills identified from the interviews of advocates and policymakers are employed by public health directors, and to identify the factors that enable or inhibit their use. The directors interviewed will be those that respond to a request extended through the Kentucky Health Department Association, a membership organization composed of most public health directors in Kentucky. All 
interviewees will be directors at one of the local county or district health departments in the Commonwealth.

I plan to conduct up to 20 interviews or to the point of data saturation when new information is no longer obtained. The content of the interviews will be analyzed to identify the common themes and responses related to the research questions.

\section{Limitations}

A goal of this study is to identify which advocacy skills are effective tools for public health practitioners to utilize in their health policy work. Additionally, this study seeks to identify the enabling factors and barriers associated with this advocacy work. Collecting accurate information through interviews will depend on asking focused questions of the appropriate people at a relatively neutral time. Kentucky's legislative sessions occur during the late winter and early spring from January until April. If interviews are conducted during this time of decisionmaking and active advocacy work, many respondents' replies may differ from responses elicited during a time of less focus on legislative activity. Therefore, I

plan to conduct most, if not all of the interviews, during the months preceding the 2011 legislative session.

Another possible limitation of this research is that selection for the interviews of experienced health policy advocates and health policymakers will be based on accessibility. That is, health advocates and policymakers will be chosen from the available pool in the vicinity of Louisville, Lexington and Frankfort, Kentucky due to the prohibitive cost of travel that would discourage 
participation by decision makers and advocates from other parts of the Commonwealth. An attempt will be made to encourage responses from advocates through statewide coalitions and informal networks of health advocates; however if this attempt is unsuccessful, this lack of diversity may influence the richness of responses.

Another factor that may limit the variety of responses collected is that health department directors and employees who choose to respond to a request for information as described may be staff of 'progressive' or forward-thinking health departments. These organizations may be more likely to apply advocacy skills in their public health work, and factors suggesting more support than barriers may be identified. In order to broaden the response pool, an appeal will be made to health department directors who belong to the Kentucky Health Department Association to assist with this study. This organization has diversity, in that most of the public health department administrators in Kentucky are members. Finally, as with most qualitative research, respondents' answers are subjective and will reflect each individual's perceptions.

Finally, although my employment should not be a limitation to this study, it is pertinent to mention that in my work as a program officer for a health philanthropy foundation, I administer funds that occasionally are granted to public health agencies. It is not unusual for potential or current grantees to be mindful of the possibility of procuring grant funding when discussing unrelated topics with a program officer. I will make every effort to continue to make clear the separation of my research as a PhD candidate and my work as a program officer for a grant- 
making organization. I will clearly communicate that the respondent's cooperation and responses will in no way affect their potential to receive grant funds from my employer.

\section{Definitions}

According to the Institute of Medicine's report, The Future of Public Health, (1988) the structure of public health agencies in the United States is variable, and in the literature, authors often have varied opinions of the form and function of public health. The following definitions are an attempt to clarify the ways in which terms are used in this study.

Advocacy, according to Wallack et al, is the "set of skills used to create a shift in public opinion and mobilize the necessary resources and forces to support an issue, policy or constituency" (1993, p. 27).

Decision makers are those people in power who establish private or public policies. They may be local authorities or state or national policymakers.

A policy is a rule that people in power establish in order to regulate behavior. Policies can relate to rules within a family, a school district, a company or a governmental unit such as a town, city, county, state or country.

Policymakers are those national, state and local authorities (whether elected or not) who make rules, regulations or executive orders with which others must comply.

Public health is the science and art of protecting and improving the health of communities through education, promotion of healthy lifestyles and research for disease and injury prevention(Association of Schools of Public Health, n.d.-b). 
The Public health community is the broad collection of individuals who contribute to the promotion and protection of the public's health. It may include providers such as doctors, nurses, mental health professionals, dentists, chiropractors, physical therapists, dieticians, educators, epidemiologists, laboratory practitioners, academic researchers and others who work to protect the population.

A Public health practitioner is a "person educated in public health or a related discipline who is employed to improve health through a population focus" (Institute of Medicine, 2003).

The Public health system is the network of providers, educators, researchers and scientists who work in the field of public health at the state, district or local level within a state or Commonwealth.

Public policy is a "guide or action to change what would otherwise occur, a decision about amounts and allocations of resources, made at any level of government" (Milio, 2001, p. 622).

\section{Summary}

This chapter introduces the topic of this research, and identifies the research questions to be answered. Additionally, the study's significance and limitations are discussed. Chapter 1 also includes a brief description of the methods planned for data gathering and definitions of important terms; Chapter 2 includes a review of the pertinent literature related to public health, health advocacy and the application of advocacy skills by public health employees. Chapter 2 also describes previous research studies that have identified advocacy 
activities in public health organizations. Chapter 3 includes a detailed description of the research methods to be used in this study. Chapter 4 will contain the results of the study's data collection and Chapter 5 will include a discussion of these results including their significance and recommendations for further study. 


\section{CHAPTER 2}

\section{Introduction}

\section{REVIEW OF LITERATURE}

This chapter reviews the pertinent literature that describes the public health system in the United States; delineates its functions and offers the evidence that historically and currently, advocating for sound health policy has been, or is, one of public health's functions. This chapter also presents how experts view the role of health department practitioners in the policy arena. Further it defines advocacy and the skills categorized as such and identifies recent research into the advocacy skills used by those working in local health departments in the United States and elsewhere.

This chapter reveals a gap in current research regarding existing conditions that help or hinder the local health department practitioners' health advocacy function. This gap reveals the need to answer the research questions posed in this study through an in-depth qualitative investigation from the perspective of local health department directors.

\section{The Public Health System}

The public health system in this country consists of private as well as public sector providers and institutions (Alpi, 2007; Badovinac, 1997; Bassett, 2003; Institute of Medicine, 2003; Partnership for the Public's Health, 2007; U.S. Dept. of Health and Human Services, n.d.; Vernick, 1999). The lead federal 
public health agency, the U.S. Department of Health and Human Services (n.d.) states that "the public health workforce includes all those providing essential public health services regardless of the nature of the employing agency" (p. v). However, most observers focus the definition of public health narrowly on those workers employed by national, state and local health departments, and much of the work of promoting and protecting healthy communities falls to these traditional public health practitioners. This may be because, according to Scutchfield and Keck (2003), "health departments are the only entities statutorily responsible for the health of their constituent populations" (p. 4). By default then, the local health department, in the minds of most observers, is public health.

In communities across Kentucky, the staffs of local health departments are usually composed of practitioners such as nurses, health educators, epidemiologists, environmentalists, dieticians, and social workers as well as support staff including clerks, finance experts, receptionists, custodians and others. Heading the local health department is a director or administrator. In large, metro health departments, this position may be occupied by a physician, but across Kentucky, it is often filled by a nurse, an environmentalist or a practitioner with experience in management and finances. Additionally, in many small health departments, several of the professional and support functions may be filled by one person (D. Chaney, personal communication with, March 17, 2010).

The Role of Public Health

The role of public health is to protect the public's health. More specifically, 
in the pivotal document the Future of Public Health (1988) the Institute of Medicine deems that a goal of Public Health is to "reduce human suffering and enhance quality of life" (p. 4). It goes on to underscore the importance of protecting populations, not individuals, by stating that public health's mission is "assuring conditions in which people can be healthy" (p. 7). Indeed, in practice, much public health work does focus on communities, not individuals. Private water sources, eating establishments, public swimming pools, communicable disease prevention, group vaccination clinics, and public education campaigns are all in the purview of the health departments.

In the 1990's, the Public Health Functions Project, a group of the major public health agencies and member organizations plus the Surgeon General of the United States Public Health Service, categorized the broad work of public health into three responsibilities or core functions: assessment, assurance and policy development (Institute of Medicine, 1988). In 1994, through the work of the Essential Services Work group of the larger Public Health Functions Project, detail was added to core public health functions, and the Ten Essential Public Health Services were developed. Since that time, most public health work is focused on these recommendations:

1. [To] monitor health status to identify community health problems

2. [To] diagnose and investigate health problems and health hazards in the community

3. [To] inform, educate, and empower people about health issues

4. [To] mobilize community partnerships to identify and solve health problems 
5. [To] develop policies and plans that support individual and community health efforts

6. [To] enforce laws and regulations that protect health and ensure safety

7. [To] link people to needed personal health services and assure the provision of health care when otherwise unavailable

8. [To] assure a competent public health and personal healthcare workforce

9. [To] evaluate effectiveness, accessibility, and quality of personal and population-based health services

10. [To] research for new insights and innovative solutions to health problems (CDC, 1994).

The assessment core function includes monitoring the community's health and diagnosing problems. The assurance core function encompasses the tasks of enforcing laws and regulations related to community health; ensuring a trained workforce that will provide needed services; evaluating these services; and serving as the safety net health care provider. The policy development core function not only means educating and empowering community members, but it also includes developing and promoting sound health policies that will result in a healthy community (Institute of Medicine, 1988).

All three of the core functions are complimentary and intersecting. The assessment function calls on public health to monitor health measures and to identify threats to community health. Assurance means that public health officials must take steps to guarantee that the threats are ameliorated and that health services are made available "through regulations or by providing services 
directly" (Institute of Medicine, 1988, p. 45). According to Rowitz (1997), there is also a direct connection between assessment and policy development. The assessment function means that public health must assess the totality of a community's health in order to study how effective and capable the health system is in addressing the needs of the public. Therefore, assessment is needed to identify which policies to develop or promote. Bassett (2003) concurs that assessment can result in activities leading to policy development because "buried in dry public health statistics is the evidence of preventable illness and death...improving population health has always been linked to action" (p. 1204). The policy development function calls for action in the form of making rules and regulations that protect and promote individual and community health -- a natural function of public health. Policy development can lead to improved systems and directives that impact the health of a whole community.

\section{An Ecological Approach to Health}

This approach to systems affecting populations is compatible with and reinforced by an accepted public health paradigm: the ecological model (Figure 1). The model is a framework that builds outward beginning with individuals, who are impacted by influences ranging from their personal environment such as close relationships and family. The framework then moves to the larger environment, namely, the communities that they are part of and ultimately to the culture and policies that affect the entire population to which the individual belongs (Dahlgren \& Whitehead, 1991). Support for incorporating this model into public health practice is broad (Institute of Medicine, 1988; McLeroy, Bibeau, 
Steckler, \& Glanz, 1988; Sokols, 1996; World Health Organization, 1986). The Institute of Medicine (2003) offers direction to the public health community in its report Who Will Keep the Public Healthy? and suggests that "addressing public health challenges requires an ecological approach" (p. 25). It goes on to say that public health practitioners must understand this approach and how the factors interact in order for them to develop more effective interventions and to inform better policies to create healthier individuals and communities.

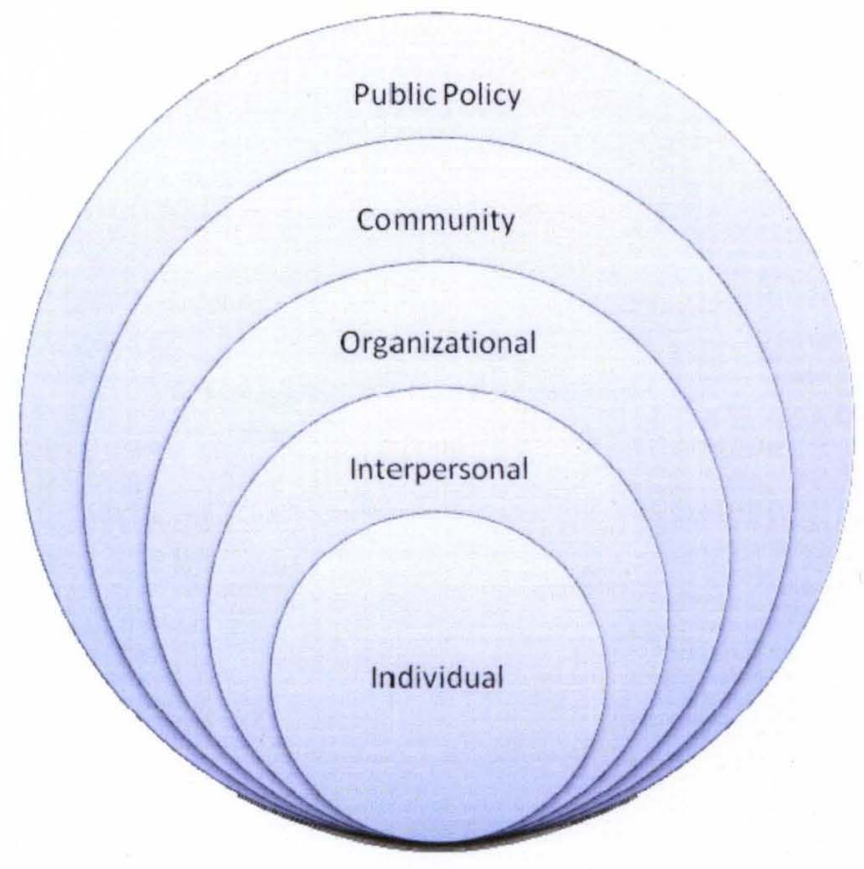

Figure 1 Socio-ecological Model

\section{Public Health Policy}

Policy, according to Acosta (2003) is "a plan or course of action selected from alternatives and intended to influence and determine decisions, actions and other matters" (p. 2). Bell and Standish define policy as the "rules by which opportunities are made. [Policy determines] what is allowed, encouraged, 
discouraged and prohibited" (2005, p. 340$)$. Policy can be private when it relates to affairs specific to a particular business, agency or institution such as a hospital, factory, or school; or policy can be public. Public policy is a "set of rules the public must follow" (Acosta, p.2). According to Meredith (2008) a policy is a rule people in power make to control what people do. It's "a decision made, carried out and enforced by government" (p. 4). When the policies are related to protecting and influencing the health of the public, these rules are public health policies.

State health departments develop policy through health planning, policy analysis and the setting of regulations, standards, health objectives and procedures (Rowitz, 2001). In the broadest sense, public health policies can include any rules, regulations, laws, executive orders or guidelines that impact the health of communities.

According to Richards and Rathbun (1997), the Constitution gives states the authority to safeguard public health through laws and regulations, and government agencies enforce these civil laws or policies. Therefore, the task of protecting the well-being of the population falls to the state and local health departments as they carry out the assurance and policy development functions by developing or advocating for policies that assure the public's health (Auld, Galer-Unti, Radius, \& Miner, 2003; Committee on Assuring the Health of the Public, 2002; Northridge, 2003).

\section{Public health policy in Kentucky.}

If all health policies were written and implemented by public health 
departments, policy development would be a less complicated function than the current system in Kentucky in which laws are often mandated by one body, the General Assembly, and monitored or enforced by another, the health departments. Additionally, much policy may impact health but is not necessarily established by law, but is established through local decisions. For instance, local agencies or bodies such as zoning boards may make land available for use as farmers' markets that provide fresh foods; and boards of education may mandate daily physical activity in the schools, or businesses may develop worksite wellness programs for their employees. Therefore, public health practitioners, in their capacity to develop and influence policy, may need to communicate with the appropriate decision makers whether they are at the federal, state or local level and whether they are legislators, local officials or business owners;

communication is exactly what several experts and planners have recommended (Auld, et al., 2003; Foege, 1994; Galer-Unti, 2009; Milio, 2001; Thomas, Sage, Dillenberg, \& Guillory, 2002).

\section{Influencing policy.}

Communication with policymakers is but one component of advocacy, a larger effort to influence policy. Advocacy, as defined by Alliance for Justice, the legal technical assistance provider for non-profits organizations, includes "efforts to influence public policy" $(2005$, p. 18). However, as indicated, not all policy is public, so advocacy is an effort to influence policy, and successful health advocacy can positively shape the environment in which people live. 
The importance of advocacy as a tool for change is supported in the literature. O'Connell (1994) states that "it is through effective advocacy [that ] power is secured and used" (p. 42). The importance of advocacy to our history is underscored by Moyer, McAllister, Finley and Soifer (2001) who write that much of the social progress this country has achieved in the past century has been done through advocacy.

\section{Public Health Advocacy \\ History of advocacy.}

There is a long record of advocacy in the history of public health (Crosier, 2009; Fee, 1997; Schmid, Pratt, \& Howze, 1995). Indeed, one of the best-known stories often related in introductory public health classes is of John Snow, an English physician, and his advocacy. Snow is credited with halting the London cholera epidemic in 1854 by appealing to policymakers to close a community well that he believed had been tainted by a polluting source. According to Crosier (2009), the "panic-stricken officials followed Snow's advice to remove the handle of the Broad street [water] pump" (p. 1), and the epidemic was halted. Although some sources suggest that the epidemic was waning at the time of his intervention, Snow's was surely a public health advocacy success.

Snow's action was followed by examples of public health successes that were initiated by health advocates. According to Fee (1997), the National Quarantine Act, as a method of disease prevention in the late 1800's, was passed at the urging of the Supervising Surgeon of the Marine Hospital (a Surgeon General precursor). In the early 1900's, a public health physician 
advocated for mosquito abatement in order to reduce the incidence of malaria that was negatively affecting the building of the Panama Canal (Kelly as cited by Fee, 1997). Additionally, record-keeping for health statistics such as birth and death is a result of public health advocacy as are campaigns for other health and safety measures such as mandatory vaccines and food inspections. Most recently, anti-tobacco regulations developed in the 1980's are a result of advocacy efforts by public health officials and the broader public health system across the nation (Elder, et al., 1997).

The changing focus of public health advocacy.

The public health advocacy efforts to promote community health by assuring safe food and water and developing efforts to prevent widespread illness are cited as public health milestones that have extended life expectancy in the United States (Pfizer, 2006). Over the years, the focus of public health promotion has shifted as the major causes of human morbidity and mortality have changed. The focus has moved from diseases which are caused by an infectious agent and can result in epidemics or pandemics to chronic illnesses that often are caused by, among other things, an individual's personal actions (Pfizer, 2006). When this shift occurred, public health focused its health promotion efforts on educating individuals in order to change their behaviors to prevent chronic diseases (Servaes \& Malikhao, 2010).

Actions at the World Health Organization (WHO) meetings in 1978 at Alma Ata, Kazakhstan and in 1986 in Ottawa, Canada broadened the health promotion focus from the individual's behavior to the community when the social 
determinants of health (education, geography, economics) were highlighted as factors significantly impacting the behavior of individuals. Health promotion by public health practitioners currently includes developing policies that positively affect the environments in which people live, work and play so that healthy behaviors can be learned and more easily practiced. The 1986 Ottawa Charter states that "Health promotion goes beyond health care...It puts health on the agenda of policymakers in all sectors and at all levels, directing them to be aware of the health consequences of their decisions and to accept their responsibilities for health" (p. 2). This charter, adopted by the World Health Organization, acknowledges that public health's role in health promotion includes policy development and change. It specifies that health organizations must pledge to "move into the arena of healthy public policy and to advocate a clear political commitment to health and equity in all sectors" (World Health Organization, 1986, p. 4).

\section{Professional organizations' support for advocacy.}

Hence, there is a history of public health advocacy as cited earlier. Moreover there is an increasing demand for public health to advocate for policies that will create environments in which positive health behaviors are enabled (Mail, 2006b; Rovniak \& Johnson, 2006; Schmid, et al., 1995; Williams-Crowe \& Aultman, 1994). The Institute of Medicine (2003) recommends that public health practitioners must be able to "inform the development of policies, laws and regulations" (p. 7). Additionally, the report predicts that "it is the well educated public health professionals who will be able to effectively shape the programs 
and policies needed to improve population health in the coming century." Holtrop agrees that the "health educator's involvement in public policy could have significant implications for improved health status" (2000, p. 134).

Public health membership organizations promote the expectation that public health practitioners advocate as part of their professional duty. The American Public Health Association has held several summits on advocacy as a health education technique (Auld, et al., 2003), and it has extensive information regarding advocacy on the organization's website that public health practitioners can access including a handbook for advocates (American Public Health Association, n.d.). Additionally, membership organizations such as the Association of Professionals in Infection Control and Epidemiology (APIC), the American Association of Health Education (AAHE) and the Society for Public Health Education (SOPHE) are actively involved in health advocacy and encourage their members to participate.

Moreover, advocacy is part of the health educator competencies developed by the Society of Public Health Educators and the Commission for Health Education Credentialing (Airhihenbuwa et al., 2005; National Commission for Health Education Credentialing, n.d.) as well as the Public Health Competencies developed by the Public Health Foundation (Public Health Foundation, n.d.).

The role of public health practitioners in advocacy.

Although there is support for advocacy in its various forms, many in the public health field state that not enough is being done by public health 
practitioners to affect health policy (Acosta, 2003; Institute of Medicine, 1988;

Mail, 2006b; Milio, 1981; Partnership for the Public's Health, 2007; Rowitz, 2001;

Turnock, 2001). Milio (1981) alleges that the right people aren't providing

policymakers with information needed to make health decisions. She asserts that

government has a "responsibility...to use its vast information-gathering, analytic, information translation and dissemination capabilities in order to design healthmaking policy options" (p. 303). Turnock (2001) agrees that policymakers are accustomed to making decisions about the health of the public with insufficient information and that "public health professionals can be a more effective part of that process" (p. 96). If public health officials are involved in advocacy for health policy, their efforts have the potential to improve the social determinants of health (Institute of Medicine, 1988) and to "make efficient use of public health budgets" (Badovinac, 1997, p. 280). According to Acosta, "the involvement of public health departments...in shaping public policy is not only possible, but also critical to protecting the health of our communities" (p. 1).

\section{Current Public Health Advocacy Practices.}

Advocacy can include "researching, organizing and building communications strategies" as well as "lobbying, networking and educating voters (University of Kansas, 2009, p. 3). The national organization of leading health philanthropies, Grantmakers in Health, has compiled a list that various funding organizations use as a guide when directing grantees' potential advocacy activities. The list includes research and analysis, evaluation and comment on administrative and regulatory proposals, community organizing; issue framing 
and messaging; convenings; public education and information campaigns; stakeholder engagement; building the capacity of diverse stakeholders; solutions identification; coalition building and media advocacy (2005).

\section{Coalition building.}

Many believe that not enough expert public health advocacy is guiding public policy despite support by professional public health associations. However, there are examples of public health involvement in many advocacy strategies although, at times, it is not identified as such. For instance, coalition building is a model of community organization and a strategy in several models of community building (Minkler \& Wallerstein, 2006), as well as an advocacy skill (Grantmakers in Health, 2004, 2005). Public health practitioners build coalitions to confront social issues and to promote disease interventions such as antitobacco efforts, lead screening, and HIV prevention (Klitzman, Kass, \& Freudenberg, 2006; Rowe, Roe, Carpenter, \& Sibley, 2000; Seamans, 2010). Coalitions are used in local health departments as system change agents using collective action to put power behind a cause (Wandersman, Goodman, \& Buterfoss, 2006).

\section{Engaging stakeholders and convening.}

Stakeholder engagement and convenings are two other advocacy skills local health departments utilize in order to earn the trust and support of communities as well as to move health policy toward enactment. El Askari and Walton (2006) convened stakeholders as part of the Healthy Neighborhoods Project in Contra Costa County and Berkeley California. Additionally, Hancock 
and Minkler (2005) describe several approaches local health departments take to bring stakeholders together in their community work such as McKnight and Kretzman's Asset Based Community Development model (2005) or the Planned Approach to Community Health (PATCH) model of identifying a population's health issues (CDC, 2010).

\section{Media advocacy.}

Media advocacy also is a tool that public health practitioners have used to develop news items in such a way that the stories may create public support for policies. This framing and messaging In fact, is a skill often used by advocates. Some smoke-free advocates credit their media efforts for the progress made to promote smoke-free workplaces and smoking cessation (Burris et al., 2010; Klitzman, et al., 2006; Minkler \& Wallerstein, 2006; U.S. Office of Special Counsel, n.d.).

\section{Policymaker and public education.}

Yet another advocacy technique, educating the public and policymakers about health issues, is a practice that has long been a public health activity. Public health practitioners share data and other pertinent information with the public and policymakers regarding the causes of a disease and the policies that can be put in place to prevent disease (Goldstein, 2009).

\section{Legal advocacy.}

Legal advocacy, too, has been used for decades to make policy and to change environments. The actions of the New York Board of Health that led to pure water, better ventilation of living space and refuse removal were the result 
of legal action (Silver, 2010). Today, the courts are used in local public health most often to enforce a public health law or regulation. The American Society of Law, Medicine and Ethics (n.d.) recently sponsored a conference promoting legal avenues to improve public health in areas such as obesity prevention, flu epidemic preparation, injury prevention and health information. Additional ways public health practitioners can advocate is by educating the judiciary at their professional seminars as well as by acting as expert witnesses. Public health practitioners can also present briefs the court and monitor court proceedings (Kromm, Frattaroli, Vernick, \& Teret, 2009).

\section{Lobbying.}

Participation in lobbying as an advocacy function of public health departments is a subject of discussion and debate. The literature discusses the appropriate role of public health workers in some advocacy activities (Regidor et al., 2007). Acosta (2003) states that "some form of lobbying or advocacy is essential for creating policy changes that improve the health status of our communities" (p. 6). Even those who question the correctness of public health advocacy due to its inclusion of lobbying, concede that educating policymakers is appropriate (Vernick, 1999).

\section{Policy advocacy in communities.}

Additional examples of advocacy leading to policy change include the work that Cheadle et al (2008) describe in which health departments and communities appealed to schools to change policies regarding their vending machine contents. In 2005, Kentucky health department educators and others, in 
an effort to combat the growing problem of childhood obesity, personally appealed to state legislators to mandate better school nutrition through legislation. The result was Senate Bill 172 known as the Junk Food Bill. This law mandates improved nutrition offerings for Kentucky children attending public schools. Although the actual lobbying was done on personal time, in the months leading up to the bill's passage, public health practitioners used a variety of advocacy skills when they convened stakeholders; educated the public and policymakers; and used media and research to promote the bill's passage (C. Dennis, personal communication, June 2, 2010).

Another topic in Kentucky is the issue of smoke-free workplaces. A new, unpublished study suggests that policymakers considering smoke-free regulations respond positively to input from local boards of health (Rayens, York, Adkins, Kaufman, \& Hahn, 2011).

\section{Level of public health advocacy.}

The literature presents examples of advocacy in the public health system but the question arises - why are some public health practitioners advocating for health policies while others are not despite the fact that policy making is an essential public health function? Fear of speaking up is one reason (Chapman, 2004; Institute of Medicine, 1988). Lack of time and funding are also identified as barriers (Deokar, Mattingly, \& Phillips, 2009; Holtrop, et al., 2000; Thompson, Boardley, Kerr, Greene, \& Jenkins, 2009). An ambitious effort to unite communities and public health in advocacy efforts in California, the Partnership for the Public's Health (2007) found the lack of flexibility and the health 
department's categorical funding were barriers to advocacy efforts. Additionally, Weed and Mink (2002) state that, in the case of public health epidemiologists, many see themselves as "scientists whose responsibility to the public is no more than that of a...private citizen" (p. 67). Another reason asserted by Rowitz (2001) is that advocacy by public health practitioners has been viewed as "too paternalistic" by the communities served (p. 132).

To protect the public's health it may be necessary to advocate for policies that affect the determinants of health, such as healthy environments, safe communities and adequate access to healthful food, physical activity and quality health care. Indeed, Scutchfield reminds us that "public health is based in social justice and equity" (2003, p. 4). Perhaps the most compelling argument in favor of advocacy is put forth by Foege (1994) who poses a hypothetical question regarding the critical need for public health advocacy: "what if public health people had taken a strong stand on tobacco when it first became obvious [in 1930 's] that this was a health problem...Imagine what could have happened if decision making was based on public health evaluation" ("What If We Could See the Future" para. 2).

\section{Current Studies of Local Health Department Advocacy}

Although there is discussion in the literature regarding the role of public health workers in advocacy, few studies investigate the level of activity. The sparse research into the actual practice of advocacy supports the fact that there is a less- than-robust public health advocacy culture. Two of these studies (Holtrop, et al., 2000; Thompson, et al., 2009) take a broad view of advocacy by 
including voting as an advocacy activity. The third study, conducted by Deokar et al (2009) identify the advocacy skills employed by health education staff as part of their professional duties. The authors described several examples of the advocacy skills cited above - those identified by Grantmakers in Health (2005).

\section{Survey of health educators.}

Holtrop et al (2000) surveyed health educators in 1995 to identify what level and type of public policy activities they were involved in and what their perceptions were regarding their involvement, knowledge and efficacy in public policy. The researchers used the membership lists of major health education organizations as well as the 1995 directory of the certified health education specialists to randomly select 700 individuals that appeared to have health education as their major job duty. Survey respondents that did not meet the established criteria were eliminated from the data set.

The researchers used a two-stage mailing procedure that included an uncoded survey, a cover letter and a stamped return-addressed envelope. The second letter included underlined text that asked the receiver not to respond if they had already returned a survey. The 18-item survey was developed to identify demographic and background characteristics and to discover the level and type of policy activity health educators were involved in during the previous two years. It also sought to identify the perceived barriers and benefits of the policy work. The respondents' self-assessed knowledge, interest, and exposure to public policy were also surveyed. 
The authors defined public policy as any policy that involves the expenditure of public funds. The survey questions did not specifically ask about health policy, but the researchers assumed many of the respondents worked on health policy. They also did not differentiate between the policy work done privately as an individual and that done as a professional. However, respondents were asked to quantify how much time was devoted to professional policy work as well as to non-professional activities. The self-reported level of involvement was rated on a Likert scale, and public policy work was indicated by the number of activities the respondent reported. The activities, barriers and benefits were chosen from the lists of activities in Tables 1, 2 and 3, respectively.

Of the 700 surveys mailed, 356 were accepted for inclusion. The sample was $79.3 \%$ female, $86.9 \%$ were Caucasian; $47.5 \%$ had master's degrees; and $28.9 \%$ had PhD's or other terminal degrees. The largest percentage of respondents, $31.6 \%$ reported that they worked in academia; others worked in local government $(17.9 \%)$; or in a medical $(10.8 \%)$ or government setting $(9.4 \%)$. The average age was 41.3 years $(S D=10.1)$. A mean of $4.84(S D=3.16)$ policy participation activities was indicated by health educators. Thirty-six percent $(36 \%)$ indicated that they were involved in two or fewer activities. The mean selfrated level of involvement was 2.54 on a scale of $1-5(S D=1.22)$. There was a positive correlation $r=.82 p<.001$ between the self-rated level of involvement and the number of activities in which the health educators were involved. 
Table 1. Advocacy Activities by Health Educators

Activities

Voted

Contacted a public official

Provided policy-related information

Worked on a coalition

Gave money

Provided technical assistance

Analyzed policies

Used mass media

Worked on a campaign

Lobbied

Testified at a formal hearing

Protested or demonstrated

Drafted legislation

Volunteered

Involved in a policy-related lawsuit

Elected or appointed as a public official

Source: Holtrop, 2000 
Table 2. Barriers to Advocacy by Health Educators

Barriers

Lack of time

Other priorities

Frustration with the process

Lack of money or other resources

Policymakers' attitudes/values

Lack access to key individuals

Can't be involved due to employment

Confronting others with opposing vies/large fund influence

Lack of support

Other reasons

Takes too long to see difference

Uncertain outcome

Probably won't make a difference

Source: Holtrop, 2000 


\section{Table 3. Benefits to Advocacy by Health Educators}

Improved health of public

Improving a situation or issue

Making a difference in others' lives

Affecting many at once

Personal gratification

Being able to get involved/participate

Potential to get needed resources

Being able to have people comply

Other benefits

Source: Holtrop, 2000

Health educators who were older, male and working in a government setting were more likely to rate themselves as being more involved in public policy. Ninety-eight percent of the respondents indicated there was at least one barrier to their advocacy. The average number of barriers reported was 3.19 (SD

$=1.71)$. The most common barrier mentioned was lack of time (69.4\%). It was followed by: other priorities (43.3\%) and frustration with the process (39\%). Only $19.3 \%$ said they could not be involved due to employment. Those respondents who were more involved in policy work reported more barriers.

\section{Benefits to advocacy.}

The average number of benefits reported was $4.1(S D=1.75)$. The perceived benefits to public policy work were improving the health of the public 
(85.5\%), improving a situation or issue $(79.5 \%)$ and making a difference in others' lives $(72.6 \%)$. There was also a significant relationship between the number of benefits indicated and the number of public policies reported $(r=.38$ $p<.001)$. There was also a relationship between level of involvement and number of benefits $(r=.4 p<.0001)$. According to the study, almost half $(49 \%)$ of those surveyed said their public policy work was done through their work as a health educator. Those working for government were more likely to be involved in policy work than those working for universities or colleges.

Using the self-efficacy theory, which consists of efficacy expectations, outcome expectations and outcome value, the authors sought to predict public policy involvement (Bandura as cited in Holtrop, et al, 2000). Using a range of 15 in which a higher score indicates greater efficacy, respondents reported the most confidence in voting $(M=4.8 \mathrm{SD}=.61)$. The activity next highest in efficacy was contacting a public official $(M=4.39 S D=.93)$ followed by providing policyrelated information $(M=3.71 S D=1.12)$. Those responding were less confident in providing technical assistance $(M=3.63 \mathrm{SD}=1.22)$; organizing, working on a campaign $(M=3.31 S D=1.32)$; lobbying $(M=2.81 S D=1.26)$; and holding public office $(M=2.42 S D=1.27)$. They felt they made the greatest impact through voting $(M=4.0 S D=1.01)$; organizing $(M=3.96 S D=.84)$; holding public office $(M=3.86$ $S D=1.05)$; contacting an official $(M=3.63 \mathrm{SD}=.95)$; providing information $(M=3.62$ $\mathrm{SD}=.82)$; lobbying $(\mathrm{M}=3.59 \mathrm{SD}=.9)$; and working on a campaign $(\mathrm{M}=3.54$ $\mathrm{SD}=.88)$. A positive relationship $(r=.49) p<.001)$ was found between efficacy expectation and self-reported levels of involvement. Positive but not strong 
relationships were found between the other two variables outcome expectation $(r=.35 p<.001)$ and outcome value $(r=.35 p<.001)$.

\section{Survey of health commissioners.}

In another study, Thompson, et al (2009) sent surveys to 700 health commissioners randomly selected from the National Association of County and City Health Officials (NACCHO) database. The authors sought to identify the advocacy efforts and the level of health policy activity of the health commissioners. The survey tool used was the same as that developed by Holtrop et al (2000) to identify the advocacy activity of health educators. A page of demographic information was added to the survey that included region of country (Midwest, East, West, South) political affiliation, gender, age, and employment setting (city health department, county health department, tribal health organization, other). The research was conducted in the fall of 2007. The researchers sent the surveys in three waves. Each first-class mailing included a hand-signed cover letter and a return-addressed, stamped envelope.

Fifty-two of the surveys were undeliverable and, of the remaining 648 delivered surveys, 327 were returned completed, yielding a $50 \%$ response rate. The demographic information identified sixty percent of the respondents as female, and $88 \%$ white. The mean age of the respondents was 52 . The educational preparation of the commissioners was nursing (27\%); heath education or public health (17\%); environmental health (12.5\%); business $(12 \%)$; and medicine $(11 \%)$. Less than $1 \%$ of the respondents had any training in 
epidemiology, biostatistics, animal science or veterinary medicine. Only $5 \%$ were certified as health education specialists (CHES).

Responding to the question of whether or not they were involved in public policy work, only $15 \%$ indicated that they had been very involved in the previous four years. However, $25 \%$ said they were somewhat involved. When asked what activities they participated in to influence public policy, they responded that they voted $(84 \%)$; contacted policymakers $(76 \%)$; or provided policy information to consumers or other professionals (65\%). Other activities included were: analyzed policies $(63.1 \%)$; created or worked on a committee $(58.4 \%)$; worked on mass media or public events (43.7\%); gave money to a campaign (34.8\%); elected or appointed a public official (25.8\%); testified or provided research (222\%); or drafted legislation (17.2\%). The least-cited advocacy efforts were lobbying policymakers $(11 \%)$; demonstrating in public $(8 \%)$; or volunteering for a public official $(6 \%)$. A positive correlation $(r=.71, p<0.0)$ was found between the level of involvement and the amount of policy-making activities. Male commissioners were more likely to be involved in public policy activities than were female commissioners. Their mean score was $3.4(S D=1.2)$. The mean for women was $2.9(\mathrm{SD}=1.1)$. There was no significant difference by race, political affiliation or type of work environment.

\section{Barriers.}

The barriers mentioned by the commissioners were: time (64\%); other priorities (46\%); lack of money and other resources (41\%); frustration with progress (30\%); and lack of support (25.7\%). Thirty-two percent said they 
couldn't be involved due to their employment. The fewest barriers indicated were ineffectiveness of the advocacy $(4.0 \%)$ and the uncertainty of the outcome $(5.3 \%)$. Twenty respondents $(6.2 \%)$ reported that there were no barriers to their advocacy.

When asked about their own ability to advocate, using a 5 point Likert scale, the commissioners indicated they were most well-trained to vote $(M=4.8$ $\mathrm{SD}=.54)$; contact a public official $(\mathrm{M}=4.8 \mathrm{SD}=.99)$ and then to provide information about a proposed policy $(M=4.0 S D=.97)$. The least self-efficacious tasks were: lobbying $(M=2.9 S D=1.3)$; working on a candidate's campaign or a campaign for a proposal $(M=3.0 S D=1.3)$ and organizing people into committees or coalitions $(M=3.3 S D=1.21)$.

Interestingly, the respondents indicated that the advocacy methods that had the most impact on public policy were voting $(M=4.0 S D=1.03)$; and organizing people for action ( $M=3.8 \mathrm{SD}=2.4$ ). The other methods (providing information about policies; providing written reports; consultation or research; contacting a public official and working on a campaign for a candidate or a proposal) were thought to have only slightly less impact.

When asked about their interest in influencing public policy, $37 \%$ reported that they were interested, and only $2 \%$ said they were not interested. Their selfrated level of knowledge of how to change policy was based on the 1-5 Likert type scale. Fifteen percent (15\%) rated their knowledge as excellent; $41 \%$ said they had a good level of knowledge; $11 \%$ rated their level of knowledge as fair and $6 \%$ reported their knowledge level was poor. When asked about their 
personal involvement in public policy work, $69 \%$ said they did not affect public policy in their professional capacity and $65 \%$ said they didn't affect public policy in their private lives. A social norms assessment question was posed about other public health practitioners' involvement in advocacy or policy work. Seventy-nine percent of the commissioners said they knew another health commissioner who was involved in public policy; $14 \%$ said they did not and $6 \%$ were unsure. Only $56 \%$ of the commissioners stated their knowledge of policy matters was either good or excellent, and those who identified the most barriers were also the most involved in policy work.

According to the researchers, health commissioners have little understanding of health policy, and what knowledge they do have is gleaned from conference sessions. They point out that, "efforts should be focused on increasing their level of involvement by increasing knowledge about the public policy making process, removing perceived barriers and increasing awareness of perceived benefits" (Thompson, et al., 2009, p. 245). They recommend that schools of public health prepare public health practitioners to participate in advocacy and policy initiatives and, furthermore, that an organization such as $\mathrm{NACCHO}$ should provide training via webinar to those commissioners currently working in local health departments. The researchers also state that those who cited lack of time as a barrier often use it as an excuse not to do policy work. They express the belief that some lack of involvement may be due to perceived deficiencies in the commissioners' advocacy and policy skills, lack of training to perform these skills, and decreased self-efficacy in performing these skills. The 
authors conclude that "health commissioners are in a unique role to influence public health policy efforts [and] should be focused on increasing their level of involvement by increasing knowledge about [the] public policy making process, removing perceived barriers, and increasing awareness of perceived benefits" (Thompson, et al., 2009, p. 245).

\section{Survey of Kentucky public health educators.}

As a final project for the Kentucky Public Health Leadership Institute, Deokar et al. (2008) surveyed health educators and health education coordinators and directors working in local health departments in Kentucky. The goals of the study were to identify the advocacy skills health educators utilized as part of their work; to identify barriers to advocacy and to identify any "education or training that health educators needed in order to influence health policies" (2009, p. 9).

The surveys were created and sent electronically through the Survey Monkey website in December, 2008, with the site available for response for four weeks. In addition to demographic information regarding the length of time in public health and educational preparation, the survey questions determined the respondents' level of involvement in influencing health policy; the advocacy efforts they had or planned to perform; and what they thought would increase advocacy activity.

Of the 125 who received the survey, 102 completed it for a response rate of $81.6 \%$. Forty-seven percent of the respondents indicated that they had a fouryear or graduate degree in health education, health promotion or another public 
health concentration. The remaining $53 \%$ responded that they had some postsecondary education or had completed an undergraduate or graduate degree in a non-public health field. Regarding their experience in health policy, $22.1 \%$ said they were "very involved"; $31.7 \%$ reported that they had mid-level involvement and $7.7 \%$ said they were not involved in health policy. The most often-cited areas of involvement were tobacco prevention (67.3\%); physical activity (47.1) and school wellness $(42.3 \%)$. Those currently involved in advocacy identified the barriers to their work as: lack of funding (53.7\%); lack of time (48.4\%); lack of community interest (42.9\%); and lack of knowledge about policy and environmental change $(22 \%)$. Three percent $(3 \%)$ indicated that there were no barriers to their advocacy and $19.8 \%$ "believed that government employees are permitted to engage in activities that influence health policy" (Deokar, et al., 2009 , p. 10). Additional responses from this group indicated that $15.4 \%$ felt that their supervisor discouraged or prohibited advocacy; and $8.8 \%$ said it was not in their job description.

\section{Barriers.}

Of those respondents who were not involved in advocacy, the most oftencited barriers were lack of funding $(42.9 \%)$ and lack of time $(42.9 \%)$. Other barriers cited were lack of knowledge of policy and environmental change (28.6\%) and that advocacy was not part of the job description (28.6\%). When asked what would support their involvement, respondents said training $(78 \%)$; time (67.3\%); community support (67.3\%); and supervisor support (52.5\%). When asked what needs existed, their responses included: clear advocacy 
guidelines for public health employees (71.6\%) and mentorship (59.5\%). Training needs cited were: marketing information; media advocacy; how to conduct public education and information campaigns; assistance with issue framing and messaging, solutions identification; how to evaluate administrative and regulatory proposals; definitions and examples of health policies; better understanding of the difference between advocacy and lobbying; knowledge about how a bill becomes a law; how to provide consultation and educate opinion leaders or policymakers; conducting stakeholder analysis; convening forums; community organizing techniques and coalition building; and how to conduct advocacy over the web.

\section{Need for qualitative data.}

Although these three studies inform our knowledge of the health policy advocacy done by local health department staff, the small number of studies indicates how little attention has been paid to this topic. Additionally, because all of the studies cited used a quantitative method and surveyed those questioned, there is a lack of qualitative information that may yield a clearer view of what enables or inhibits public health officials' advocacy endeavors. Holtrop et al. (2000) stated that their study is "broad and general in nature, as to serve as a beginning point in the understanding of this topic" (p. 136). Thompson et al. (2009) indicated that a limitation of their study is the forced choice format that a survey approach offers.

The studies described above reported the advocacy activities and barriers to advocacy that public health practitioners participated in and experienced, but 
little emphasis was placed on what enables the advocacy that was occurring. Deokar, et al. (2009) identified conditions that may enable advocacy work, and Holtrop et al (2009) hypothesized that self-efficacy is related to policy involvement. However research into what conditions enabled the advocacy work of those public health practitioners currently working in local public health departments was needed. My study took an in-depth look at the advocacy skills local health department directors apply in their work as the county or district public health leaders in Kentucky. Using semi-structured interviews, the directors were offered an opportunity to describe the activities that public health practitioners use in the course of their work and to identify those circumstances that enable or inhibit their advocacy work.

\section{Conclusion}

This chapter reviews the literature regarding the critical role of public health in policy development that improves and protects the health of individuals and their communities. The literature identifies the core functions and essential advocacy skills that are necessary to support that effort. While there is a history of public health practitioners advocating for policies that are in the public's best interests, there is scant research into public health advocacy practice. This review of literature and examination of the few studies describing public health advocacy provide a beginning understanding of the factors that enable or inhibit public health practitioners' advocacy work. There clearly was a need for qualitative investigation into the barriers that inhibit the performance of advocacy 
skills and the enabling factors that promote advocacy activities. Chapter 3 will describe the methodology that framed this investigation. 


\section{CHAPTER 3}

\section{METHODOLOGY}

\section{Introduction}

The purpose of this study is to identify the barriers and enabling factors that impede or support the advocacy work of local health department practitioners. To accomplish this, I conducted semi-structured interviews with current Kentucky health department directors of local county or district health departments. The design and methodology of the study are described in this chapter. Included is an overview of the study, the methodological design, a description of the role of the researcher, and a design for interviews of health advocates and policymakers that informed the design of the procedures for collecting the health department directors' interview data. Additionally, the chapter includes a description of the development of the interview questions, procedures for the interviews of health department directors and analysis of the data.

\section{Overview of the Study}

A review of the literature in Chapter 2 reveals that policy development is one of the Ten Essential Public Health Services that public health practitioners are encouraged to perform (CDC, 1994). The literature also describes and supports the practice of a variety of advocacy skills that can lead to the implementation of policies that improve public health. Despite the fact that there 
are examples of public health practitioners using a variety of advocacy skills, there is little evidence of vigorous advocacy in public health departments in the United States (Acosta, 2003; Mail, 2006b; Partnership for the Public's Health, 2007; Turnock, 2001). Previous investigations into the health advocacy skills employed by health department practitioners are quantitative studies that provide answers to "how many" advocacy skills health department directors (Thompson, et al., 2009) and health educators report using in their public health work (Deokar, et al., 2009; Thompson, et al., 2009), but the studies do not delve deeply into why the practitioners do or do not advocate. In fact, the authors of one research study indicate that theirs is a beginning study and not a thorough review of the subject (Holtrop, et al., 2000). Another study's authors state that the forced choice survey is a limitation of their investigation (Thompson, et al., 2009). Clearly, more research is needed to determine what barriers to advocacy exist and what factors can facilitate advocacy.

To achieve this, I conducted a qualitative study using interviews for data collection. I interviewed the directors of local health departments in Kentucky: the health department directors. They are the public health facilities' chief executives charged with carrying out the public health functions of protecting and promoting health in the counties of the Commonwealth. As such, they were asked to describe the skills they use to advance policies that can lead to better health for their constituents.

In order to develop a protocol and a set of questions, I conducted separate interviews with two populations, experienced health advocates and state or local 
policymakers familiar with public health issues. The former group understands effective health advocacy and the latter group is often the target of the advocates' efforts. These interviewees provided information regarding what advocacy skills are effective and appropriate for public health practitioners' use in order to advance health policy in Kentucky. Moreover, these interviews provided an insider's view of the health advocacy environment in Kentucky.

Next, I reviewed the results of the interviews to develop open-ended questions to guide one-on-one interactions with directors representing a variety of local health departments. In Kentucky, there are large and small, urban and rural health departments as well as single county and multi-county independent or district health departments. I interviewed directors representing different types of health departments in order to gather data from public health practitioners serving in a variety of communities.

\section{Study Rationale}

\section{Rigor of qualitative methods.}

A decision that researchers confront is how best to apply various methods to inform their research questions. In the past, many researchers noted that experimental rigor only occurs through the use of quantitative methods that yield numerical results. According to Kerlinger (1986) research must include hypothesis testing - a feature of much quantitative research. However, Patton (2002) maintains that the methods of qualitative inquiry now stand on their own as reasonable ways to learn details of what "is happening in programs and other 
human settings" (2002, p. 107). Patton (2002) goes on to say that qualitative inquiry adds depth, detail and meaning to quantitative analysis.

Qualitative research is naturalistic because it is conducted in "real world settings and the researcher does not... manipulate the phenomena of interest" (Patton, 2002, p. 39). For this study, qualitative inquiry was the most appropriate method for delving more deeply into a topic that previously has been researched through quantitative methods. It enabled me to go into the real world of the local health departments and draw conclusions about their activities and culture. According to DePoy and Gitlin (1993), "when there is no theory to explain a phenomenon, or the theory is inadequate...naturalistic designs are preferred" ( $p$. 127). This is not to suggest that all qualitative research yields theory; rather, Green and Thorogood (2009) challenge the idea that qualitative research is inductive and quantitative deductive. The authors state that both types of research have some inductive and deductive qualities and that qualitative researchers may have hunches about their study even if specific theories are not being tested. They conclude that, regardless of whether a researcher uses quantitative or qualitative methods, it is not the label, but the rigor that is significant,

\section{Characteristics of qualitative research.}

Patton (2002) enumerates the characteristics of qualitative research. It is flexible that is, the researcher can follow where the information leads; sampling is done to get "information rich" subjects; and data collection strategies include up close and personal observation or communications with the subjects. Qualitative 
research answers the "what, how and why of a phenomenon" (Green \& Thorogood, 2009, p. 5) rather than how much. McCracken (1988) agrees that interviews, in particular, let the researcher see the beliefs and experiences of the interviewee and "the logic by which [the speaker] sees the world" (p. 9). Interviews help give context to the numbers generated by quantitative studies such as the surveys of health educators and directors conducted in the past (Deokar, et al., 2008; Holtrop, et al., 2000; Thompson, et al., 2009).

As Patton (2002) states, qualitative research, unlike quantitative, is context specific. That is, it is true only about the population studied. Therefore, it is not generalizable over a broad population; however, that doesn't mean that one cannot draw conclusions from the data. Recurring themes emerge as a result of the deep inquiry and others can use these data to test transferability. So this study describes the Kentucky health department directors I interviewed, and it also uncovers findings that may help a broader audience of public health practitioners.

\section{Interviews as sources of data.}

According to DePoy and Gitlin (1993), all research should be logical, systematic and understandable for the reader, as well as useful and confirmable. Through the interviews, I discovered the respondents' perspective and am able to understand the "meaning they assign to [their] behavior and experience (DePoy \& Gitlin, 1993, p. 264), that is, to their advocacy work. These interviews investigate not only whether or not advocacy is something local health department directors do in Kentucky but the attitudes and beliefs that enable or 
inhibit their policy work. This methodology will add to the utility of public health practice, a requirement of research, according to DePoy and Gitlin (1993).

The existing studies (Deokar, et al., 2008; Holtrop, et al., 2000; Thompson, et al., 2009) that have inquired into the subject of public health advocacy and policy work have used forced choice surveys to describe the advocacy work of public health department practitioners. These studies are logical, systematic, understandable and confirmable. They have yielded important results that have informed the field of public health advocacy, but there remains much that is not known about this topic. The studies indicate that the health educators and directors surveyed do not participate in numerous health advocacy activities in their professional capacity. They attribute this to a lack of time, budget support and training. However, to develop a more extensive view of the health department advocacy environment and the directors' values and attitudes regarding this policy related work, a discussion elicited through qualitative design yields a deeper investigation than would a survey.

\section{Researcher as interviewer.}

According to Green and Thorogood, "an interview is a conversation that is directed...towards the researcher's ...need for data" (2009, p. 93). The purpose of the interview therefore, is what the researcher intends. In this study, my intention was to learn what characteristics related to the health department or its director that make advocacy more or less likely to occur. With this in mind, I was able to get close enough to the interviewees and their environments to know what is going on, to capture what is taking place and to record what is being said 
(Patton, 2002). But as the researcher, it was not enough that I recorded what was said and what occurred, but it was imperative that I determined the importance of what I learned by applying it to what I know about public health practice and health advocacy in Kentucky.

\section{The interviewer's experience.}

In McCracken's (1988) view, the researcher in an interview setting is a device: an instrument that hears the interviewees' responses through the filter of the researcher's own experiences. In this study, interviewees were asked about their experiences regarding health advocacy and policies. As a result of my experience, I am familiar with both advocacy and public health. I am a program officer at a Kentucky health foundation, and many of the grants the organization gives provide funding to advocacy organizations with the purpose of affecting health policy in Kentucky. In this capacity, I have the opportunity to observe experienced advocates. Moreover, as a public health professional, I understand the dilemma some directors face regarding whether to advocate or how to advocate for policy change. I understand this because I was employed in a local health department for several years. As a health educator, I saw the many opportunities public health practitioners had to influence systems that encouraged healthy behaviors and/or protected the community. Additionally, I saw situations in which the health department staff, for a variety of reasons, declined to seize these opportunities to work at the policy level.

Being aware of the background I brought to the interviews and being aware of the potential bias this may have had on my perspective was imperative 
for honest data collection. I drew upon my experiences during the interviews, and I used them as "possibilities, pointers and suggestions... [used] to plumb the remarks of a respondent" (McCracken, 1988, p. 19).

\section{Protecting against bias.}

Although having personal knowledge of the topic I researched may have been an advantage, I avoided the temptation to offer too much of my own interpretation. If I believed that I was drawing a conclusion based on my experience rather than what the respondent was saying, I asked for clarification or probed more deeply into their response.

Having a background in public health was both a source of potential bias and a benefit. An advantage to my public health experience is that I did not need a gatekeeper to grant me access to the respondents. The public health community in Kentucky is small, and due to my past work experience, I was able to schedule interviews with directors easily. Likewise, due to my current communication with advocates and policymakers, I was able to make contact with them directly. I did, however, make clear to all interviewees that this study and my position as a program officer for the foundation are distinct and unrelated.

McCracken (1988) warns that the researcher must maintain a balance between being engaged and being obtrusive. He recommends refraining from using "active listening" (p. 20) and paraphrasing the interviewee's responses. As an interviewer, I maintained control by using prompts to guide the discussion, while still allowing the interviewees to tell their story (keeping in mind that the 
conversation must have a time limit). In order for the interview to be flexible, I was a careful listener and I followed up on questions that needed further investigation, but I also recognized when a question had been adequately covered.

\section{Study Design}

The chronology of the study was as follows: first, in order to identify effective public health advocacy skills and the role of the practitioner in advocacy, I conducted individual interviews with several experienced health advocates and also with several health policymakers. Using the results of these interviews, I developed a set of questions to guide semi-structured interviews with health department directors from local health departments in the Commonwealth. I conducted all the interviews in person with one exception. I conducted a phone interview with this respondent because he had recently moved out of state after serving as a health department director in Kentucky for twelve years. The interviews were recorded and additional notes were kept. Transcripts were developed from the tapes and used for data analysis.

\section{Subjects as participants.}

After I received my dissertation committee's approval, I completed my application for approval from the University of Louisville Institutional Review Board (IRB). After I received IRB approval, I contacted specific advocates and policymakers and asked them to participate in the planned interviews described below. Additionally, I began recruiting subjects for the health department directors' interviews as described below. 


\section{Risks to participants.}

Although the risk to interviewees was minimal, there is never a total absence of risk. According to Gallant (2009), a breach of confidentiality is a potential risk as is the violation of the interviewees' privacy. In order to protect against this, the identity of the interviewees was protected during the study. Interviewees were referred to as Director 1, Director 2, etc. on both the voice recorder and in the transcripts. All records of the interviews were kept in password-protected electronic form except on the voice recorder. However, the audio file was downloaded from the voice recorder to a password-protected computer as soon after the interview as possible. Most interviews were downloaded on the same day as the interview. The interviewees are not identified in the written results of the study or in the discussion.

Although it was possible that I may have asked a question that was offensive to a respondent, I was respectful of the interviewee and did not note any sign of discomfort or offense. I attempted to eliminate any potential risk to the respondents during the interview, as well as in the presentation of the study's results.

\section{Models of Inquiry}

\section{Advocate and policymaker interviews.}

I interviewed four policymakers individually and the same number of health advocates in order to understand how each group defined effective health advocacy and how each describes the role of public health in this advocacy. By 
questioning both sets of respondents, I was able to identify the diversity as well as the agreement in thought (Patton, 2002). Through analysis of the data from these interviews, I developed a list of questions which I then posed in the interviews with health department directors.

I queried advocates about the advocacy skills they found effective in changing or developing policy, the components of a successful health advocacy campaign and the contribution of public health practitioners in these campaigns. During the interviews with policymakers, I asked them which of the advocacy skills in Table 4 are appropriate and effective for public health practitioners to use when attempting to change or to developing public health policy. Additionally, I asked them about their experiences with public health practitioners as advocates. The answers policymakers and advocates provided, helped to identify what advocacy skills public health practitioners do or should use in their efforts to create or influence sound health policy. The results of the interviews provided a list of advocacy skills around which the health department directors' interviews were developed. The policymakers' interviews provided a list of advocacy skills that decision makers find effective for use by public health practitioners. 


\section{Table 4 Advocacy Skills}

- Research and analysis - collecting and presenting data regarding the issue

- Evaluation and comment on administrative and regulatory proposals regarding the health issue

- Community organizing - developing interest within a group of people to activate them regarding the heath issue

- Issue framing and messaging - formulating wording, talking points and phrasing advantageous to the health issue or position

- Convenings - hosting groups of people interested in the health issue

- Public education and information campaigns - about the health issue

- Stakeholder engagement - engaging people in the health issue

- Solutions identification - identifying or formulating a solution to advance the health issue or position

- Coalition building - identifying and organizing a group of people or organizations to advance the health issue or position

- Media advocacy - using print, electronic and other mass communication to advance the issue or position

- Lobbying - a call to action regarding a particular piece of legislation

o Grassroots - a call to action aimed at the public to lobby directly

- Direct - a call to action aimed at a policy maker or staff

Adapted from Funding Health Advocacy, Grantmakers in Health, 2005

\section{Sampling for advocates' interviews.}

In order to identify which health advocates to interview, I selected three members of the Kentucky Voices for Health coalition. This coalition is composed 
of the major statewide non-profit health advocacy organizations. Additionally, I invited two advocates currently working on food policy or school health policy campaigns in the Commonwealth. All potential respondents were selected because they had worked in positions that are traditional public health fields - for instance, social work, dietetics or health education. Some of the invitees were full-time, paid advocates who work to advance a variety of health and social justice issues such as children's health coverage, access to health services and healthy schools and communities. Other invitees were part-time or volunteer health advocates who worked or have worked on statewide or local campaigns focused on issues similar to those of the full-time invitees.

\section{Sampling for policymakers' interviews.}

To assemble the list of policymakers for interviews, I requested an appointment with four members of the Joint Health and Welfare Committee of the Kentucky General Assembly and three members of the Cabinet for Health and Family Services leadership. These individuals were chosen after consulting the Legislative Research Commission's website to identify members of the Health and Welfare Committee and by seeking the counsel of experienced health advocates with knowledge of the members of the committee and the leadership team of the Cabinet for Health and Family Services. Additionally, I identified members of the Cabinet's leadership team by consulting the Cabinet's website.

One of the legislators interviewed was a Republican and two were Democrats. All were House members. The members of the Cabinet's leadership team were not identified by political affiliation; however, they serve in their 
positions at the pleasure of the current Democratic administration. Two of the legislators are from rural western Kentucky, one is from an urban area in central Kentucky and one was from an urban area in Northern Kentucky. All of the policymakers were identified because of their knowledge about or participation in health or public health programs and policies.

\section{Initial communication with interviewees.}

An introductory email (Appendix A) was sent to advocate invitees and another, similar email (Appendix B) was sent to policymaker invitees, requesting their participation in an interview. Additionally, a follow-up letter of invitation (Appendix C) was sent to each legislator's Frankfort address inviting them to participate in an interview regarding effective health advocacy in Kentucky. I did not send a follow up email to the invited advocates. The e-mails and letters explained the goals of the study and requested their participation in identifying which advocacy skills are most effective for advancing health policy in the Commonwealth of Kentucky. The policymakers' letters were sent by first class mail and replies were requested via e-mail or phone. Follow-up phone calls were made to the advocates' homes or offices. Calls were also made to the policymakers' offices in Frankfort. These calls were made to insure that all had received the invitation and an offer was made to clarify any issues that needed to be explained and to schedule a convenient date, time and location.

The advocates made their own meeting arrangements, and all but one agreed to be interviewed. That advocate did not respond until after the interviews had been conducted. Six of the policymakers agreed to be interviewed. The 
representative from Northern Kentucky did not respond until all the policymaker interviews were completed. Two of the Cabinet for Health and Family Services leadership had conflicts arise the day of the interview and I was not able to interview either. However, I was assured that the member of the leadership team I interviewed was knowledgeable and would provide me with appropriate information.

\section{Interview setting.}

For the subjects' convenience, interviews were held in locations convenient to all those who agreed to participate. Travel reimbursement was not offered because I traveled to the planned interview sites. For policymakers, the interviews were conducted during the legislative session, so even those interviewees who were from western Kentucky were in Frankfort as part of their duties. One of the policymaker interviews was conducted over the telephone because the House member was running late en route to the Capitol for a committee meeting and requested a phone interview.

\section{Interview questions.}

As I conducted the interviews, I guided the discussion around the main interview question:

- What advocacy skills are effective and appropriate for public health practitioners in order to advance effective health policy?

As the advocates' and policymakers' interviews progressed, I was guided by suggested questions (Appendices $D$ and $E$ ). I limited the number of main questions to ten or fewer as suggested by Patton (2002) in order to provide time 
for a deep discussion of each; however, I also posed additional questions regarding public health's role in communicating with policymakers. The interviews were semi-structured and my goal was to understand which skills are effective and appropriate for public health policy advancement as reported by the respondent's experience. An electronic voice recorder was utilized to capture the discussions and to allow time for me to concentrate on what was being said.

\section{Coding and analysis.}

After each interview, I made a transcript of the recording using voice recognition software. The transcripts were analyzed to determine which advocacy skills were most often mentioned by the participants as appropriate for health department practitioners' use. This was done by coding each positive comment made in reference to a particular skill. Additionally, negative comments or suggestions that a skill is unnecessary or ineffective were also noted. The most commonly noted advocacy skills or activities were then the foci of the questions to be used to guide the interviews with the health department directors. I also asked each set of respondents to describe effective advocacy experiences they had had either as public health practitioners or as policymakers. I wanted to understand if and how health department practitioners were seen by the respondents as having influenced public health policy. I could then use this knowledge to assist my interviews with health department directors.

\section{Results.}

The results of the policymakers' interviews and the advocates' interviews yielded a list of skills that public health practitioners can use to communicate with 
policymakers and others as a way to advocate for health policies. These conversations helped me focus parts of the interviews on certain advocacy skills and on the relationships the health department directors have with their policymakers, other stakeholders in the community and with their Boards of Health.

\section{Pilot Interviews with Former Health Department Directors}

Prior to beginning the directors' interviews, I consulted two former health department directors to pilot the format and design of the interview questions. I contacted two retired directors of local health departments by email and explained the nature of my study. I requested their assistance in evaluating the appropriateness and thoroughness of my interview questions. I selected directors with whom I had worked or had conversations about my interest in public health advocacy in the past. I knew that they also had an interest in health advocacy. One is an avid proponent of physical activity, especially physical activity opportunities for children. The other has been a legislative liaison for the Kentucky Public Health Association. I thought both of them would offer candid responses and constructive suggestions.

Each of them provided useful feedback. One of the directors answered the proposed questions in a mock interview format. The other critiqued the format and the interview content. I used their suggestions regarding additional questions and formatting, which I incorporated into my existing list of questions.

\section{Interviews with Health Department Directors}

I conducted individual interviews with 18 health department directors until 
saturation, the point at which no new information is gleaned from the discussions (Patton, 2002). Interviews were conducted from February 28, 2011 until March 29, 2011.

\section{Sampling of directors.}

I gathered the interview sample using purposeful sampling, that is, intentionally selecting participants (Green \& Thorogood, 2009). I selected interviewees that reflected the variety of local health departments in Kentucky. The directors interviewed are representative of both urban and rural health departments, large and small departments, and both single county and multicounty district health departments. Additionally, in order to interview a variety of directors, I invited male and female directors and those from the various areas of the Commonwealth: western Kentucky, southeastern Kentucky, Northern Kentucky, south central Kentucky and the urban areas of Louisville, Lexington and Bowling Green. By getting responses from a diverse group of directors, I avoided having unequal representation based on geography, gender or typology of health department. Figure 2 indicates the approximate location of the health departments. I assured the directors interviewed that their responses confidential. I have also attempted to keep their identities confidential.

I invited 23 directors and received responses from 19. The one interviewee, who responded but was not interviewed, contacted me after the other interviews had been completed. He had just had a medical procedure, and we were unable to coordinate a time and place for the interview. 
In order to identify and request an interview with a varied group of directors, I consulted with the executive director of the Kentucky Health Department Directors' organization and an administrator from the Kentucky Department for Public Health. He assisted me in identifying directors from different parts of the Commonwealth new as well as experienced directors and those directors that administered traditional health departments as well as those that had an innovative approach to public health. Additionally, I requested interviews from directors of different ages, races and gender. I interviewed new as well as experienced directors. Experienced directors are defined as those that have been in their position for more than five years.

An introductory email (Appendix F) was sent to each of the health department directors in the sample. I followed up with a phone call to the director or their scheduler to verify receipt of the invitation and to schedule a mutually agreeable time to conduct the interview with those willing to participate. Preliminary contact with prospective respondents indicated a positive response to my request for additional information.

\section{Settings for interviews.}

All data was collected in February and March, 2011. I conducted the interviews in a setting that was familiar to each interviewee. Several of the interviews were conducted at the director's local health department office. However, because the Kentucky Public Health Association meeting was being held in Louisville during the time I conducted the interviews, and most local health department directors attend that event, several of the interviewees 
suggested we meet at that event. Several of the interviews were held at the hotel. The respondent chose the location, but an effort was made to find a private setting. According to Patton (2002), all qualitative research should make the interviewee comfortable in a "real-world setting" (p. 39). I wanted the interviewee to be at ease so they knew that I valued their responses and wanted the experience to be pleasant and not threatening. I drove to all but two of the chosen locations. These two exceptions were: a telephone interview (described below) and an interview for which the respondent suggested that we talk in my office building because she had another meeting in the same location. I was unaccompanied during all of the interviews.

I conducted all interviews face to face with the exception of one interview with a respondent who, until October of 2010 , was the director of a local Department of Health and Wellness. I was not able to travel to meet with this respondent because he had moved out of state, so the interview was conducted over the telephone. I made this exception because the former director is a wellknown public health practitioner - nationally recognized for his work advocating to reduce health disparities. I thought his participation was important to this project.

I realize that, by interviewing subjects in their place of business, I ceded control over the interview setting. Gorden (1992) suggests the placement of furniture, lighting and noise level should be manipulated in order to reduce any barriers that may inhibit the respondent's participation. However, I made an effort to create a quiet, private comfortable setting for the interviews. I took notes as 
unobtrusively as possible and, after getting permission from the interviewee, I located the voice recorder so that it was not a distraction.

\section{Establishing rapport.}

Gorden (1992) points out that anything I say can influence how respondents view me, therefore, to establish rapport, I explained who I am, and acknowledged my employment with the foundation, but I provided assurance that my work there and the study being conducted were distinct and separate. I explained what I wanted to learn from the interview, the objectives of the research, why I wanted to tape the interview and why I might ask personal questions. Additionally, I asked if the interviewee has any objection to the conversation being recorded, I assured them that their identity would be concealed to all except me. They would be referred to by number alone during data analysis and neither their name, nor county nor health department name would be used in the narrative report. As suggested by Gorden (1992), I also explained the purpose of the study and how I planned to use the data gathered. Moreover, I also assured them that I would be the only person to hear the tapes and that anything they said during the interview would be held in confidence.

In order to create a feeling of camaraderie, I made clear that I had experience in local public health work in the Purchase District and that I understood the staffing and duties of various health department employees. Moreover, I explained that I understood the Kentucky merit system under which many of the local health department employees work. I did this because I have encountered many merit system employees who believe that their status as a 
merit system employee inhibits their ability to speak freely as advocates. I wanted them to know that I understood the public health culture in Kentucky and that my interest was in learning if and how they used advocacy skills related to public health policy work.

\section{Interview style.}

Prior to introducing the questions, I asked the interviewees to read and sign the consent form developed as part of the University of Louisville's Institutional Review Board (IRB) procedure. I explained the purpose and procedures of the study, as well as the fact that the IRB did not identify any foreseeable risks to their participation. I asked if they had any questions. I then proceeded with the interview. I used a combination of the interview guide method and the standardized open-ended interview method (Patton, 2002). Using these two methods, I had the benefit of structured questions recommended in the former and the flexibility available in the latter. The standardized open-ended method employs questions posed to all respondents in the same order with the same wording in order to treat each subject the same. For instance, each was asked which advocacy skills they employ. Additionally, all interviewees were asked to describe their health department and their views about policy work. The interview guide method is appropriate to be able to probe topics that arise as a result of a respondent's answers. According to Patton, then "the interviewer remains free to build a conversation...to establish a conversation style with the focus on a particular subject that has been predetermined" (2002, p. 343). 


\section{Interview questions.}

According to Gorden (1992), questions need to relate to the objective of the interview. The objectives are:

- To identify the enabling factors that encourage and assist effective advocacy by public health practitioners

- To identify the barriers that inhibit or impede effective advocacy by public health practitioners

The interviews were guided by questions developed during my interviews with policymakers and advocates and modified with input during pilot interviews. I used a variety of questions, including experience and behavior questions that identify what advocacy the respondent has done. Opinion and values questions were asked to determine what they think about advocacy as a method to advance policy, and feeling questions were used to probe their confidence about and enthusiasm for advocacy. Additionally, I posed knowledge questions to find out what the directors know about the suggested role of public health practitioners in advocating for health policies, and I asked demographic questions to learn how the directors describe themselves and their health departments (Patton, 2002).

\section{Descriptive questions.}

During the interview, I initially asked descriptive questions about how and if health policies are promoted by the interviewee. As Patton (2002) advises, once an activity is described "opinions and feelings can be solicited" (p. 352). 
Knowledge and skill questions followed. Demographic questions were interspersed throughout so not to ask a consecutive litany of factual questions.

Patton (2002) suggests that questions should be singular, clear and neutral. That means each question should include only one idea and it should not require multiple answers at one time. Clear questions use terminology with which the respondent is familiar. For instance, because many people equate lobbying and advocacy, in order to be clear about the definition of advocacy skills, I presented the inventory of skills listed in Table 4, and I provided a clear distinction between lobbying, which is a call to action to influence the passage of a specific policy, and advocacy which may include all other skills in the table.

\section{Neutral questions.}

I asked neutral questions which were nonjudgmental, that is, I did not deem their answers to be positive or negative, acceptable or not. Gorden (1992) discusses avoiding "ego threat" (p. 24) that is, asking questions that the respondent avoids answering candidly. In the interview, I avoided asking questions about advocacy skills in such a way as to communicate my positive view of advocacy, and I also indicated that some health department directors choose not to use these skills. I emphasized the importance of the respondents' viewpoints and their unique ability to provide the information I was seeking.

According to Gorden, questions are most useful if the interviewer defines or offers a context for them (1992). At times, I posed scenarios I believed the directors faced such as the opportunity to promote a smoke-free community, or the prospect of developing a multi-use trail for physical activity. 
Patton (2002) suggests using a time frame matrix in combination with the different types of questions to determine if the directors' answers vary if asked regarding the present, the past or the future. This may be a useful technique because public health practice may change over time, and therefore, answers may change over time. However, I was interested in each director's current practice. I did, however, note if the interviewee expressed intent to change their behavior related to advocacy in the future or if they had changed it in the past.

The specific questions that guided the interview are included in Appendix $H$. The general topics of the interviews are: advocacy skills employed; barriers to those skills that are not used, and factors that enable the skills that are employed. Additionally questions about the role of the health department and the director specifically as a health advocate were probed. Patton (2002) suggests a final question should be, "Is there anything I should have asked?" At the end of each interview, I gave the director an opportunity to provide information I had not requested.

\section{Recording the interviews.}

I recorded all of the interviews using a digital voice recorder (except the first advocacy interview and one policymaker interview) in order to accurately capture each question and response. Additionally, I took notes during each session in order to capture any non-verbal gestures or events that might add to the description and to indicate any key words or wording I wanted to emphasize or use as quotations. After each interview, I saved the audio file on my computer and listened to the recording while I reviewed my written comments so that I 
could correct any unfinished remarks or clarify any vague, confusing or partial notations I may have made. As suggested by De Poy and Gitlin (2005), I wanted to use all methods to "capture the experiences, meanings and events of the field" (p. 205) so every attempt at accuracy was utilized.

As Patton (2002) suggests, at the beginning and at the end of each interview, in order to capture the exact words, phrasing and emphasis, I checked to make sure that the digital recorder functioned correctly. It did, so I did not have to reconstruct any of the recorded interviews based solely on my notes. De Poy and Gitlin (2005) state that this is an impossible task. I carried a backup recorder in the event that the primary device failed.

I transcribed the interviews as soon as possible after each interview using Dragon Natural Speaking voice recognition software. I then printed each transcript in large font and double spacing so that I could make notations easily on the pages. DePoy and Gitlin (1993) suggest listening to each tape 6-8 hours for every one hour of recording. This would have required more time than I could reasonably commit. However, I read and reread the transcript of each interview several times to assure that as much of the information had been captured as possible.

\section{Coding data.}

Coding is the step between data collection and analysis. The act of coding is identifying recurring words or phrases that "assign[s] a summative, salient, essence-capturing and/or evocative attribute for a portion of language-based or visual date" (Saldaña, 2009, p. 3). According to Saldaña, codes lead to 
categories or to subcategories which, when combined, make up categories. Multiple categories become themes or concepts that lead to a theory.

I used a two-cycle method in which codes are identified during the first cycle and more focused coding and analysis occurs during the second cycle. First cycle coding included Attribute Coding that organized demographic and descriptive data about the interviewees and their organizations, and Descriptive Coding that provided labels to data in order to inventory the topics.

Saldana (2009) recommends that the novice qualitative researcher code everything to avoid overlooking the salient features of an interview. As soon as possible after each transcript was complete, I read it and referred to my notes in order to recall the conversation in its totality and to make notations regarding the tone and mood of the interview. These are what Saldana calls "preliminary jottings" (p. 17). Then, analyzing for patterns and/or themes (Patton, 2002), I identified and highlighted often-repeated words or phrases. I used different colored highlighters to indicate the different codes.

I read and coded one transcript at a time. After each interview had been read and coded, I reread it to confirm that I had recognized and indicated all pertinent concepts. I wrote major categories in the margins of the transcript so that I could readily see the topics when I aggregated the data. I began to review the comments from the interviews as they were being completed in order to determine which terms and concepts were most often repeated. In this manner, I was able to identify common findings and my analysis was an ongoing process while I continued with the interviews. 


\section{Data analysis.}

Data analysis in qualitative research is not a discreet task. Rather, the data collection, coding and analysis, and narrative writing are done simultaneously (Creswell, 1994). Because of the volume of information collected, qualitative researchers must be immersed in the data collected (Patton, 2002). The information is dissected to see similarities and differences assembled into categories and assembled into themes when ultimately a bigger picture emerges (Creswell, 1994).

Despite the popularity of using the NVivo or other similar software programs to search the transcripts for common themes and patterns produced by often-used words and phrases, Patton (2002) suggests new researchers use the manual approach to stay close to the data. DePoy and Gitlin (1993) suggest organizing, sorting and manipulating the data by using index cards or binders and folders to catalogue themes.

I used the codes and categories and themes identified during coding for interpretation. Additionally, I referred to the notes and insights in side bar notations if they helped provide a context to better recall any of my thoughts. This also creates an "audit trail" (DePoy \& Gitlin, 1993, p. 235) if others care to conduct a similar study in the future. Additionally, it will provide a context from which to view and understand my field notes and the context in which they were recorded.

Patton (2002) defines interpretation as "going beyond the descriptive...attaching significance to what was found, making sense of findings, 
offering explanations, drawing conclusions..." (p. 480). In my analysis of the data, I used a framework built on issues, and I kept in mind that each interview is unique, but I looked for patterns in responses, themes and relationships among respondents' answers. I compared the responses of those who were actively advocating and sought to identify the common characteristics. I also sought to find the common traits of those directors who report little or no advocacy and I then contrasted both groups.

My goal was to develop a "thick, rich description" of the interviews (Patton, 2002, p. 437). However, because description and interpretation are different skills (Patton, 2002), I used the resulting themes of the interviews and my knowledge of public health practice and what I learned in the review of literature regarding public health advocacy to identify the factors that enable or inhibit effective advocacy from occurring. My goal was to produce a report that provides sufficient description to "allow [the reader] to understand the basis for [my] interpretation" (Patton, 2002, p. 503).

According to Patton (2002) the purpose of the research should not be lost during the analysis. It is my intention that this study be applied. That is, that it inform public health practice by identifying the characteristics that enable advocacy and by identifying the barriers to advocacy so that they can be overcome or avoided and the enabling factors can be strengthened. Keeping this purpose in mind, I focused the analysis of data gathered and developed the order I needed for interpretation. 
The analysis process comes to a close when "sources of information have been exhausted, when sets of categories have been saturated so that new sources lead to redundancy, when clear regularities have emerged that feel integrated and when the analysis begins to overextend beyond the issues and concerns guiding the analysis" (Patton, 2002, p. 466). After the eleventh or twelfth interview, I observed that themes were being repeated and no new information regarding barriers or enabling factors were emerging. Additionally, the directors that indicated they employed advocacy skills reported essentially the same activities. I conducted more interviews to strengthen my findings, but stopped after the eighteenth interview, just prior to reaching the maximum number of twenty.

\section{Trustworthiness and Verification}

The final step of a qualitative study is establishing its trustworthiness. In qualitative research, there is "substantive significance" (Patton, 2002, p. 467), rather than statistical significance. This significance can be determined by: how consistently themes are repeated during the data collection; how much the study's findings deepen understanding of the topic; the usefulness of the research and whether the findings are consistent with what was found in the literature, and the possibility of replicating the study.

Reliability in qualitative research is dependent on consistency of coding and thoroughness of the analysis (Green \& Thorogood, 2009). By recording the interview sessions, I have a complete record of the communications, and I carefully analyzed the results. Additionally, I conducted the interviews to the point 
of saturation or "the point at which [l]... obtained sufficient information to obtain an understanding of the phenomenon [advocacy] under study" (DePoy \& Gitlin, 2005, p. 205). Other methods for establishing trustworthiness include triangulation of data collection by finding agreement among researchers or confirmation from respondents. As I analyzed the data and drew conclusions, I contacted some of the interviewees to verify the conclusions.

The ability to generalize the study's conclusions is desirable in quantitative research, however, a qualitative study, by design, describes a "unique interpretation of events" (Creswell, 1994). A replicated study therefore, may yield different results. Despite this, another researcher can follow the steps detailed in this methodology to replicate this study.

\section{Potential Limitations and Considerations}

One of the limitations of interviews is that they reflect "only.... what people say, not what they do" (Green \& Thorogood, 2009, p. 104). Such is the nature of an interview, and that is why triangulation or using multiple sources or verification by subjects, as described above, is desirable. Another limitation of qualitative research is that it is accurate for the subjects interviewed and not generalizable data, so another researcher may interpret the study's findings differently.

There may be recall error or distorted responses due to bias (either on my part or on the part of the interviewees). Anger, anxiety or political preferences may have affected the accuracy of the interviews, too. However, I did not detect these emotions. Patton (2002) observes that "interviews can be greatly affected by the emotional state of [the] interviewee at [the] time of the interview" (p. 306). 
However, I worked to establish an easy rapport and communication devoid of negative emotion both on my part and that of the respondents.

I attempted to minimize or avoid these limitations by establishing positive rapport with the interviewee. I spoke about my work with advocates; however, I explained that I also understood the realities of working in a local health department and the fact that health department directors have a governing body and budget constraints. Additionally, I explained that as a health educator, I had experience promoting public health through education.

\section{Summary}

This chapter describes the study methodology. The chapter includes a description of the interviews of policymakers and health advocates and how these findings informed the development of questions used in interviews with local health department directors. The chapter describes how subjects were selected for interviews, the role of the researcher, the interview settings and questions, and how coding and analysis were done. Additionally, the chapter includes a discussion of the trustworthiness and the limitations of the study and how I attempted to reduce these limitations. The next chapter will present the results of my data collection. 


\section{CHAPTER 4}

\section{STUDY RESULTS}

\section{Introduction}

This chapter presents the results of interviews with four Kentucky policymakers and four public health advocates, as well as results of semistructured interviews of 18 directors of Kentucky local health departments. Interviews with policymakers and health advocates identified the effective and appropriate advocacy skills employed in health departments and the interviews with health department directors identified the barriers and enabling factors that impede or support the advocacy work of local heath departments in Kentucky.

This chapter is divided into six sections. The first section presents the results of interviews conducted with health policymakers in Kentucky. The second section presents the results of additional interviews - those with Kentucky health advocates. The results of these interviews identify the advocacy skills that, according to advocates and policymakers, are effective and appropriate for use by public health practitioners. These results helped shape the questions used during the interviews with local health department directors. The third section is a description of participants and the settings of the interviews with health department directors. The fourth section presents the results of the interviews with the health department directors. The fifth section is a discussion 
of the findings from these interviews and the sixth section is a summary of this chapter and an introduction of the next chapter.

\section{Results of Policymaker Interviews \\ Profile of participants and settings.}

I interviewed four health policymakers to identify which advocacy skills from the list in Table 4 are most effective for use by local health department practitioners. Three of the policymakers were members of the Kentucky General Assembly House Health and Welfare Committee, a legislative body that considers many public health issues. Of the three legislators, two represented rural counties and one was from an urban metropolitan area. The fourth policymaker was a senior staff member from the Kentucky Cabinet for Health and Family Services located in Frankfort, Kentucky. I interviewed three of the policymakers in their House offices in Frankfort and one over the telephone, at his request. I recorded and transcribed all interviews.

All policymakers were agreeable and willing to offer their views of public health advocacy. The legislators spoke most about communications with their local constituent public health professionals. All of the policymakers insisted that, as part of the public health system, public health officials have a responsibility to be spokespersons for community health issues.

\section{Why public heath opinion is needed.}

The policymakers unanimously agreed that public health department input into their decision-making was of great value. The legislators expressed the desire to hear from their public health directors as constituents with unique 
knowledge that could help the policymaker make health decisions. The Cabinet staffer concurred that it was important for local health department directors to give voice to public health concerns in the community, as well as on issues that affect the state as a whole. This is particularly important because local health department practitioners have the ability to speak out whereas the state government employees are less able to speak out due to constraints on their ability to communicate with policymakers.

\section{Effective advocacy skills.}

The most effective advocacy skills, according to the legislative policymakers I interviewed were: educating policymakers, solutions identification, research and analysis and developing coalitions of constituents. All policymakers stressed the importance of health department practitioners developing relationships with policymakers. The legislators expressed the desire for contact with their health department directors in order to hear their expert opinions on public health matters. One legislator said communication was imperative for him to make an informed decision. He said, "I'll listen and make my own decision based on both sides...I don't take anyone's research as gospel." Another legislator said the input received from the health department director had been especially helpful in making budget decisions. The legislator suggested, "Health department directors [should] bring data and research... [and] say 'if you fund us with $\$ 1$ million to prevent teens from smoking, this is going to save so much money on the Medicaid budget."' 
One legislator dismissed the utility of stakeholder engagement just for the purpose of meeting. She said, "I go to a lot of meetings, and you come out with a four-point solution and then that's it; nobody carries it forward." However, another legislator suggested that information from coalitions within his district was especially valuable because he doesn't listen to those people who are not constituents. Yet another respondent indicated that hearing from a constituent who can be trusted to have accurate data was very useful.

Despite the fact that the policymakers requested contact with public health practitioners, all of the respondents insisted that this was not done often enough. One policymaker said, "They [health department employees] may feel a little intimidated when their budgets are determined by us...I think there's a misconception that they can't call me up at home. That's advocacy, and that's an important part because they know about it [health issue]."

The legislative policymakers I interviewed concluded that local health department directors could be most effective by communicating data and research-based policy positions to their local policymakers with the support of local constituents through coalition building and education. Moreover, health department directors should present justification for public health funding by explaining how funding is used, and the value and necessity of public health programs.

\section{Results from Cabinet Leadership Staff}

The fourth interviewee in this group of policymakers was a member of the Kentucky Cabinet for Health and Family Services leadership staff. He was not an 
elected policymaker, but a public health official suggested I interview him. I was told that his responses represented the views of the public health administration. Like the other respondents in this group, he indicated that all the skills listed In Table 4 were effective in influencing policy, but that solutions identification, educating the public and policymakers and convening stakeholders were particularly useful. He and one of the legislators agreed that framing and messaging were particularly effective if the communication was presented as a public health message and not as government regulation. He said that public health actions could either be perceived as steps to protect the public's health or they could be seen as actions of a controlling government agency, depending on how the message was structured.

This respondent also stated that the local health departments have broad authority to protect the public's health. He explained that public health departments can do this through advocacy. He cited examples of communities successfully advancing smoke-free policies through their fiscal courts or boards of health. He recounted how, in some counties, the health department, with the support of its board of health, acted to protect their community's health in the absence of action by the elected officials. It did this by convening constituents in coalitions, educating the public and policymakers, presenting research and analysis and messaging. For example, the boards of health issued regulations if the fiscal court would not establish an anti-smoking ordinance. He said,

The counties couldn't wait for the elected officials to find the will to do what needed to be done, so they advocated on their own from a health 
standpoint. [They said] "We're going to act because we have the authority to act and we find this to be a serious health issue." Local health departments have a great deal of latitude when advocating.

The next section presents the results of the interviews conducted with the four health advocates. This information, coupled with the previous result of interviews with policymakers, guided the interviews with health department directors.

\section{Results of Advocates' Interviews}

In addition to the opinions of policymakers, I wanted to hear which skills listed in Table 4 were effective from an advocate's perspective. I interviewed four veteran children's advocates, three of whom worked on the Junk Food Bill of 2005 that changed the policies affecting nutrition in Kentucky schools. The fourth advocate was an employee of one of Kentucky's independent urban health departments. She previously had been a children's advocate in Washington, DC.

The advocates interviewed indicated that all the advocacy skills in Table 4 were effective. However, in relating their own experiences, they said presenting research and analysis, convening or building coalitions and educating policymakers and the public were the most effective. They reported that lobbying, too, was a useful tool. Three of the advocates cautioned that, for those employed in public health or the school system, lobbying was a tenuous path to influencing policies because many public health practitioners believed and many had been told by their superiors that they were not allowed to communicate directly with policymakers. One advocate described the process of speaking with legislators, 
"It's hard when fear gets in the way. I was scared to death...." Another said, "I was afraid I might be doing something I wasn't supposed to." Although two of the advocates reported that they had communicated extensively with policymakers when they were employed in public health, they still expressed some uncertainty about the acceptability of this communication and a desire for clear guidelines. One advocate said, "I don't know if there is a Ten Commandments of public health advocacy, but there should be."

\section{Importance of relationships.}

Despite hesitation about crossing a line between advocacy and lobbying, the advocates said that developing relationships with policymakers, community members, other advocates, and those who influenced policymakers was a skill necessary for successful policy change or development. Stakeholder engagement, convening and community organizing, specifically were mentioned as being essential to relationships that develop, support and reinforce communications with policymakers.

Three of the four advocates stated that the power to convene stakeholders such as influential health care providers and the leadership of professional organizations was extremely important for successful advocacy because of the credibility of these individuals and/or their positions. One advocate said "the tipping point [for the success of the Kentucky school health bill] was when doctors got involved because they had no financial incentives, they just cared about kids." 
All of the advocates insisted that the voice of the grassroots was essential in a health advocacy campaign and that educating the public was a method of garnering this support. One of the advocates stated that the ultimate goal of public health advocacy is to develop skilled community members who will then advocate on their own behalf on health issues.

All advocates stated that having access to dependable research and sharing it with policymakers, the press and community supporters were valuable methods to advance policy. One advocate explained, "I formed relationships with members of the media, and I encouraged others around the state to do the same. I fed them a lot of information...I talked to the editors of both papers, the Courier Journal and the Herald Leader."

One of the supporters of the Kentucky school nutrition bill emphasized that commenting on regulations was an important advocacy step after the bill became law. She explained, "You have to go at that piece [monitoring regulations] as strongly as you did the statute, or it will fall out."

Although only one of the interviewees was working as a public health practitioner at the time of the interview, they all described the potential of the local health department advocate. One respondent stated, "Public health departments are critical to making health policy changes. They are uniquely positioned to influence policymakers by virtue of being the perceived voice for health in a community and the collector and repository of health data." Additionally, another advocate said, "Some legislators have respect [for public 
health practitioners] because we don't have anything to gain from it. We're doing it for the good of the citizenry."

\section{Summary of Preliminary Interviews}

The results of both the policymaker interviews and the health advocate interviews were similar. Both groups said that all of the advocacy skills listed in Table 4 were effective, but the policymakers stressed that education, research and analysis and constituent coalitions specifically were very effective. The health advocates agreed and also stressed the importance of developing relationships with policymakers and the public. The topic of public health practitioners communicating with policymakers was a recurrent subject with the advocates. Policymakers indicated that this communication was needed, desired but often absent. Advocates expressed a need for clear guidelines related to advocacy. The results of these three sets of interviews helped shape those that followed with health department directors.

\section{Results of Interviews with Health Department Directors}

I interviewed eighteen health department directors separately in 45 minute to $1 \frac{1}{2}$-hour sessions. My goal was to answer the study questions through the directors' responses to interview questions.

The study questions were:

1. What advocacy skills are effective and appropriate for use by public health practitioners in order to advance effective public health policies?

2. What are the enabling factors that allow and assist effective advocacy by public health practitioners? 
3. What are the barriers that inhibit or impede effective advocacy by public health practitioners?

I directed the interviews using a question guide (Appendix $\mathrm{H}$ ), however, in some interviews; I added additional questions in order to probe certain responses for deeper understanding of the topics. Additionally, in some interviews, I omitted questions that were not germane. For instance, if a question from the interview guide was answered in response to a previous question, I did not ask it again.

In addition to asking them about the advocacy skills employed, I asked each respondent to describe their health department and community. These descriptors can are included in Table 5. I also asked them to discuss their governance structure, any communication they had with their local or state policymakers, and their policy priorities. Additionally, I asked them to enumerate policies attempted or successfully advocated by the health department. The approximate locations of the interviewees' worksites are plotted in Figure 2.

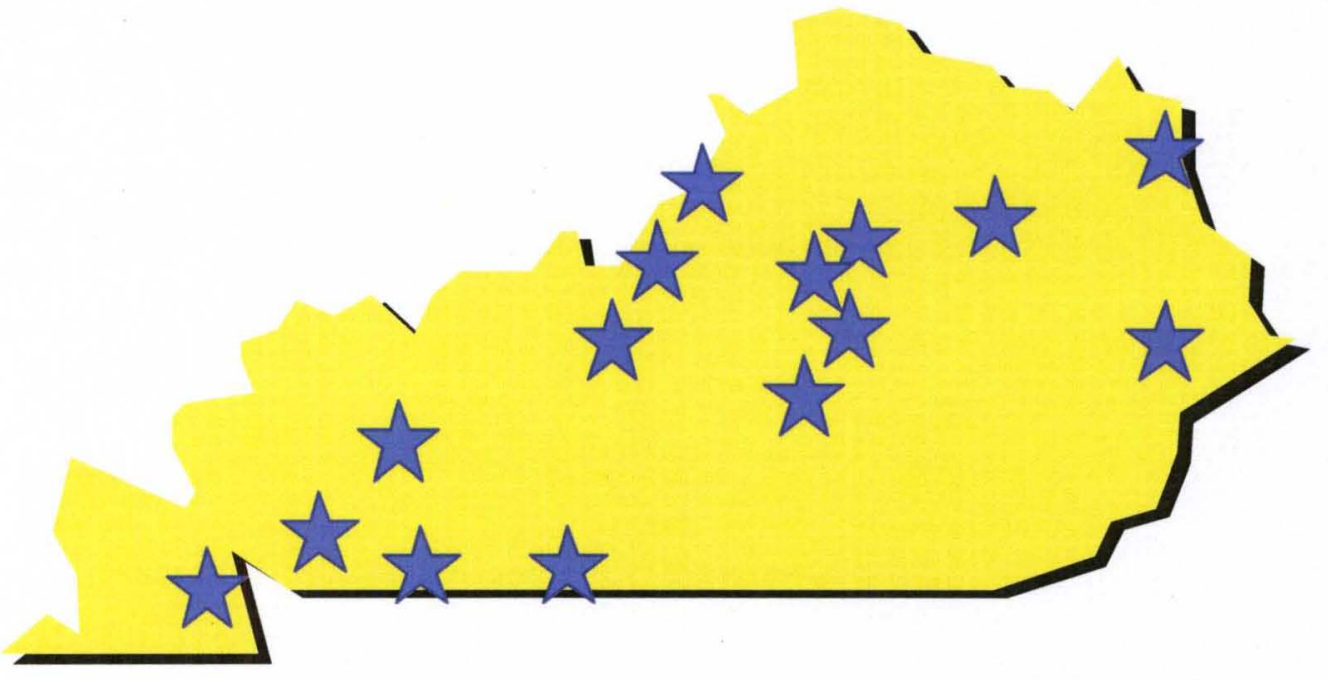

Figure 2 Approximate Locations of Directors' Worksites 
All eighteen of the health department directors graciously gave of their time, described their experiences and offered what I perceived to be their candid opinions. I have included verbatim quotations in this section in order to convey the spirit of the conversation and level of detail. In some cases, the text does not reflect perfect prose, just as in much of everyday conversation; we do not always speak in complete sentences, follow rules of grammar, or express our ideas succinctly. 
Table 5 Description of Health Departments

\begin{tabular}{|l|c|c|l|l|}
\hline $\begin{array}{c}\text { Health } \\
\text { Department } \\
\text { Organization }\end{array}$ & $\begin{array}{c}\text { Population } \\
\text { Served }\end{array}$ & $\frac{\underline{\text { Staff }}}{\text { Size }}$ & \multicolumn{1}{|c|}{ Location } & $\begin{array}{l}\text { Population } \\
\text { Description }\end{array}$ \\
\hline Single County & 47,687 & 75 & Central KY & Urban/rural \\
\hline District & 193,452 & 270 & South Central/Eastern & Urban/rural \\
\hline Single County & 295,803 & 350 & Central KY & Urban \\
\hline Single County & 693,604 & $325-360$ & Central KY & Urban \\
\hline Single County & 46,519 & 81 & Western KY & Rural \\
\hline Single County & 19,111 & 21 & Central KY & Rural \\
\hline District & 126,342 & 100 & Western KY & Urban/Rural \\
\hline Single County & 11,971 & 13 & Western KY & Rural \\
\hline Single County & 37,121 & 8 & Western KY & Rural \\
\hline District & 243,742 & 220 & Central & Urban/rural \\
\hline Single County & 30,125 & 50 & Western KY & Rural \\
\hline District & 225,000 & 210 & Southwestern KY & Urban/rural \\
\hline Single County & 20,817 & 20 & Northeastern KY & Rural \\
\hline Single County & 36,891 & 31 & Eastern KY & Rural \\
\hline Single county & 13,332 & 30 & Southeastern KY & Rural \\
\hline Single County & 27,697 & 17 & Eastern KY & Rural \\
\hline Single county & 22,554 & 53 & Eastern KY & Rural \\
\hline Single County & 75,028 & 42 & Central KY & Rural \\
\hline
\end{tabular}

${ }^{*}$ KYHealthfacts.org website.

${ }^{* *}$ From US Census Bureau 


\section{Definitions of Advocacy.}

When I asked if they advocated, all directors responded in the affirmative. An initial major influence on the responses of the interviewees was their definition of advocacy. At the start of each interview, I explained that the type of advocacy I was interested in was advocacy leading to policy change. I further offered examples illustrating that the policy change could be established by a school district, a business or agency as well as through a local regulation, ordinance or statewide law. Even though I carefully defined advocating for policies, a few of the directors stated that health departments do much individual advocacy; for instance, advocating for a patient to locate services for a client family. One respondent described this type of advocacy as "brokering on behalf of someone." Additionally, directors cited the advocacy that health departments do to promote their services to the community. One respondent stated, "Everything we do is advocacy!"

I acknowledged the importance of these types of advocacy, while emphasizing that I wanted to learn about advocacy leading to policy change. One of the Ten Essential Public Health Services suggests a local health department has the duty to "set policies and plans that support individual and community health efforts" (CDC, 1994). I did not remind the directors of this so as not to create an expectation that they should be setting and supporting policies and thereby influencing their answers. During the interviews, however, I offered policy examples such as smoke-free campuses established by school administrations; 
community smoke-free regulations or ordinances established by boards of health or fiscal courts, respectively; and policies leading to the installation of bicycle lanes, walking paths and other pedestrian thruways. I also offered other examples such as policies establishing farmer's markets, school nutrition guidelines or workplace wellness programs.

Seven respondents answered that they advocate when they request funding for programs and health services. The targets of this type of advocacy were policymakers such as boards of health, elected officials as well as members of the Kentucky General Assembly, and Members of Congress.

When I asked respondents if the specific advocacy skills in Table 4 were used at their health departments, all of the directors indicated that they did, in fact, employ some of the skills. The skills most often reported are listed in Table 6 and a sample of responses regarding each of the advocacy skills follows. I have presented the skills in order from those most often mentioned those least often cited.

\section{Advocacy skills employed.}

\section{Public education and information campaigns.}

The most commonly reported advocacy activity was public education and information campaigns. Thirteen of the eighteen directors interviewed indicated that they used education as an advocacy technique. Education was used to achieve several goals. One goal was to garner enough support from the community to move a policy forward. For instance, one director explained that it was a public health necessity to educate residents about the importance of a 
regulation that would require property owners to install septic systems or sewers instead of having "straight pipes" that delivered waste directly into waterways. The director said that it was important to explain to residents through "Education, public awareness and not trying to impose something on people without their understanding of the consequences of whatever you are doing." She insisted education was necessary in order to develop support for a public health policy. She further explained, "To me, the secret is moving [policy] slowly and with purpose... with having a plan, because unless you do that, unless you change people's minds one at a time, you're not going to be able to impose policy on them."

Another goal was to motivate the public to follow good public health practices so a mandate would not be necessary. Several directors indicated that educating the public about the dangers of second-hand smoke was effective advocacy toward establishing a voluntary community-wide smoke-free effort. One director equated educating with "cajoling" the public. She said it was a way to encourage the community business owners to voluntarily make their establishments smoke-free without imposing it though legislation.

A third goal of education was to create a grassroots demand for policy. One director, when discussing his community's desire for policies leading to safe neighborhoods, stated, "If you do education, it puts everybody in the position of demanding that things be safe." Another respondent spoke about the community's smoke-free campaign. He said, 
I think that when you're trying to pass something like that [smoke-free ordinance] you need to get the grassroots support and it can't be just the public health department wants to do this. I think our role is to educate why we need this, but it takes the grassroots people to go to the city commissioners and fiscal court and say 'we want restaurants that are smoke-free.'

\section{Educating policymakers.}

Educating policymakers was a skill mentioned by eleven of the eighteen interviewees. This education may inform policymakers about public health activities, provide data or justify funding requests. The targets of this type of advocacy included various policymakers such as those on boards of health, elected officials of fiscal courts and city, county or metro council members as well as those in the Kentucky General Assembly and federal legislators. One director said, "We have a responsibility to keep our legislators informed." Another explained that educating groups of policymakers was an efficient way to impact community health. He described how, "We may set up a little reception and get several of them [legislators] at one time...or we will send something out. [For instance, to explain] this is what we're doing about health care reform."

Three directors emphasized the critical importance of educating all policymakers who make significant decisions about their community's health. Often these policymakers are members of the local governing board. One of the directors described the board's education. 
I've worked hard on educating our board on a lot of different things and in addition to that, I have a legislative update as part of the board meetings. I have the local state senator and the local representative come in and update them themselves rather than me saying "this is what's going on in Frankfort." That gives us the opportunity to say, "This is what the board of health really wants the state to do."

Another director acknowledged that his goal was to educate policymakers about their role in public health.

A lot of advocacy l've had to do is with the courthouse - with the local powers that be, and one of the things that I have been trying to help them understand is their responsibility when it comes to the health of their constituents...There's a movement with the Association of Counties trying to get the local governmental officials to understand their responsibility for health.

Another director said education was a skill that was more inclusive and it should reach all community members, not just those who are able to develop policies. He stated,

A director should act on behalf of the health and welfare of a community or a disparate group or a group of students, or whatever [population] you're looking at. Advocacy would be educating folks about...the reality of the statistics... educating policymakers, lawmakers...the Board of Education, [it] could be the board of health or [it] could be employees in a workplace. Advocacy is facilitating all of that. 
Table 6 Advocacy Skills Employed in Local Health Departments

\begin{tabular}{lc}
\hline \multicolumn{1}{c}{ Advocacy Skill } & $\begin{array}{c}\text { Number of Directors } \\
\text { Responding Affirmatively }\end{array}$ \\
\hline Public education and information campaigns & 14 \\
Research and analysis & 13 \\
Coalition building & 13 \\
Stakeholder engagement & 12 \\
Educating Policymakers & 11 \\
Lobbying & 9 \\
Media Advocacy & 9 \\
Comment on administrative regulations & 8 \\
Community organizing & 6 \\
Solutions identification & 6 \\
Convening & 5 \\
\hline Framing and messaging & \\
\hline
\end{tabular}




\section{Research and Analysis}

Health departments gather much data about the communities they serve. Immunization rates, birth and death records and chronic disease morbidity data are routinely collected. Additionally, many local heath departments assess the community's health status as part of their health promotion programs. These data are often distributed to the public and decision makers to publicize health needs. Twelve directors stated that they used research and analysis as an advocacy technique, and one director explained how he prepares for taking an issue to policymakers. The respondent said, "I must research an issue to make sure I have some knowledge of it...before I...talk to a legislator about something. I don't go in there about just a feel-good issue or a feel-bad issue." Another affirmed, "You have to have data...you will make a better case with data."

Two of the directors said that one of the health department's priorities was to use public health data to make informed decisions about which of the community's needs to address. There are three core functions of public health assessment, assurance and policy development. One director of a small, western Kentucky county posited that research and analysis could be used to assure that there is quality health care available to the community. She suggested that health departments should, for instance, identify and advocate for efforts that are effective in providing access to care for community members, especially those that are uninsured. The director said that other service providers are setting an example that local health departments should follow. "Federally qualified health centers (FQHC's) have provided this access [to care], and they've produced 
[health] outcomes which healthcare should be producing all along. It's what public health should be producing -- [reportable] outcomes."

Four of the directors characterized their research and analysis as gathering data through community assessment models such as the Mobilizing for Action through Planning and Partnerships (MAPP) process. The data was gathered to assess the needs of their community and to develop priorities that are then made public. Another director described the extent of their health department's data collection, "You know, we went to every third household in [the] county and did a survey of needs. We had a public health doctoral student do some of the analysis for us."

Yet another director of a large district explained how they used grant funds to research the need for and advocate for the ultimate passage of safety legislation. He described how the health department, Collected emergency room data as it related to unintentional injuries. We wanted to better understand...we had an idea that we needed to affirm [regarding] MVA's [motor vehicle accidents] and teens... we produced a five-year study and a report. Our state senator was chairman of the transportation committee...We did a district report and individual county report and released them at a press conference regarding emergency room utilization. This kind of public health work [is] research, data-driven policy development...We were somewhat instrumental in advancing that [seat belt] law from being a secondary offense to being a primary offense. 
Public health research has been a highly effective tool for moving policy forward regarding smoke-free workplaces. Of the 18 directors I interviewed, nine of their counties had smoke-free ordinances. The directors in five of those counties stated that the health department played a significant role in the effort by collecting data on air quality and public opinion to establish the need for the ordinance. However, one of the directors in an area that is not covered by an ordinance related that, despite the health department collecting data to advance a smoke-free policy, it did not result in successful advocacy because the board of health was not supportive of the effort. In fact, the director related, I would state the stats [statistics] for the area [regarding tobacco use]...As a public health director, I can't say I'm not for it [smoke-free ordinance], and the Board should have known that. Offering statistics should have been a neutral thing, but some of the board members saw that as being proactive.

One director, who had successfully advocated for the primary seat belt legislation, emphasized the importance of research in public health work. "It [public health advocacy] has to be data-driven because there are too many great causes out there and tremendous need, and we don't have the resources to address them all."

\section{Coalition Building.}

Coalition building is identifying and organizing a group of people or organizations to advance a health issue or position. Many directors spoke of the importance of building coalitions in the community to accomplish tasks related to 
public health. Twelve of the respondents indicated that they worked in coalitions to advocate. However, the health department was not always the coalition builder. In fact, according to one of the directors, working as part of a coalition was a method of advancing a potentially sensitive issue such as smoke-free workplaces without the health department being the lead agency that might meet with resistance from those with an opposing view. One director explained, We have revised our coalition structure, and we have a Healthy Communities coalition that has a tobacco component of it, along with physical activity and nutrition. We think it [the smoke-free issue] is going to fit a little bit better into that. So coalition building is one of the things we've had to evaluate to move this issue forward.

Another director said that the health department, as part of the Alcohol and Substance Abuse Prevention (ASAP) coalition has been able to work on issues seemingly unrelated to public health policies. He explained,

Using that group as a coalition to get some other things done...it didn't really have anything to do with ASAP, but we sent a letter to the city about a sidewalk. The middle school kids were walking home when there wasn't a sidewalk...so that when it's coming from this ASAP board and not one particular bunch [of advocates]...we got the sidewalk.

\section{Engaging Stakeholders}

Twelve directors indicated that engaging stakeholders in advocacy was a skill often practiced to build consensus on an issue. One director explained that a critical mass of community members is needed to create political will. He said 
until enough people in the community understand the health consequences of smoking, a smoke-free policy would not be successful.

You need enough [stakeholders]. It depends on who it is, too. [You need] influential people who understand and then buy into it [public health policy]. I can imagine what it would have been [like] a couple of years ago if I tried to move all the smoke-free stuff, especially at a time when tobacco farmers were just getting involved in the buyout. This is just a process to get people to move toward those ends...I don't believe in and I don't think it's effective to try to impose something on somebody unless you have a majority of the people who are at least leaning toward it. Another director whose health department had tried unsuccessfully to establish a smoke-free policy described a current effort, "We have a strategy for how we want to move forward and part of that includes identifying stakeholders to find out their position on it."

\section{Lobbying.}

Directors often remarked that the line between lobbying and advocacy was unclear. Lobbying is defined as "communications that are intended to influence specific legislation" (Alliance for Justice, 2003, p. 8). There are two types of lobbying - direct and grassroots. The former is "made to a legislator, an employee of a legislative body, or any other government employee who may participate in the formulation of the legislation. It must refer to a specific piece of legislation and express a view on it." (p. 8). The latter is: 
An attempt to influence specific legislation by encouraging the public, other than the organization's members, to contact legislators about that legislation. It must refer to specific legislation, reflect a view on it and encourage the recipient to take lobbying action on it. (p. 8).

In the preliminary interviews I conducted with members of the General Assembly, they indicated that they would welcome more information about public health issues from the health department directors in their districts. In the directors' interviews, there was much discussion about informing policymakers, and respondents indicated that they felt much of their advocacy work centered on educating elected and appointed individuals and, at times, discussing specific legislation. However, there was confusion about the terms lobbying and advocacy and what was allowed. One director said, "I am glad you are using the word advocacy because some health departments are afraid of lobbying, though we must advocate." Another director said, "When I hear the word advocacy, the first thing I think is 'OK, we can't do that' you know, because we are state employees."

A majority of the directors said they were not able to lobby, and several made comments suggesting that advocacy was not allowed. In fact, respondents often repeated the sentences, "We don't lobby, we educate." and "We don't advocate, we educate." They used these phrases to describe communication with policymakers. It appeared to a majority of the directors believed if an interaction with a policymaker was called education; it was acceptable behavior 
and did not violate any actual or perceived prohibition on lobbying, even if the director was communicating about specific legislation.

Seventeen of the eighteen directors I interviewed responded that public heath employees could not lobby. One director stated that lobbying was prohibited, but, "I've never looked to see that it's written [anywhere], but we were always instructed very clearly [that] as a government entity we are not to lobby." Others indicated that the administrative manual prohibited lobbying. Despite these responses, during the course of the interviews, eleven directors acknowledge that they had contacted a legislator and expressed an opinion about a specific bill. One director admitted, "Well sure, to let them know how that a particular bill would impact our health department." Another responded, "I don't have any problem calling my legislator and saying...l'll give you my understanding of it [a bill]." Yet another said, "I probably wouldn't say, 'l'd like you to vote for'...I would probably say, I would appreciate it if you would ...."

Seven directors drew a distinction between lobbying for a bill related to the financial well-being of the health department and other legislation. One director remarked, "I say we don't do lobbying and we don't do lobbying for policy, but we do lobby on financing...I picked up my cell phone and called the state rep [about the budget bill]." Another director stated, "We can't lobby unless we are defending ourselves." This is a common understanding since the Internal Revenue Service makes this same accommodation for non-governmental nonprofits that have lobbying limits except when they are protecting their funding. 
Only one director who acknowledged that he often talked to policymakers about specific legislation, did not seem to be conflicted about the matter. "I call that education," he said. When I clarified the definition of lobbying as referring to specific legislation, he reiterated, "I call that education."

Two of the directors said it would be helpful to have more training about acceptable types of communications with policymakers. One interviewee said he would like to know the best manner and time for a health department director to become involved in the policy making process.

Only one director acknowledged employing grassroots lobbying with the general public; that is, issuing a call to action asking the public to lobby directly. Another director stated that grassroots lobbying was unethical because the community members are potential patients. The director said "we don't organize patients because... [if they don't take action], we don't want them to have the fear...that we might jerk the rug out from under them or violate their confidentiality."

\section{Media Advocacy.}

Much of the public health advocacy literature encourages using various forms of media to advocate for policies related to public health, and nine of the interviewees responded affirmatively when asked if they used media advocacy. One director had recently used a local television show to promote immunizations as a public health imperative. Another director said that the health department uses the media as part of their public education campaigns. Another director 
explained that the health department had hired a media specialist to advocate for environmental change in the community.

However, not all of the media use that respondents mentioned appeared to be true media advocacy. Several directors said that various media were used to promote health department programs such as the $\mathrm{H} 1 \mathrm{~N} 1$ influenza vaccine programs or tuberculosis prevention efforts. One director explained that this type of working relationship with the media could create a positive image of the health department for subsequent policy work. One director said, "The nursing supervisor will be interviewed [on radio] on a wide variety of things. That's a good, positive way [of pursuing policy change] instead of saying 'we need to have better county zoning."' Another director described media advocacy as, "Communicating to the media why an issue is important." Using media in this manner was akin to education as an advocacy skill.

\section{Solutions Identification.}

Six of the directors responded affirmatively that they identified solutions as part of their advocacy for better public health policies. For instance, one director said that the health department introduced the idea of creating walking paths and sidewalks to promote physical activity to the community. According to the director, "These people [community members] had never thought of it [improving the built environment] until we [the health department] were involved [in the process] to think about what we wanted to advocate for."

Another director explained that the health department is the source of solutions to many of the community's problems, some of which were not directly 
health-related but rather affected and improved social determinants of health. The director cited an example in which one underserved region of their service area lacked economic and social capacity. In order to address the inequity, the health department procured a grant from the Appalachian Regional Commission. "We started this initiative for leadership empowerment. Out of that came a...volunteer fire department, community activists, and now we have an architect who is going to help us design a community cultural center for that part of the county." According to the director, the center will revitalize a part of the county that needed a gathering place for health education purposes and other community convenings.

One respondent described how the health department's solutions had emerged in conjunction with stakeholder engagement or coalition building. The director asserted, "The solutions reached by a group of partners were stronger because of the depth of the bench."

\section{Convening.}

Five of the respondents indicated that they convened other advocates in order to move policy forward. Directors described this advocacy as a combination of the coalition building, community organizing and stakeholder engagement. The discussion of this kind of group effort usually referred to a community's effort to develop a smoke-free regulation or ordinance. Therefore, there was no information about convening that was different from the discussions concerning stakeholder engagement and coalition building. 


\section{Issue framing and messaging.}

How a health message is delivered can affect whether the receiver perceives it to be positive or negative. Two of the health policymakers mentioned this skill in the preliminary interviews, and four directors indicated that they advocated by using framing and messaging. They put forth a health issue in a deliberate manner to encourage support from specific audiences. One director said, "You figure out how you want to say something if you're talking to a community group... is it presented the same way as if you're talking to a university professor versus a legislator? You tailor your message. It is most important because it can kill the issue or discussion faster than anything else."

One director described how, in communication with legislators, framing the message positively impacted health department budget cuts. He explained, "After health department funding was cut, to get the money restored we [two directors] took a printout of [the reduction] every health department would take. I gave a copy to every legislator and they restored the funding."

\section{Comment on administrative regulations.}

In the health advocate interviews, one respondent insisted that monitoring the agency that wrote regulations was as important as advocating for passage of legislation. During the directors' interviews, eight respondents said they had commented on legislation or administrative regulations as part of their advocacy. One director described how he was often asked to review bills that came out of the Health and Welfare Committee if the bills had any impact on public health. He said, "The legislators used to send public health bills down to me to read and 
give my opinion on them. I would give them my opinion and that built up a lot of trust...they knew I wasn't telling them something that wasn't true."

\section{Summary}

After reviewing the transcripts of directors' interviews, I quantified the responses regarding the specific advocacy skills used, as indicated in the results above. None of the directors employed all of the advocacy skills in Table 4. However, a few of the directors were enthusiastic about most of the recommended skills. Some of the directors used very few advocacy skills, and a few reported that they did not think advocacy for policy change was the responsibility of local public health. I examined the transcripts to discover the commonalities in the interviews that identified the barriers and the enabling factors to this advocacy. A number of themes emerged.

\section{Themes from Directors' Interviews}

Although each interaction with a director was unique, some comments came up repeatedly in the interviews. I discovered that the same factors appeared to impact the advocacy efforts of different health departments. Some of these comments were about the communities, while others were about the health departments, and still others were about the public health system and how it functions.

The themes that emerged were: the influence, composition and roles of the governing bodies; the effects of a community's political environment; the composition of the health department staff; the goals and requirements of funding sources; the guidance from the Kentucky Department for Public Health; the roles 
of community partners; the functions of public health professional organizations; the directors' personality traits and values; and the directors' beliefs about advocacy or lobbying.

\section{Influence, composition and roles of governing body.}

For most local health departments, the governing body is the board of health. Sixteen of the directors indicated that their board of health was their governing body. In large, urban health departments, a metro or city council may govern the health department or a mayor or mayor designee may be the health department director's line of authority. According to the respondents, one of the governing body's functions is to hire and supervise the health department director; another is to determine or recommend the amount of the public health tax. Directors reported that this body also oversees much of the advocacy that is done or not done by the health department director and staff. One director stated that advocacy is successful "If your director or your board sees it [a health issue] as valuable and champions it." Conversely, these bodies can also be a barrier to advocacy. One director said, "You have to build up a relationship with your board of health...if you don't have a good relationship, you're not going to get anywhere anyway."

\section{Board of Health as Enabler.}

Eight directors indicated that their boards were supportive of their advocacy and enabled it. When I asked one director how the health department's successful advocacy efforts were accomplished, the director said, "I have the backing of the board and I have a strong board. They are an informed board, but 
I want them to be more informed." Another director said, "I've never had someone tell me I can't do something. Our board is very supportive of me." Yet another director credited the board with advancing advocacy efforts. He said "It's primarily the board of health that moves this [smoke-free policy] along because they are an integrated part of the community because of the composition...doctors, engineers, veterinarians, nurses...."

Another director whose board of health supported a smoke-free regulation expressed the belief that the effort was catalytic. After the board of health showed support for the local smoke-free effort, the director was also able to lend a voice to the effort to pass statewide smoke-free legislation. The director said, "It's [supporting a statewide effort] much more [uncomplicated] now than before. Now I have the backing of the people I work for."

In another county, the board chairman had so much potential influence that the smoke-free effort was suspended while he recovered from an accident. The director explained.

Our board chairman wanted to come back to it [the smoke-free issue]. He's a physician, a medical advisor...so he's very much in support of it, but it had to go on hold again because he is our primary champion and he had a very bad car accident. So we felt it wasn't a good time to move forward again.

Three interviewees who were not governed by a board of health described a similar, positive and enabling relationship. One director said, "I talked to the 
governing council often [and] certainly when we were working on specific things like the smoking ban."

\section{Board of health as barrier}

However, not all boards enable the health department's advocacy, but rather may impose some barriers. Again, the most common issue directors cited was the passage of a smoke-free regulation or ordinance. Six directors indicated that their boards were not amenable to the health department advocating for this public health issue. In some instances, the source of the difficulty was the elected judge executive who very often also sat on or chaired the board of health. One director recounted, "The judge [executive] is on the board of health and he has said that he opposes it [a smoke-free regulation]. He feels like businesses should be smoke-free, but he does not feel that it should be imposed on them, so the...board of health is not going to do it with him sitting there." In another county, the judge invited a legislator to hear his position on a public health matter. The director described, "The judge executive invited the state representative to come to the board [of health] meeting so that they could be very clear that this was not something they were in favor of." Other respondents were less direct about who was resistant. One director said,

I think I know how my board would vote if we took it to them tomorrow, but I might not. We've never really come out and individually asked people as new board members. We didn't say, "Oh, by the way, how do you feel about a smoking ordinance?" I tell you I have a little bit of fear. We have to 
be very careful about how we, as a public health agency, position ourselves.

A new health department director in a small, rural county acknowledged that if the board of health stood as a barrier, the director would not contest the decision. The director said, "As passionate as I am about it [smoke-free], I probably would not push it. Just to keep my job, I could be passionate about it with friends and family, but as an employee, l'd have to have respect for them [board of health]."

The smoke-free ordinance was not the only issue that was controversial to a board of health. One director said the chairperson of the board objected to the family planning services supported by Title $X$ federal funding. The director related,

She [chairperson] turned out to be someone who doesn't believe in family planning. She doesn't think we should be handing out Plan B because she thinks it's abortion. I spent...almost a year trying to fight with her...to prove that, in order to have Title X [funding], we need to do these things.

This situation was not unique to small or rural counties. Even those large health departments governed by a city's administrative body reported experiencing barriers. One director explained that "if it [a public health issue] is something the mayor feels strongly about, he can say 'cease and desist"'.

\section{Effect of community's political environment}

As described in Chapter 1, the composition of boards of health is dictated by statute. They are made up of community leaders such as doctors, dentists, 
veterinarians, pharmacists and often the judge executive or a designee. Several directors indicated that community leaders' view of government often indicated whether or not a health policy was enacted or even discussed. During interviews, five of the respondents said that community members were concerned with government interference in their freedom and that this affected the health department's advocacy efforts. One director said, "Eastern Kentucky culture for example...people think 'well, it's my property, I should be able to do whatever I want to."

Another director described how political views impacted the issue of zoning. The health department wanted stronger landlord-tenant agreements to protect the physical conditions of rental units, but opponents interpreted the move to be an affront to property owners' rights. According to the director, The landlord-tenant agreement needed a lot more education on our [health department] part. I don't know how familiar you are with rural Kentucky, you know the city has zoning but the county...one of the county commissioners said "ain't gonna do it." When you establish zoning parameters, they see that as the government trying to tell them how to use their land.

Respondents also indicated that tobacco issues are politically charged because Kentucky is a tobacco-producing state. The issue of smoke-free workplaces, according to the interviewees, has the potential synergistic effect of restricting tobacco usage and impinging on a business owner's freedom. One director said, "The county has tobacco farming, so we have to be really careful of that [smoke-free efforts]." Another director maintained that the economic effect 
limiting smoking might have on tobacco retailers and the tax revenue would have an influence on the health department's position on tobacco issues. The director stated,

Here's where we run into our problem... why they [business owners] see it this way, because we are a border state between Ohio and Kentucky. Revenue-wise, we have the cigarette outlets right across the river, you drive right across the bridge and turn right and you're at the cigarette outlet; and they are big moneymakers and they bring in lots of taxes. Another director said in one rural area of Kentucky, elected officials were becoming less likely to support anti-smoking efforts. The director related, "I tried to talk to our legislator several times about tobacco...they don't support those [smoke-free] positions. Our area continues to elect folks that, if anything, have moved further away from the position [of smoke-free policies]."

One director expressed frustration about the fact that health care has become politicized and that the local health department, as the safety net health care provider in a community, has the potential to be unwillingly thrust into the political debate.

I really struggle. I hate that public health has to be political sometimes because I don't think politics should enter into it. And right now with this governor's race, we are a political hot potato right now -- not public health but the healthcare system and Medicaid and all the players in it. Another director agreed that a community's political position was a barrier to advancing a public health issue through advocacy. When asked if the health 
department does much advocacy, the director responded, "Not as much as is needed....we have to be very careful in a small...Kentucky county about how we advocate for policy and the kinds of policies we advocate [for]...because [of] the culture, the political culture."

\section{Composition of the health department staff.}

\section{Staff enables advocacy.}

Eight of the directors indicated that staff other than the director were either responsible for all or some of the advocacy at the local health department. The health educators and environmentalists were mentioned as enabling advocacy efforts. One director expressed the desire to know more about advocacy, but said, "I always send one of my health educators [to advocacy training] but I need to go to one of [the] trainings." Another interviewee concurred that health education is where advocacy lies. The director explained, "We've taken on that role [advocacy] a little bit more in health education because they, in the health education group, have taken on the clean indoor air initiative...we're taking that to the board [of health] right now."

Another director credited her environmentalist with being able to advance policy development through board of health action. The director said, A lot of our policies have been environmental changes which have been some of the most difficult because those have been controversial. Going to fiscal court [and] explaining [policies] I give all that credit to the environmentalist...she is young...she believes in public health and she does it the right way. 


\section{Goals and requirements of funders.}

\section{Funding enables advocacy.}

Although several health department directors indicated that it was necessary to advocate for public health funding in order to keep services available to the public, grant funding could also be the impetus for advocacy. Two of the health department directors stated that they had received Action Communities for Health, Innovation and Environmental Change (ACHIEVE) grants from the National Recreation and Parks Association. The terms of the grants mandated policy-level advocacy work. One director said, "The ACHIEVE program...educated me about policy development and the effects you get out of that rather than just educating people about programs." Another director explained that their work assisting schools in developing policies that increased students' physical activity was a result of the ACHIEVE grant.

\section{Funding as a barrier.}

An equal number of directors cited funding as a barrier to advocacy. Two directors reported that barriers to advocacy were: categorical funding provided for a specific service and a lack of funding earmarked for advocacy activities. One director of a district said, "If it [advocacy] is essential, they [funders] would put money behind it. Is it a good idea? Yes. Is it feasible? No. If you don't put resources behind it, how are you going to do it?" The director continued, "I have four health educators. I have to laugh when I hear...we have to do community work when $90 \%$ of our funding goes to services." Another admitted that some of the health department's staff was able to work on advocating for public health 
issues but, he added, "We might [advocate] but we don't have the staff that all they do is advocacy." Another director said that one of the advocacy skills, community organizing, is not done because "[it] is too labor intensive."

One director said that time and money are related barriers to advocacy. Staff time to do advocacy costs money but also takes staff away from other duties.

There are some big ticket items that you advocate for like school health...and you back off sometimes because you think, "Was it really worth all that effort?" You know, because really, you believe in what you are doing...truly, it's better for the child but you got to have some money or you can't do it.

Another director cited that the categorical funding distributed by the Department for Public Health in small amounts was a barrier to working on those issues of real concern to the community. The director explained,

Nobody's giving us any money to deal with prescription drug abuse...we get tobacco money, we get physical activity money; we get some nutrition money [but] who would advocate with five hundred dollars a year? We're not talking a lot of money...it covers me talking to the Kiwanis, Rotary and a few churches.

\section{Community partners.}

\section{Community partners as enablers.}

Ten directors reported that a coalition of community partners was an effective advocacy medium. Often these bodies are called interagency coalitions 
or councils. Some of those that work specifically on substance abuse issues are Alcohol and Substance Abuse Prevention (ASAP) boards. One director affirmed that the health department acting as a member of this group can advance an issue such as smoke-free workplaces. He said, "That [coalition] would be the group that could sit down and talk intelligently about something we'd want to support." Another director said that his county, as a tobacco-producing area, is made up of many opponents to smoke-free efforts, so the health department is shielded from criticism if the ASAP board is the lead agency. He explained, "I would rather it [advocacy for a smoke-free ordinance] is coming from the ASAP than the health department because in an ASAP group you have a big variety of people. Schools are represented, the YMCA is represented...more people, more agencies."

The director of a county that successfully advocated for a smoke-free ordinance reported that they worked for the policy as part of a smoke-free coalition and now they are part of a complete streets coalition working to increase bicycle and pedestrian venues. The director stated, "We tend to be partners and don't care who gets credit so long as it [policy change] gets done."

\section{Partners as Barriers.}

Stakeholder engagement, convening and coalition building are advocacy skills that some respondents suggested were so similar that they considered them the same thing. In small counties, especially, coalitions were composed of stakeholders, and several of the respondents indicated that their community partners enable their advocacy. However, two of the health department directors 
reported that stakeholders were not always collaborative partners but rather they could be barriers to advocacy if the health issue in question was not a shared cause. These directors said that in their communities working on advocating for tobacco control policies with other substance abuse prevention advocates seems like a natural collaboration because,

From a public health perspective, we see those [drugs and tobacco] as similar...but you have people who are really passionate against drugs and alcohol who say, "If my kids were just doing tobacco, I would be lucky." They don't consider that [tobacco] a substance even though you educate and say tobacco is a drug, it's a precursor that can lead to other things, and they don't get that.

In another health department, the public health director attempted to partner with the school district to improve the health environment for students, however, the superintendent was uncommunicative. She explained, The superintendent never returned a call or an e-mail. He was fired the next year, but it was just unfortunate that they went through several years of something like that and it put them behind, and it kept us from pursuing what we wanted to do in the schools.

Despite this comment, more interviewees reported that partners were allies in advocacy. One director concluded, "There are a lot of groups that are supporters of public health and you have to get their support."

\section{Guidance from the Department for Public Health}

Fifteen directors mentioned the Kentucky Department for Public Health 
(DPH) in our discussion of advocacy. Local health departments are dependent on DPH for much of their funding. In addition, directors look to the state authorities for technical assistance and current public health information. Several directors mentioned that they wished DPH offered more guidance on policy issues than is currently offered. When I asked if the Department supported or discouraged the advocacy efforts by local health departments, ten of the directors said that DPH was neutral and neither encouraged directors to nor discouraged directors from speaking out. One director reported, "I've never heard from them [DPH] one way or another, but l've never asked." However, a director with many years of experience said, "I think they encourage local advocacy but discourage state level advocacy with legislators."

Functions of Kentucky public health member organizations. Member organizations enable

Both the Kentucky Public Health Association (KPHA) and the Kentucky Health Department Directors Association (KHDA) were mentioned often as advocacy organizations that enabled directors' advocacy efforts by sending alerts that directors could then pass on to others and act on themselves. The policy priorities that the organizations listed and publicized were cited by six of the directors as useful methods to advance public health policies. One director said "If KPHA says we need to get this voted, I'll pick up the [phone] line...I just sent out a big email last week about House bill 305 [budget bill]. I mean, I just did it." Another director expressed appreciation for these organizations that act as surrogates for the directors. "You can say you support policy but you can't 
actively go out and necessarily say that you are going to advocate for legislative change on things. This is one of the fortunate things about KHDDA and KPHA. [Directors can advocate] without personally going out and advocating for something."

\section{Directors' personality traits and values.}

Although the governing body (usually the board of health) can influence much of the advocacy work a local health department does, the personality or character traits of the director can often be a barrier or enabling factor to public health advocacy.

\section{Director's traits enable.}

Some of the directors expressed a desire to make a change in the lives of their community members through any means possible, including advocating for policies. One director said, "To hear people - folks in the know - talk about it, policy is more effective than education. [l] try to find a place where people are making an impact... if it's educating...that's what we want to do. If it's policy, that's what we want to do." Another director said, "My role as director is to advocate for the agency itself..." One director in a poor, rural Kentucky county explained why she advocates for better conditions in her community. "It's a calling. I just feel that the Lord wanted me to do it. I was going back to my home county to make a difference for the people there. And I believe I have." Additionally, she said,

I do more advocacy on behalf of the people, I guess. I guess you'd call it that. When I am in Washington saying we have to do something about this 
substance abuse problem, and whenever I'm in Washington saying our people need this new facility, I'm advocating.

How a director viewed the mission of public health had much to do with whether or not they used advocacy skills. A director who was also a medical doctor interested in health disparities defined the role of public health.

One of the core functions of public health is policy development, and early on in my administration, we pushed the notion of public policy development and the subsequent advocacy for the passage of policy throughout the city. It was about being active in the community, advocating for people to be involved in and understanding what the policy issue was.

\section{Director's traits as barriers.}

One director stated that he didn't think that advocacy was imperative for influencing policy. "Some may say that you have to advocate in order to do that [make policy] and some may say you don't." Another director explained that advocacy was not a requirement of the position. He reported, "Advocacy isn't that high on my list...there is a place in the world for the trailblazers and whistleblowers. Maybe I just don't have that impetus." Another agreed that policy setting and regulation wasn't the role of the health department. He asserted, "As far as coming up with the rule [policy] that needs to be policed, I don't think that's how I would go about it."

Two interviewees expressed the opinion that advocacy was not a director's responsibility. One respondent said, "The director is just carrying out 
the services that they [the board of health] deem necessary for the community." Another affirmed that the responsibility for advocating for policy change rested with others, not the health department. The director said, "Policy is mandated for local health departments from the state and feds. We just implement it."

One director drew a distinction between being an annoyance and being an advocate. The director said, "I think there is a difference between being an advocate and being a pain...l've made sure that people know our collective view on what the health department stands for, but on the other hand I don't want to be a thorn that then causes our other relationships with partners to be tainted by that."

\section{Directors' views of advocacy and lobbying.}

Several directors expressed the opinion that advocacy and policy development were important public health activities, but often their views of beliefs about advocacy affected whether or not they employed advocacy skills. Many directors expressed indecision or confusion about the ability.

\section{Directors' views as barriers.}

Another common theme that every interview contained was the discussion of the limitations on a health department employee's advocacy activities. I defined lobbying, both direct and grassroots, during each interview. Although not all communication with policymakers is lobbying, and all of the directors indicated that they communicate with their legislators at least occasionally, one director said they didn't do it "as much as I should." 
Two new directors indicated that they were unsure of the legality or propriety of their ability to speak with legislators. When I mentioned the word lobbying, or the director introduced it, all but one of the respondents immediately commented that they could not lobby. When I asked why not, the answers varied. One director replied, "I'm not sure if it's in statute, but you can look at some of our grants. Our grants say you can't lobby." Two other directors said, "It is somewhere in the administrative manual." Still others said public money cannot be used for lobbying. One director said that health department directors were bound by the same administrative ethics rules as members of the Governor's administration.

\section{Directors' views enable.}

Several directors stated that they believed they were not supposed to lobby, but they did anyway because they were educating the policymakers about what will improve the community's health. One said, "Directors may pick up the phone and call and say 'this is how it [a bill] affects our health department', but technically, we are not supposed to." Another stated, "We can advocate versus lobbying. I don't know; somewhere there's a statute. I've never paid much attention to it because I'm a risk taker. I'm very calculated." Eight of the directors who expressed indecision about the propriety of communicating with legislators, did attempt to influence their policymakers. Therefore, it is difficult to label this confusion as being a barrier or an enabling factor. However, because this issue was so prevalent in the interviews, I have reported it. 


\section{Summary of Results}

The interviews I conducted with policymakers and advocates began my qualitative data collection and confirmed that the advocacy skills in Table 4 were effective and appropriate for public health professionals to use in their efforts to develop and support health policies for their communities. The policymakers underscored the importance of communication between the local health department and those people making decisions about the public's health. They specifically cited educating policymakers with research and analysis, building coalitions and identifying solutions as most effective and welcome. The health advocates affirmed that these skills were most useful. The advocates also emphasized that relationships with policymakers and community members were equally important. The advocates introduced the idea that despite the importance of communication between policymakers and public health practitioners, many in the latter group believe that some of their contact with policymakers is limited by policies.

The interviews I conducted with eighteen health department directors yielded results about what advocacy skills were utilized by their health department employees. All of the advocacy skills in Table 4 were mentioned by at least one of the respondents, but the most common skills used were public education and information campaigns, research and analysis, coalition building and stakeholder engagement.

Based on the interviews, several influences either impeded or enabled public health advocacy. One influence was the governing body, either a board of 
health or an urban council. These governing bodies were either supportive of health policies or refused to introduce policies, and the director, as an employee of this body was directed to support this decision. Likewise, the environment of a community was either supportive of the health department's advocacy and thus, enabled it or the community members were a barrier to advocacy if they perceived public health promotion as government interference. This dichotomy was often present in communities where the issue of smoke-free workplaces was raised.

Community partners who often served on coalitions with health department staff enabled advocacy by being the lead agencies on public health issues; however, occasionally they were barriers to advocacy when they opposed or neglected to support health policies.

The health department's staff, including the health educators and environmentalists in addition to the director enabled advocacy through a variety of methods including educating the governing body and the public. Similarly, the Kentucky Public Health Association and the Kentucky Health Department Directors' Association enabled advocacy by directly lobbying for or against health policies.

The directors' views about advocacy and their willingness to act also impacted whether or not the advocacy skills were utilized. Some directors stated that some advocacy skills were not appropriate activities for the health department; others stated that there was insufficient funding for advocacy activities. Still other directors were concerned that certain types of advocacy 
might endanger their livelihoods, and others were unclear about which advocacy skills they were allowed to carry out. These were all barriers.

Conversely, enabling factors were directors' beliefs that policies were effective and needed. Some directors stated that the role of the health department was to identify those health issues that called for policy development or change and to use advocacy to advance the work.

\section{Summary}

This chapter presents the results of interviews I conducted with Kentucky policymakers and advocates. Their responses regarding which advocacy skills are effective and appropriate for public health practitioners' use formed the questions for the study's main interviews - those of local health department directors. I have also presented the results of the eighteen interviews I conducted with health department directors from across Kentucky. The directors indicated which activities they used as part of the health departments' work, and they also discussed their experiences, beliefs and attitudes about advocacy. Several themes emerged that enabled or posed barriers to their activities. In the next chapter, I will present a brief background and summary of the study's procedures as well as a discussion of the findings and conclusions. Additionally, I will also include the limitations of the study and recommendations for future research. 


\section{CHAPTER 5}

\section{DISCUSSION, LIMITATIONS, STRENGTHS AND RECOMMENDATIONS}

\section{Introduction}

This chapter is divided into six sections. In the first section, I will describe the background that led to the study. The second section is a summary of the procedures I followed to collect the research data. The third section is a discussion of the findings. The fourth section presents the limitations of this study. The fifth section presents my recommendations, based on the study results. These are recommendations for health department directors, boards of health and other governing bodies, the state Department for Public Health and public health member organizations in Kentucky. This section also includes recommendations for future research. The fifth section enumerates the limitations of this study. The sixth and final section contains the study conclusions.

\section{Background}

The history of public health is grounded in advocating for public policies that will improve or maintain the health of populations. From John Snow's effort to convince policymakers to close a community well (a source of the local residents' cholera infections) to the current campaigns to legislate for smoke-free 
workplaces, advocacy has been a public health practitioners' tool. This commitment to advocacy was underscored in 1994 when the Core Public Health Functions Steering Committee developed the Ten Essential Public Health Services. This list "serves as a working definition of public health and a guiding framework for the responsibilities of local public health systems" (CDC, 1994). Service number 5 recommends that health departments, "develop policies and plans that support individual and community efforts." (CDC, 1994). In order to develop the recommended public health policies, health department directors can use a variety of advocacy skills, and in order to do so, they should practice in an environment that supports this work. I conducted this study to add to the knowledge of how public health practitioners can use advocacy skills to better promote policies that improve and protect the health of their communities. The research questions of this study are:

1. What advocacy skills are effective and appropriate for use by public health practitioners in order to advance effective public health policies?

2. What are the enabling factors that allow and assist effective advocacy by public health practitioners?

3. What are the barriers that inhibit or impede effective advocacy by public health practitioners?

\section{Summary of procedures}

In order to answer question 1 of this study and identify which advocacy skills to include in my interviews with health department directors, I turned to experienced health policymakers and health advocates. I interviewed members 
of each group and asked them which of the advocacy skills listed in Table 4 were most effective for public health practitioners. Additionally, I interviewed four health advocates.

The results of the interviews of advocates and policymakers helped to guide the third set of interviews - those with the 18 health department directors. The health department directors' interviews provided me with a list of skills used by health department practitioners in the course of their work for comparison with those identified in the preliminary interviews. Additionally, the directors' responses aided me in understanding the advocacy environment within the health departments and in the communities they served. I was then able to identify the enabling factors that allow and assist public health advocacy and the barriers that inhibit or impede that advocacy.

My definition of policy advocacy was not limited to the interaction between advocates and elected officials only, but rather, it included policies at schools and workplaces. Both the policymakers and the advocates, however, concentrated their answers on issues that are or have been raised during legislative sessions. The skills identified as effective and appropriate by policymakers and advocates differed only slightly. I present a summary of their responses in the following two sections.

\section{Skills identified by policymakers}

The policymakers I interviewed initially said that all advocacy skills were important, however; during discussions, they eventually narrowed the list of skills 
they said health department directors should use in their communications with policy makers. The skills most often identified were:

- Research and analysis

- Identifying solutions

- Educating policymakers

- Coalition building

Research and analysis combined with identifying solutions offered the policymakers the value of what they called the "expert opinions" of public health professionals that were based on data. The lawmakers explained that they relied on others to educate them about the impact of bills they were considering during legislative sessions, so the knowledge that health department directors could offer would help the legislators make informed decisions. This introduced a skill that did not appear on the list I offered them, that is, educating policymakers.

The policymakers also reported that hearing constituents' opinions was the factor that most influenced their decision-making. Therefore, if local health departments developed coalitions of constituents that communicated with their representatives about matters of public health, the constituents' voices would impact the policymakers' actions. All of the legislators said that they did not hear from their public health departments as much as they would like, and that they would welcome the information to help them make informed decisions.

The one non-legislative policymaker I interviewed stated that local health departments had the authority to influence public health policies by using all of the advocacy skills listed, but they did not use them often enough. In addition to 
the list of skills recommended by the legislators, this interviewee suggested that health department directors can become knowledgeable about framing and messaging public health communications. He said this was important to establish the health department as an advocate for health and to avoid being perceived as a government official interfering with individual rights on issues. He offered examples of issues such as menu labeling or smoke-free workplaces.

Skills identified by health advocates.

The health advocates interviewed spoke about their experiences communicating public health concerns to both policymakers and the public. The list of advocacy skills the health advocates described as most useful included:

- Research and analysis

- Coalition building and convening

- Educating policymakers

- Public education and information campaigns

- Lobbying

Like the policymakers, the health advocates described how having data and current research gave them credibility with policymakers and provided them with messages that formed public education campaigns. They also said that building coalitions of other public health advocates and the representatives' constituents gave a local voice to the health issues they were promoting. These coalitions created a synergy that made the public education campaigns farreaching and successful. Furthermore, communication in the form of letters, e- 
mails and phone calls from coalition members influenced the policymakers who relied on the opinions of their constituents.

The interviewees also admitted that they directly lobbied legislators to vote for public health issues, but one advocate said she was careful not to identify herself as a public health employee when she lobbied, for fear of violating some prohibition on lobbying by public heath workers. This advocate introduced the subject of limits on public health advocacy and the confusion around what was permissible.

The health advocates I interviewed stressed the positive power of developing relationships. They emphasized that relationships with policymakers, with the media, with other advocates and with the public were absolutely essential when advocating for and promoting health policies. According to these interviewees, relationships engendered trust, developed camaraderie and created the critical mass that resulted in effective policy advocacy.

The results of the policymaker interviews and the advocate interviews assured me that the advocacy skills I had previously identified in Table 4 were appropriate. Furthermore, the results of their interviews added another skill to the list; that is, educating policymakers. This provided guidance that helped me in the next set of interviews. The next section briefly describes the results of these interviews with health department directors.

\section{Skills identified by health department directors.}

I interviewed a total of 18 health department directors during March and April of 2011. Seven of the respondents were women and 11 were men. Their 
tenures at the health departments ranged from less than 1 year to 18 years. The backgrounds and academic preparation included hospital administration, social work, education and government positions including public health. Two of the directors were medical doctors. Four of the directors administered multi-county district health departments and the remainder worked in single-county organizations. The health departments were located in a variety of geographic areas of Kentucky and the sizes of the staff and of the populations served varied, although the sample was not random.

During the health department directors' interviews, they were asked if and how they employed the advocacy skills in Table 4 at their health department. Some of the respondents did, in fact, use those skills most often identified by the policymakers and advocates, but only three of the directors reported using all of the skills which had been identified. Several directors reported that they did no policy development. Others said they did not advocate.

The policymaker interviews stressed the advocacy skills that assisted policy-makers in their work. The advocates' interviews named some of the same skills, but their emphasis was on convincing policymakers of the importance of a public health issue.

The following section offers more detail about how the most commonlycited advocacy skills were described by the interviewees from all three groups -policymakers, advocates and directors.

\section{Research and analysis}

Research and analysis was a skill that health advocates and policymakers 
both identified as effective and appropriate for public health advocacy. Almost $75 \%$ of the directors reported that they did use this advocacy skill when they collected and shared a variety of data with policymakers or the public to demonstrate a health need, public opinion about a public health issue or the potential efficacy of a policy. Data collection and analysis contributes to the assessment function of public health, one of the three core functions recommended by the Institute of Medicine (1988). According to the Institute of Medicine, each public health agency should "regularly and systematically collect, assemble, analyze and make available information on the health of the community"(p. 7). Several directors discussed their data collection efforts, especially these community needs assessments.

Seamans (2010) recounted how the division of public health in North Carolina used data showing how many of that state's resident were exposed to smoke in work places and the cost of these exposures in an effort to promote smoke-free workplaces. Public health educators in Kentucky, aided by the Kentucky Center for Smoke-Free Policy, have used similar research to successfully advocate for local ordinances protecting workers in restaurants and bars. The result is that more than $1 / 3$ of Kentuckians now live in a community with this protection (personal communication with Dr. Ellen Hahn, July 23, 2011). However, not all of the directors interviewed actively advocated for this important public health issue although they acknowledged its importance.

One director offered a clear example of using research and analysis when he cited how county data was collected and used to successfully advocate for a 
primary seat belt law. He stated specifically how his research enabled him to proffer an expert opinion as a solution to a public health problem (motor vehicle accidents by teens). Other directors described how community needs were assessed through data collection; in one instance, the assessment was done through canvassing every third household in an entire county. This type of research can serve multiple purposes. Data collection can provide the health department with priority issues for intervention. It can also create an opportunity for the health department to be viewed as a credible source of information by policy makers and the public. Additionally, data collection can give the health department practitioners a forum to educate and hear community members' concerns, thus creating the relationships that the advocates interviewed found effective.

\section{Solutions identification.}

Solutions identification was another skill suggested by policymakers; however fewer than half the directors reported that they used this skill. One of the directors that did, related how the health department was instrumental in developing a volunteer fire department and procuring funding for a community meeting place. Neither of these is a responsibility of the health department, but both might have an impact on the community's collective well-being by improving what are known as the "social determinants of health" (Edelman, 2008). The determinants include jobs, housing, education and other social conditions that can impact health, thus making them public health issues (Breton, Richard, \& Gagnon, 2007; Edelman, 2008). 
Public health practitioners, armed with data about the needs and health status of the community, perform the assessment core function. They can develop solutions and advocate for needed health services, health systems, and the infrastructure necessary for healthy lives, as well as the policies leading to equitable access to all of these needs. However health departments need the time, funding and expertise for this advocacy.

\section{Educating policymakers.}

Just slightly more than half of the directors indicated that they regularly educated their policymakers about public health issues despite the legislators indicating the importance of this, and two of the policymakers described the absence of this communication. Of course, because of the small sample of legislators, it may be that the directors were not the policymakers' constituents. In the literature, the importance of educating decision makers is emphasized (Acosta, 2003; Directors of Health Promotion and Education, n.d.; Institute of Medicine, 2003) and several of the directors acknowledged that they didn't contact their representatives often enough or as often as they should have to inform them about public health issues.

All of the interviewees used the words communication and education repeatedly. Policymakers said it was important that public health directors educate them about health issues. Advocates said education was an essential method for informing both decision makers and the public. In interviews with the directors, it seemed that communication with policymakers often depended on factors. One was a director's level of comfort with their policymaker. Two 
directors said that they did not have a relationship with their representatives and did not care to contact them. However, others said they had regular, collegial meetings with their legislators.

Another condition was the perceived protocol or legality of contacting legislators. Several directors said that policymakers contacted them, not the other way around. One director said that his representatives knew how to reach him, so he waited for that overture. Contact with local policymakers such as judge executives was frequently reported although those relationships were not always described as being productive. More commonly expressed in the interviews was the belief that communication between policymakers and local health department directors was subject to certain rules, and many of the directors expressed uncertainty about the legality of their contact with legislators.

\section{Coalition building.}

Coalition building was a skill often discussed. Thirteen of the 18 directors reported that they participated in or built coalitions. The coalitions were most often community groups organized to work on smoke-free efforts. Others were formed to create active communities, or they were formed to combat substance abuse, a problem the directors said was widespread in rural Kentucky. Directors indicated that their health educator, not the director, often attended coalition meetings. Although the literature supports the effectiveness of community coalitions for policy advocacy (Hoefer, 2005), in some small counties in Kentucky, the same people form coalitions for each health issue. This can and does lead to fatigue or apathy (M. Nall, personal communication, July 23, 2011). 
Coalitions need to have fresh members and renewed enthusiasm to be effective advocacy tools.

\section{Public Education and information campaigns.}

Educating the public is a standard public health activity. Some directors insisted that education was what health departments did in lieu of advocacy or lobbying. Other directors I interviewed used the term advocacy when they described health education about the public's need to embrace a healthy lifestyle or to change an unhealthy behavior or to access health services such as immunizations. However, the public education and information campaigns of advocacy refer to developing support in the community around needed policies or systems change. Milio (1981) describes this education as fulfilling the public's need to be involved in policy change. Servaes and Malikhao say education "heightens public interest and demand for health issues" $(2010$, p. 6$)$.

The policymakers I interviewed stated that constituents' voices were the most powerful influences on their decision-making. If this is the case, public health could work hard to educate the public about the policies that will improve their lives and then encourage their advocacy. Health department directors said this is occurring. For example, health educators are teaching the public about the advantages of a smoke-free community in an effort to promote public advocacy. Public health could replicate these efforts to encourage advocacy for other policies such as zoning regulations that encourage physical activity or regulations that discourage alcohol advertising targeted to certain demographics. 


\section{Lobbying.}

Lobbying, the communication about specific legislation (Alliance for Justice, 2003), was a topic that arose in all interviews with directors and advocates, but not in the policymakers' interviews. The advocates interviewed declared that lobbying policymakers was effective, and nine of the directors acknowledged that they have asked their representatives to support or withhold support for specific legislation. Much of the literature supports a public health official's right and need to lobby for issues that clearly are a public health concern (Acosta, 2003; Cheadle, et al., 2008; Vernick, 1999). This was a confusing subject for some Kentucky public health practitioners for a variety of reasons. First, most directors said they believe they are not permitted to lobby, but many said they didn't know the source of the prohibition. Second, even if they are permitted to lobby, directors reported that if they were to lobby for or against an issue that was in opposition to their governing body or the chair of that body, the director could be terminated for insubordination. Finally, the confusion surrounding lobbying was clear when policymakers I interviewed expressed a desire to hear the directors' opinions, while many directors don't believe they can freely offer that. It is beyond the scope of my study to determine the appropriate lobbying parameters of local health department practitioners.

\section{Relationships.}

The health advocates interviewed stressed the positive potential of relationships to energize the public, develop coalitions and create trust in policymakers and the media. The health department directors did not speak 
specifically about relationships; however, partnerships with other community organizations and coalitions were cited as being instrumental in efforts to improve community health. Additionally, the relationships directors formed with their governing bodies were critical to the local health department's policy development efforts.

\section{Summary of advocacy skills}

The lists of advocacy skills policymakers and advocates recommended were similar. Both groups suggested that research and analysis, educating policymakers, and coalition building were effective skills. Policymakers added solutions identification and the advocates added lobbying and educating the public as strategic steps in policy work. Three of the 18 directors indicated that they employed all of the recommended skills. If policy development is one of the core functions of public health and also one of the Ten Essential Services as well as being a competency of public health professionals and required for accreditation, one would expect these skills to be practiced more widely. So, what are the enabling factors for employing these skills, and what are the barriers?

The next sections present the themes that emerged from the interviews with local health department directors. The themes relate to those factors that either enable or pose barriers to public health advocacy.

\section{Enabling factors to advocacy.}

Study question 2 is: What are the enabling factors that allow and assist effective advocacy by public health practitioners? Based on the interviews with 
health department directors, the factors that enabled advocacy were:

- A supportive governing body

- A director with a vision for the community or the health department and its staff who:

- described the importance of policy in addition to services.

- utilized data to plan for the future.

- allowed staff (especially environmentalists and health educators) to advocate.

- Active member organizations (The Kentucky Health Department Association and Kentucky Public Health Association)

- Community partners

- Funding

\section{A supportive governing body.}

Various types of governing bodies supervised the directors interviewed. A board of health led most counties and districts. Health departments in major urban areas are governed by alternate governance structures. According to several directors, if they and their governing boards disagreed on the work of the health department, the directors might be in danger of losing their jobs. However, the relationship between the council or board and the director could be collaborative, and this enabled the health department's mission to protect the public's health. Just as a chairperson of the board could scuttle a director's efforts, a supportive chair could assist these efforts. One director said the chairperson of the board was supportive of his work with the Kentucky Public 
Health Association and the Kentucky Health Department Directors' Association as well as his work serving on statewide committees. He reported that this support was welcome and energizing.

In several counties, strong boards of health were the stimulus behind the smoke-free ordinances. In one county in particular, the board of health passed the smoke-free regulation and then the fiscal court passed an ordinance to strengthen the policy. When I asked what the next issue would be for the board, the director said, "That healthcare will be available for everyone." Although the Patient Protection and Affordable Care Act has not been embraced in much of Kentucky, he indicated that the board would support that goal. A governing body that will support and advance policies that protect the community's health regardless of political pressure enables a director's advocacy efforts. However, this assumes that the director is willing to act as the board's designated advocate.

\section{A director with vision for the community, the health department and staff.}

The directors who were most enthusiastic about working on policy rather than solely continuing the traditional public health work of programs and services, were also the directors who spoke about the vision they had for the community, the health department and their staffs. These directors reported strategic planning or needs assessments that gave their organizations direction and goals.

They described surveys they had done, committees that were established and professional development opportunities offered to their staff members. The 
literature supports the importance of this leadership and staff development (Partnership for the Public's Health, 2007; U.S. Dept. of Health and Human Services, n.d.).

One director said she didn't mind training her nurses with new skills only to have them leave for other positions. She was happy to have motivated, fulfilled nurses while they worked for the health department.

\section{Described the importance of policy.}

It was no surprise that those directors who were most likely to employ advocacy skills were those who expressed the desire to "work at the policy level" rather than solely through direct service programs. Two of these directors received grants that encouraged or mandated policy development or advocacy, and they enthusiastically discussed the value of policies rather than programs that were not sustainable. Other directors acknowledged that policy work was the only path to sustainable change.

\section{Utilized data to plan.}

The directors who had implemented population needs assessments or conducted other research projects were also likely to describe the various advocacy skills they used to address the needs of the community.

\section{Allowed staff to advocate.}

Several directors credited their staff members with advancing policy issues. Environmentalists especially were credited with promoting board of health regulations. Directors also indicated that much advocacy work in the community was undertaken by health educators. Researchers in past studies (Deokar, et al., 
2009; Holtrop, et al., 2000) have surveyed health educators to identify the barriers they face in policy making efforts.

\section{Active member organizations.}

The major public health membership organizations in the state, the Kentucky Health Department Association (KHDA) and Kentucky Public Health Association (KPHA) were described as having an annual advocacy agenda that enabled even reluctant directors to advocate and express their opinions about public health legislation. KPHA distributes a detailed list of policies related to public health and issues action alerts to all members during each legislative session. Directors mentioned both KPHA and KHDA as helpful to the directors' advocacy efforts. The latter group's membership is limited to health department directors, but it, too provides information and support. The activities of these two organizations enable public health advocacy.

\section{Community partners.}

Much of the literature supports the advocacy health departments do in conjunction with community partners (Acosta, 2003; Hoefer, 2005; Scutchfield \& Keck, 2003). As one director stated, "There are so many worthy causes." The work of improving Kentucky's health can be shared by schools, nongovernmental organizations, parents, churches and businesses to be most successful. Partnering with community organizations was a common theme in the interviews. However, it was as frequently mentioned in the interviews with directors who did little advocacy as it was in the interviews with those who did a great deal of advocacy work. 


\section{Funding}

Although the issue of funding was not central to most interviews, it bears mentioning that for those interviewees who had received grant funding encouraging policy development, advocacy was discussed enthusiastically. Receiving fiscal support and training for policy work aided these grantees in becoming champions of sustainable change.

\section{Summary of enabling factors.}

According to the analysis of the transcripts, there is a variety of factors that enabled health department directors and staff to advocate for public health policies in the community. One enabling factor is a supportive governing body that understands and embraces its duty to protect the public health. The board does this by hiring an able director and allowing that director to promote programs, services and policies that create a healthy place for the community members. Another enabling factor is a director who articulates a vision for the community, the agency, and its employees. This type of director also was enthusiastic about changing environments at all levels of the socio-ecological model. The combination of the forward-thinking director and a governing body that offers support and encouragement can be the motivation for a community that values and sustains a healthy atmosphere.

In addition to enabling factors, there were also themes that emerged that inhibited the advocacy work of the directors. In the next section, I present those elements described in the health department directors' interviews that pose barriers to advocacy. 


\section{Barriers to Advocacy}

Question 3 is: What are the barriers that inhibit or impede effective advocacy by public health practitioners?

Based on the interviews, the major barriers were:

- Lack of support or action by governing bodies

- Community attitudes about the functions of public health

- The directors' lack of clarity regarding advocacy and lobbying

- Directors' personalities and priorities for the health departments

- Partners who are opposed to certain policies

- Lack of funding for advocacy

\section{Lack of support or action by governing body.}

One of the most common topics of discussion during the interviews was the power of the health department's governing body. Very often this discussion arose in conjunction with the popular issue of smoke-free ordinances or regulations that are currently being imposed in Kentucky by fiscal courts and boards of health, respectively. Establishing smoke-free community ordinances has reduced the incidence of acute cardiovascular events (Sargent, Shepard, \& Glantz, 2004). Hence health departments around Kentucky have encouraged fiscal courts to establish smoke-free ordinances or boards of health to issue regulations mandating smoke-free workplaces. According to the interviewees, some fiscal court members, because they are elected officials, are often reluctant to risk alienating voters who may be opposed to a smoke-free law, so the board 
of health in a community has imposed a regulation to protect the public's health. According to the local health department administrative manual:

The governing board [of health] must: Assure that the services provided meet the needs of the local citizenry, to protect and promote public health. Establish priorities and objectives based on a community assessment and resources of the agency for: Service delivery, considering federal and state disease prevention and health promotion objectives; and Specific health and safety needs of the community. [italics added] ("Board of Health Requirements," 2001).

Therefore, it is the duty of the board of health or other governing body to assure that the community's health is protected and promoted. The board of health is not an elected body; it is appointed by the Secretary of the Kentucky Cabinet for Health and Family Services based on local nominations. Directors reported that, if the chairperson of the board was the judge executive, an elected official, and they or their constituents were opposed to smoke-free laws, the board might not act on, or consider a regulation.

Tobacco issues were not the only examples cited. The metro council in one area chose not to pursue a ban on trans fats in restaurants, although research suggests that trans fats may be linked to cardiovascular health (Lands, 2005). In another county, a board of health chairperson attempted to block the delivery of family planning services to clients on moral grounds despite this being a funded public health service. Directors cited times when a member of a board put personal opinion ahead of accepted public health practice. This appeared to 
be an issue of concern to several directors; however, none of the interviewees expressed a willingness to confront the governing body.

Several directors in counties without a smoke-free policy spoke about the dilemma they faced because they were aware of the health dangers posed by smoking and secondhand smoke. They knew that smoke-free workplaces were good for the community, but the board of health was their supervisory body and had hired them and had the power terminate them. This situation caused several of the directors to say that they would not pursue issues that they knew were good for the community, but bad for their own employment status. This may be a barrier to the health department's advocacy to improve the community's health, and it might be avoided if the boards of health understand and embrace their duty to promote health.

\section{Community attitudes about the functions of public health.}

A related potential obstacle to advocacy is the influence a community's views about personal rights and the role of public health has on the work of the health department. This may be a barrier if the director knows or instinctively 'feels' that the community would be opposed to a policy, even if it would advance or improve the public's health. Several directors reported experiencing this. Again, the most commonly mentioned topic was a community's opposition to smoke-free regulation and community members' interpretation of public health's policy development function as a violation of an individual's personal freedom.

A public health department, that is, the staff and the board of health, has the obligation to act in the best interest of the community's health. Policy 
decisions can be made with this obligation in mind. When property rights or personal freedoms enter the discussion, the health department can reiterate the functions of public health to assess, assure and promote good health based on sound research. The advocacy skills of framing and messaging can be instrumental in making this case. So, too can carefully composed public education campaigns implemented by the health department's health education program.

\section{The directors' lack of clarity regarding advocacy and lobbying.}

There was occasional confusion over the role of the health department director in showing support for and promoting specific policies. This lack of clarity appeared to be a barrier to the health department's advocacy activities. Although the directors expressed the most uncertainty about whether speaking to policy makers about specific legislation was lobbying, at times the interviewees used the word advocacy and said that they couldn't advocate due to their positions as government employees. When I probed about the exact wording of the rule that defined and prohibited specific actions, none of the respondents were able to produce a document, although the source of the prohibition was variously mentioned as the administrative manual or a statute.

One director said that health departments were bound by the same ethics to which the members of the administration adhered and that the ethics rules precluded lobbying. Another director forwarded an email to me from the Kentucky Public Health Association leadership. The email contained a reference to the prohibition against employees working on partisan political campaigns. This is 
consistent with the federal Hatch Act, a law that prohibits any one receiving federal funding from working on a partisan campaign.

The confusion over lobbying, advocacy and what was allowed and disallowed did not stop seven of the directors from expressing an opinion to policymakers about specific legislation; however, this barrier may have been the reason other respondents did not do so. If health department practitioners are not allowed to lobby, it can be beneficial for them to be aware of the source and wording of this policy. Additionally, all health department practitioners who develop and promote policy should understand the difference between advocacy and lobbying in order to maximize their effectiveness and to utilize acceptable skills.

\section{Directors' personalities and priorities for the health departments.}

Although a clear definition of what is and is not acceptable advocacy for public health practitioners may elucidate the parameters for some of the directors I interviewed, others were not likely to actively promote policy change due to a professed lack of desire or enthusiasm for policy work. Yet others held the belief that setting policies is not the best way to improve the health of their community. None of the directors expressed a lack of concern or respect for the community's health. Rather, it seemed that some directors thought that advocacy was not a function of the health department. Others said policy development was the duty of the board of health, and others indicated that developing policies was not how change was made in some communities. This dichotomy between the 
recommendations of the Ten Essential Public Health Services and how some directors discussed advocacy was evident.

\section{Partners opposed to policies.}

Although community partners were often mentioned by the interviewees as being instrumental in advancing public health issues, occasionally partners appeared to be potential barriers to making progress in areas like tobacco control. In some counties with considerable methamphetamine or prescription drug abuse problems, partners were interested in working on these issues and not on tobacco control. According to the interviewees, this was not because the community partners did not perceive tobacco to be a harmful substance, but rather, in comparison to drugs, tobacco was less harmful. Drug use was a more pressing issue in those communities and required the advocacy efforts.

\section{Lack of funding for advocacy.}

In Holtrop, Price and Boardley's study (2000), the health departments' advocacy was limited, in part, by the amount of time and money available. In my interviews with health department directors, these factors were mentioned as barriers, although not with great frequency. One director presented the irony that health departments are tasked with developing and promoting policies but are primarily funded to provide health services. If this is true, it may be because health services are reimbursable through Medicaid funding, and health departments rely on this source of revenue. Health promotion activities that require advocacy are funded through grants such as the Preventive Health Services Block Grant from the Centers for Disease Control and Prevention or the 
Master Settlement Tobacco funds both of which are dwindling rather than increasing (E. Russell, personal communication, July 25, 2011).

Funding and time are closely linked. Like other studies' subjects (Deokar, et al., 2009; Holtrop, et al., 2000; Thompson, et al., 2009), two of the directors interviewed for this study also mentioned lack of time as a barrier. Health department directors are administrators and those with large staffs have many personnel issues to attend to. Those directors in small counties may have responsibility for more than administrative tasks. In fact, one of the directors reported that he performs environmental services for the health department in addition to his administrative duties.

According to the health advocates interviewed, relationship building was essential for effective advocacy, but advocacy takes time that may not be available to the directors depending on other duties. Funding dedicated to advocacy activities by directors or other appropriate staff may provide the resources that are lacking currently in some health departments.

\section{Summary of Barriers}

The results of the interviews suggest that the barriers to public health advocacy are a governing body that does not support certain public health issues, community attitudes that, at times, thwart public health efforts, characteristics of the director, unsupportive partners and insufficient funding. Just as a supportive governing body was an enabling factor, the unsupportive or oppositional board of health or council can be an obstacle for a director who is supervised by that body. This lack of advocacy can have a detrimental impact on 
the health of the community. If the members appointed to protect the public's health will not issue a regulation or create or support a policy that would create a healthier place for the residents, community members may suffer.

Likewise it is incongruous if the health department director does not advocate to the governing body and other policymakers for policies and systems that protect and promote health. Whether this incongruity is due to confusion over the role of the director in advocacy, or if it is due to a disinclination to advocate, without that leadership, residents may be negatively impacted. The ultimate outcome might be a population with poor health and an undesirable environment that does not attract new residents or social capital.

The policymakers interviewed for this study expressed the desire to hear from their public health practitioners. Additionally, several of the directors acknowledged they should do more to inform their policymakers. If policy development is a priority for public health, funding could be dedicated to this work. Regular communication among the director, the governing body or other policymakers, and the entire community can recognize and support the primary role of the health departments - t o make decisions based on sound public health science.

There are limitations to every study, and this one is no exception. In the next section, I will present these limitations.

\section{Limitations}

A limitation is that the interviews yielded self-reported results, and the accuracy of the data is presumed. Also, according to Creswell (1994) one of the 
measures of the trustworthiness of a study is triangulation or multiple methods of data collection. For a qualitative study in which data is collected by interview, triangulation can occur through observation. To add to the validity or trustworthiness of the interviews of health department directors I could have observed the work of the directors and strengthened the findings. Additionally, I could have conducted interviews with other community members or policymakers to affirm the accuracy of the directors' responses.

An influence on the accuracy of the directors' responses may have been the influence of current or future health department accreditation and/or grant requirements. Some Kentucky health departments are preparing for or involved in accreditation processes that require them to promote policies to improve community health. Moreover, current directives from the Centers for Disease Control and other funding organizations direct grantees to promote policy changes; therefore, some respondents may have felt pressure to overstate their advocacy work in order to appear compliant with these requirements.

As with any qualitative research, I cannot generalize responses beyond the small sample of directors interviewed. Finally, although I offered a brief definition of each advocacy skill, directors may have answered my questions based on their own definition of an advocacy skill.

A potential limitation on the accuracy of the directors' responses was the fact that I am employed by an organization that funds advocacy efforts. Although as part of my protocol, I announced to each interviewee that my work as a program officer at a health foundation that funds advocacy activity had no 
bearing or connection with my research, the interviewees may have deduced that I would prefer to hear positive answers about advocacy and therefore responded in that manner. However, I did not perceive that this was the case. Some of the directors acknowledged that they neither developed nor changed policies. This acknowledgment may indicate that my position as a program officer was not a limitation.

\section{Strengths}

Just as there are limitations to studies, there are strengths. The strengths of this study included the qualitative design, the purposeful sampling and the fact that I have experience working in the public health system in Kentucky.

By conducting interviews rather than surveys of policymakers, advocates, and directors, I believe I was able to obtain a clearer understanding of the advocacy process, the effective skills and the factors that enabled and inhibited public health advocacy. The face-to-face, semi-structured, recorded interviews I conducted afforded me and the interviewee the time to discuss many subjects related to the health department structure, staff, governance and priorities. Additionally, after I transcribed the interview, I was able read and review the transcripts to identify common responses.

Although the sampling was not random, the purposeful sampling was a potential strength. I intentionally requested interviews from health directors who administered a variety of different types of local health departments. The invitees were from each geographic region of the Commonwealth and represented urban and rural health populations. The health department structures were single 
county and district health departments. Moreover I chose to invite a variety of directors with different lengths of tenure. Their gender, race and the size of their staffs and populations served also were diverse.

Finally, I believe the fact that I, the interviewer, had experience as a public health educator facilitated the rapport with the directors and those advocates who also had worked in public health. Kentucky is not a large state, and professional networks are often close-knit. The public health system is no different. The fact that I had first hand knowledge of public health practice in Kentucky may have caused some interviewees to be more candid than they may have been with another interviewer.

\section{Implications and Recommendations}

\section{Implications.}

Based upon the findings of this study, there are potential implications for the public health system in Kentucky and the individuals, agencies and organizations affected by them. Public health practitioners can use the results and recommendations of the study to evaluate their own advocacy efforts. I identified the enabling factors so they can be a guide to best practices for public health advocates. Conversely, health departments, boards of health and public health partners can see opportunities to overcome the barriers identified in this study. Additionally, all members of the extended public health system, led by the local health departments can promote strong public health policies that protect the health of all Kentuckians. Finally, national public health organizations that are 
responsible for defining competencies and offering trainings to public health practitioners may use these results to help develop future offerings.

Although the extended public health system consists of more than just the local health departments and DPH, the majority of my interviewees were local health department directors. Therefore, most of my recommendations are limited to public health dept practitioners and those closely associated with their work.

\section{Recommendations.}

\section{Health department directors.}

The results are the basis for several recommendations for local health departments. Local health departments can be the voice of authority and a source of data driven information regarding public health practice. Directors, with the approval and support of their boards of health, can develop and support policies based solely on what research indicates is best for the health of the local community. These matters may include statewide policies; however board of health members can provide the director with the support necessary to take a stance regarding local policies affecting the community.

This recommendation does not mean that the health department director or the staff must take the lead for all policy campaigns and efforts to improve the health of the community. The results of the interviews indicated that partnerships on campaigns to improve health or services often can have successful impact when multiple stakeholders work together. Indeed, the results demonstrate that for issues that are potentially contentious in a community, building a critical mass of support has been shown to be an effective strategy to resolve a conflict 
surrounding a policy solution. Moreover, the health department can use its position as a public health authority to speak out to advance a cause when it is appropriate and strategically timed.

Health department directors often advocate for, and sometimes lobby for the funding necessary to continue to serve as the provider of public health services in their communities. When interviewed, many of them were passionate about the need for funding in order to provide a health care system for community members. However, the directors often discriminated between the need for services and the need for a healthy environment. To make needed changes in the community, they will need to show the same enthusiasm to promote clean air; adequate food sources and opportunities for healthy behaviors for all as they currently do for adequate funding for health care services.

Finally, local health department directors should have staff skilled in public health competencies. More students in Kentucky are entering the public health workforce with graduate degrees in public health. Directors can delegate advocacy to these prepared individuals when appropriate.

\section{Governing bodies.}

The health department's governance body can be composed of individuals who 1) understand the tenets of public health, including the Ten Essential Public Health Services that health departments are expected to perform; 2) understand their responsibility to develop regulations and support existing regulations that provide a safe, clean and healthful environment, including adequate access to 
fundamental healthcare and an environment that supports healthful living; 3) accept without political bias the responsibilities mentioned above.

It is a responsibility of the board, of course, is to hire a director who is grounded in public health principles and who can and will suggest and support the policies that will provide the community with needed programs and services in a fiscally responsible manner. The board's duties are well served if the board chairperson pursues policies that meet the health needs of the community regardless of other influences.

The Kentucky Department for Public Health.

Local health departments, despite being independent organizations, look to the state Department for Public Health (DPH) for guidance and direction in addition to fiscal support. Many directors expect DPH to provide the local health departments with clear positions, messages and accurate information regarding the pursuit of public health policies that impact local and statewide health concerns.

Based on the responses of the health department directors, many are unsure of the propriety, ethics and even the legality of their advocacy efforts. Therefore they sometimes do not take a position on issues of public health concern. The Department for Public Health or the Cabinet for Health and Family Services (CHFS) can provide a bright line so that the health department practitioners can know what they legally can and cannot do.

The Department for Public Health offers an orientation for Board of Health members on the Training Finder Real-time Affiliated Integrated Network (TRAIN) 
electronic website (Davis, 2010). This training can be made available and can be required periodically of all board members. Additionally, directors could be provided with a definitive statement regarding the parameters of health department directors' and the boards' of health communication with policymakers and their staffs on specific legislation. Some health department directors reported that they were unsure about the propriety of their advocacy for (or against) specific legislation regarding public health issues. New directors especially could be offered this information in a clearly written or verbal form.

\section{Kentucky health department associations.}

The Kentucky Public Health Association (KPHA) publishes and disseminates a policy platform each year stating the position of the organization on a variety of issues. Additionally, KPHA issues alerts to members regarding these positions and encourages the association's members to act on the alerts by contacting their policymakers. Either KPHA or the Kentucky Health Department Association (KHDA), an organization composed of most health department directors, can offer orientation sessions for new or established health department directors, especially around the issue of advocacy and what is acceptable and expected behavior.

National public health organizations, too, can provide advocacy training at their annual meetings or by webinars and conference calls. National advocacy organizations such as Alliance for Justice, the Public Policy Institute and others are available to provide technical assistance to organizations and agencies that advocate for or develop health policies. 


\section{Funders.}

Government agencies and other health funders can provide guidance and fiscal support for advocacy related to evidence-based public health efforts. According to statements made by some directors, it may be beneficial for health departments and funders to have a contractual agreement to advocate for policy work.

\section{Partners.}

Community partners such as the University of Kentucky Extension agents, providers such as hospitals, non-profit health agencies and advocacy organizations often employ advocacy skills for their specific goals. When these goals are in accord with the work of health departments, these organizations can support the advocacy of local health departments.

\section{Additional research.}

This study informs the field of public health advocacy by identifying the self-reported advocacy skills that health department directors utilize to promote public health policies. However, the study also points to additional research that can further advance this work. For instance, in order to triangulate the data collected, the public health practitioners interviewed and their staffs can be observed to verify that the skills directors have reported are practiced.

The work of boards of health can be observed and actions documented to determine if the boards are promoting policies that protect the communities' health. Additionally, a survey of boards of health members could be conducted to determine the members' interpretations of the roles and responsibilities of the 
position. An additional study of the governing bodies could be conducted regarding the members' attitudes and beliefs about the role of the health departments in policy development and advocacy.

Additionally, directors, health educators and environmentalists have been identified in this study as being the staff members that most often use advocacy skills to promote public health policies. A study could be conducted to identify the advocacy competencies that are required by the merit system job classification system for each of these positions. Additionally, a survey could be conducted to determine what type of advocacy training these individuals received prior to or during their employment with the local health department. The results of this research could identify the training needs of the health department practitioners who are responsible for health policy advocacy.

Because directors identified lack of funding for advocacy work as a barrier, a comparison could be made of what type of advocacy skills grantors require of health departments and how much funding is provided for that work.

\section{Conclusions}

Through public health advocacy, local health department practitioners can promote and protect the health of the communities they are tasked with serving by supporting sustainable health policies. I interviewed health policymakers and advocates to identify effective and appropriate public health advocacy skills.

Subsequently, I interviewed 18 Kentucky health department directors to determine what factors enable or impede employing their identified skills. These conclusions are based solely on the responses I received from the policymakers, 
advocates and health department directors I interviewed from February to April of 2011. They are not generalizable to other health department directors in Kentucky or elsewhere. These findings suggest many implications for ways the public health system in Kentucky could be improved to enhance the practice of advocating for policy development and change resulting in better health for the communities served by local health departments. 


\section{REFERENCES}

Acosta, C. M. (2003). Improving public health through policy advocacy. CommunityBased Public Health (Vol. 8).

Administrative Reference for Local Health Departments. (2011). Frankfort, KY.

Affordable Care Act. (2010). The Patient Protection and Affordable Care Act.

Washington, DC: Retrieved from http://democrats.senate.gov/reform/patientprotection-affordable-care-act-as-passed.pdf.

Airhihenbuwa, C. O., Cottrell, R. R., Adeyanju, M., Auld, M. E., Lysoby, L., \& Smith, B. J. (2005). The National Health Educator Competencies Update Project: celebrating a milestone and recommending next steps to the profession. Health Education \& Behavior: The Official Publication of the Society for Public Health Education, 32(6), 722-724.

Alliance for Justice. (2003). Worry-free lobbying for non-profits. Retrieved November 20, 2010, http://www.afj.org/assets/resources/resources2/Worry-Free-Lobbyingfor-Nonprofits.pdf

Alliance for Justice. (2005). Build your advocacy grantmaking - Advocacy evaluation tool. Washington, DC.

Alpi, K. M. (2007). We are all public health, Editorial, Journal of the Medical Library Association, pp. 229-231. Retrieved from http://search.ebscohost.com/login.aspx?direct=true \&db=aph\&AN=26019289\&sit $\underline{\mathrm{e}=\text { ehost-live }}$

American Heart Association. (2009). American Heart Association website Retrieved $11 / 20 / 09,2009$, from http://www.americanheart.org/presenter.jhtml?identifier $=4670$

American Public Health Association. (n.d.). American Public Health Association Retrieved 9/1/10, from http://www.apha.org

American Society of Law, (n.d.). Retrieved September 19, 2010, from http://www.aslme.org

Association of Schools of Public Health. (n.d.-a). MPH Core Competencies, from http://www.asph.org/document.cfm?page $=851$

Association of Schools of Public Health. (n.d.-b). What is public health, from http://www.whatispublichealth.org

Auld, E. M., Galer-Unti, R. A., Radius, S., \& Miner, K. R. (2003). Making the grade in public health advocacy. American Journal of Public Health, 93(12), 1984-1985.

Badovinac, K. (1997). Policy advocacy for public health practitioners: Workshops on policy change. Public Health Nursing, 14(5), 6.

Bassett, M. T. (2003). Public Health Advocacy. [Editorial]. American Journal of Public Health, 93(8), 3. 
Bell, J., \& Standish, M. (2005). Communities and health policy: A pathway for change. [Article]. Health Affairs, 24(2), 339-342. doi: 10.1377/hlthaff.24.2.339

Board of Health Requirements (2001).

Breton, E., Richard, L., \& Gagnon, F. (2007). The role of health education in the policy change process: Lessons from tobacco control. Critical Public Health, 17(4), 14.

Bull, M. J., \& Miller, J. F. (2008). Preparing teacher-scholars to reduce health disparities. Nursing Education Perspectives, 29(3), 5.

Burris, S., Wagenaar, A. C., Swanson, J., Ibrahim, J. K., Wood, J., \& Mello, M. M. (2010). Making the case for laws that improve health: A framework for public health law research. Milbank Quarterly (Vol. 88, pp. 169-210): Milbank Memorial Fund.

Butterfoss, F. D., \& Cohen, L. (2009). Prevention works. Health Promotion Practice, 10, $81 \mathrm{~S}-85 \mathrm{~S}$.

Caira, N. M., Lachenmayr, S., Sheinfeld, J., Goodhart, F. W., Cancialosi, L., \& Lewis, C. (2003). The health educator's role in advocacy and policy; principles, processes, programs, and partnerships. Health Promotion Practice, 4(3), 10.

Centers for Disease Control and Prevention. (1994). The ten essential public health services. Retrieved from http://www.cdc.gov/od/ocphp/nphpsp/EssentialPHServices.htm

Chapman, S. (2004). Advocacy for public health: A primer. Journal of epidemiological community health, 58,6 .

Cheadle, A., Hsu, C., Schwartz, P. M., Pearson, D., Greenwald, H. P., Beery, W. L., Casey, M. C. (2008). Involving local health departments in community health partnerships: evaluation results from the partnership for the public's health initiative. Journal of Urban Health: Bulletin of The New York Academy of Medicine, 85(2), 162-177.

Committee on Assuring the Health of the Public. (2002). The future of public health in the 21st Century: National Academy of Sciences.

Creswell, J. W. (1994). Research design: Qualitative \& quantitative approaches. Thousand Oaks, CA: Sage Publications.

Crosier, S. (2009). John Snow: The London cholera epidemic of 1854. Retrieved July 10, 2010 from: http://www.csiss.org/classics/content/8

Dahlgren, G., \& Whitehead, M. (1991). Policies and strategies to promote social equity in health. Stockholm: Institute for the Future Studies.

Davis, S. (Producer). (2010, 7/24/11). Board of health orientation. Retrieved from http://kennect.chfs.ky.gov/viewerportal/vmc/home.vp?programId=esc program:1 $\underline{202}$

Degutis, L. (2008). The future of public health: Where do we go from here?, Nation's Health, pp. 3-3. Retrieved from http://search.ebscohost.com/login.aspx?direct=true \&db=aph\&AN=35032702\&sit $\mathrm{e}=$ ehost-live

Demers, A. R., \& Mamary, E. (2008). Assessing the professional development needs of public health educators in light of changing competencies. Preventing Chronic Disease Public Health Research, Practice and Policy, 5(4), 6.

Deokar, A., Mattingly, J., \& Phillips, S. (2008). Kentucky public health leadership institute Project. Frankfort, KY. 
Deokar, A., Mattingly, J., \& Phillips, S. (2009). Health educators literate in policy for Kentucky. Final Changemaster Project. Kentucky Public Health Leadership Institute.

DePoy, E., \& Gitlin, L. N. (1993). Introduction to research: Multiple strategies for health and human services. St. Louis, MO: Mosby.

DePoy, E., \& Gitlin, L. N. (2005). Introduction to research: Understanding and applying multiple strategies. St. Louis, MO: Elsevier Mosby.

Directors of Health Promotion and Education. (n.d.). Tools for shaping public policy. Retrieved July 7, 2010, 2010, from http://www.dhpe.org/ToolsLaws.htm

Duties of Local Health Departments (2005).

Edelman, L. (Writer). (2008). Unnatural causes. In L. Edelman (Producer), Unnatural Causes. United States

El-Askari, G., \& Walton, S. (2006). Local government and resident collaboration to improve health. In M. Minkler (Ed.), Community organizing and community building for health (2nd ed.). New Brunswick, NJ: Rutgers University Press.

Elder, J. P., Edwards, C. C., \& Conway, T. L. (1997). Tobacco control. In F. D. Scutchfield \& C. W. Keck (Eds.), Principles of public health practice. Albany, New York: Delmar Publishing.

Fee, E. (1997). History and development of public health. In F. D. Scutchfield \& C. W. Keck (Eds.), Principles of public health practice. Albany, New York: Delmar Publishing.

Flynn, L., \& Verma, S. (2008). Fundamental components of a curriculum for residents in health advocacy. Medical Teacher, 30, 6 .

Foege, W. H. (1994). Public health without the barriers Leadership in public health. New York, NY: Milbank Memorial Fund.

Galer-Unti, R. A. (2009). Guerilla advocacy: Using aggressive marketing techniques for health policy change. Health Promotion Practice, 10(3), 325-327. doi: $10.1177 / 1524839909334513$

Gebbie, K., \& Hwang, I. (2000). Preparing currently employed public health nurses for changes in the health system. American Journal of Public Health, 90(5), 6.

Gilmore, G. D., Olsen, L. K., Taub, A., \& Connell, D. (2005). Overview of the National Health Educator Competencies Update Project. Health Education \& Behavior, $32(6), 13$.

Goldstein, H. (2009). Translating research into public policy. Journal Of Public Health Policy, 30 Suppl 1, S16-S20.

Gorden, R. L. (1992). Basic interviewing skills. Itasca, IL: F.R. Peacock Publishers, Inc.

Grantmakers in Health. (2004). The path to policy change. Washington, DC.

Grantmakers in Health. (2005). Funding health advocacy. Washington, DC.

Green, J., \& Thorogood, N. (2009). Qualitative methods for health research (2nd ed.). London, England: Sage Publications.

Hancock, T., \& Minkler, M. (2005). Community health assessment or healthy community assessment: Whose community? Whose health? Whose assessment?

Hearne, S. A. (2008). Practice-based teaching for health policy action and advocacy. Public health reports, 123, 6 .

Hoefer, R. (2005). Altering state policy: Interest group effectiveness among state level advocacy groups. Social Work, 50(3), 9. 
Holtrop, J. S., Price, J. H., \& Boardley, D. J. (2000). Public policy involvement by health educators. [Article]. American Journal of Health Behavior, 24(2), 132.

Institute of Medicine. (1988). The future of public health. Washington, DC: National Academy Press.

Institute of Medicine. (2003). Who will keep the public healthy? Educating public health professionals for the 21st century. Washington, DC: National Academies Press.

Kerlinger, F. N. (1986). Foundations of behavioral research. New York: Holt, Rinehart \& Winston.

Klitzman, S., Kass, D., \& Freudenberg, N. (2006). Coalition building to prevent childhood lead poisoning: A case study from New York City. In M. Minkler (Ed.), Community organizing and community building for health. New Brunswick, NJ: Rutgers University Press.

Kromm, J. N., Frattaroli, S., Vernick, J. S., \& Teret, S. P. (2009). Law and the public's health: Public health advocacy in the courts. [Article]. Public Health Reports, 124(6), 889-894.

Lands, W. E. M. (2005). Learning how membrane fatty acids affect cardiovascular integrity. Journal of Membrane Biology, 206(2), 75-83. doi: 10.1007/s00232005-0785-0

Mail, P. (2006a). Editorial. American Journal of Public Health.

Mail, P. (2006b). We each have a part to play in public health advocacy, Editorial, Nation's Health, pp. 3-3. Retrieved from http://search.ebscohost.com/login.aspx?direct=true\&db=aph\&AN=21372986\&sit e=ehost-live

McCracken, G. (1988). The long interview. Newbury Park, CA: Sage Publications.

McKnight, J. L., \& Kretzman, J. P. (2005). Discovering community power. Retrieved from http://author.liveunited.org/clc/upload/Asset_Based_Community_Development Guide 1A7.pdf

McLeroy, K. R., Bibeau, D., Steckler, A., \& Glanz, K. (1988). An ecological perspective on health promotion programs. Health Education \& Behavior, 15(4), 351-377. doi: 10.1177/109019818801500401

Milio, N. (1981). Promoting health through public policy. Philadelphia: F.A. Davis Company.

Milio, N. (2001). Glossary: Healthy public policy. Epidemiology and Community Health, $55,2$.

Minkler, M., (Ed.), Community organizing and community building for health. New Brunswick, NJ: Rutgers University Press. (Reprinted from: 2nd).

Minkler, M., \& Wallerstein, N. (2006). Improving health through community organizaton and community building: A health education perspective. In M. Minkler (Ed.), Community organizing and community building for health. New Brunswick, NJ: Rutgers University Press.

Moyer, B., McAllister, J., Finley, M. L., \& Soifer, S. (2001). Doing democracy: The map model for organizing social movements. British Columbia, Canada: New Society Publishers. 
National Commission for Health Education Credentialing. (n.d.). Responsibilities and competencies for health educators Retrieved June 2, 2010, from http://www.nchec.org/credentialing/responsibilities/

Northridge, M. E. (2003). Partnering to advance public health: Making a difference through government, community, business, and academic vocations, Editorial, American Journal of Public Health, pp. 1205-1206. Retrieved from http://search.ebscohost.com/login.aspx?direct=true\&db=aph\&AN=10595955\&sit $\mathrm{e}=$ ehost-live

O'Connell, B. (1994). People power: Service, advocacy, empowerment. New York, NY: Foundation Center.

Partnership for the Public's Health. (2007). Strategies for building community public health partnerships.

Patton, M. Q. (2002). Qualitative Research and Evaluation Methods (3rd. ed.). Thousand Oaks, CA: Sage Publications.

Pfizer (Ed.). (2006). Milestones in public health: Accomplishments in public health over the last 100 years. New York, NY: Pfizer Global Pharmaceuticals.

Powers and Duties of County, City-county, and District Health Boards (2005).

Public Health Foundation. (n.d.). Core competencies for public health professionals Retrieved June 2, 2010, 2010, from http://www.phf.org/link/corecompetencies.htm

Rayens, M. K., York, N. L., Adkins, S. L., Kaufman, E. L., \& Hahn, E. J. (2011). Political climate and smoke-free laws in rural communities.

Regidor, E., de la Fuente, L., Gutierrez-Fisac, J. L., de Mateo, S., Pascual, C., SanchezPaya, J., \& Ronda, E. (2007). The role of the public health official in comunicating public health information. American Journal of Public Health, Supplement 1, 5.

Richards, E. P., \& Rathbun, K. C. (1997). The legal basis for public health. In F. D. Scutchfield \& C. W. Keck (Eds.), Principles of public health practice. Albany, NY: Delmar Publishers.

Rovniak, L. S., \& Johnson. (2006). Reducing the gap between the economic costs of tobacco and funds for tobacco training in schools of public health. Public Health Reports, 121(September - October), 9.

Rowe, K. M., Roe, K., Carpenter, C. G., \& Sibley, C. B. (2000). Community building through empowering evaluation: A case study of community planning for HIV prevention. Community Planning for HIV Prevention, 16.

Rowitz, L. (2001). Public health leadership: Putting principles into practice. Gaithersburg, MD: Aspen Publishers.

Saldana, J. (2009). The coding manual for qualitative researchers. Thousand Oaks, CA: Sage Publications Ltd.

Sargent, R. P., Shepard, R. M., \& Glantz, S. A. (2004). Reduced incidence of admissions for myocardial infarction associated with public smoking ban: Before and after study. British Medical Journal, 328(April 24, 2004).

Schmid, T. L., Pratt, M., \& Howze, E. (1995). Policy as intervention: Environmental and policy approaches to the prevention of cardiovascular disease. American Journal of Public Health, 85(9), 5. 
Scutchfield, F. D., \& Keck, C. W. (1997). Concepts and definitions of public health practice. In B. Burgower (Ed.), Principles of Public Health Practices (1st ed., pp. 3-9). Albany, NY: Delmar Publishing.

Scutchfield, F. D., \& Keck, C. W. (2003). Concepts and definitions of public health practice. In B. Burgower (Ed.), Principles of Public Health Practices (2nd ed., pp. 3-9). Albany, NY: Delmar Publishing.

Seamans, P. (2010). The long road to success: advocating for public policy change. North Carolina Medical Journal, 71(1), 79-83.

Servaes, J., \& Malikhao, P. (2010). Advocacy strategies for health communication. [Article]. Public Relations Review, 36(1), 42-49. doi: 10.1016/j.pubrev.2009.08.017

Silver, L. (2010). Obesity prevention and the use of law: How far can localities go? Paper presented at the Using law, policy and research to improve the public's health, Atlanta, GA. http://www.aslme.org/PHLConference2010/index.html

Sokols, D. (1996). Translating social ecological theory into guidelines for community health promotion. American Journal of Health Promotion, 10(4), 16.

Thomas, J. C., Sage, M., Dillenberg, J., \& Guillory, J. (2002). A code of ethics for public health. American Journal of Public Health, 92(7), 3.

Thompson, A., Boardley, D., Kerr, D., Greene, T., \& Jenkins, M. (2009). Public Policy Involvement by Health Commissioners. J Community Health. doi: 10.1007/s10900-009-9158-4 [doi]

Turnock, B. J. (2001). Public health: What it is and how it works. Gaithersburg, MD: Aspen Publishers.

U.S. Dept. of Health and Human Services. (n.d.). The public health workforce: An agenda for the 21 st century Public Health Functions Project: Department for Health and Human Services.

U.S. Office of Special Counsel. (n.d.). About the Hatch Act Retrieved November 20, 2010, from http://www.osc.gov/haStateLocalwhoiscovered.htm

University of Kansas. (2009). The community toolbox: Our model of practice: Building capacity for community and system change, from http://ctb.ku.edu/en/tablecontents/section_1002.htm

Vernick, J. S. (1999). Lobbying and advocacy for the public's health: what are the limits for nonprofit organizations? American Journal of Public Health, 89(9), 14251429.

Wallack, L., Dorfman, L., Jernigan, D., \& Themba, M. (1993). Media advoacy and public health: Power for prevention. Thousand Oaks, CA: Sage.

Wandersman, A., Goodman, R. M., \& Butterfoss, F. D. (2006). Understanding coalitions and how they operate as organizations. In M. Minkler (Ed.), Community organizing and community building for health. New Brunswick, NJ: Rutgers University Press.

Weed, D. L., \& Mink, P. J. (2002). Roles and responsibilities of epidemiologists. Annals of Epidemiology, 12, 6.

Williams-Crowe, S. M., \& Aultman, T. V. (1994). State health agencies and the legislative policy process. [Article]. Public Health Reports, 109(3), 361.

World Health Organization. (1986). The Ottawa Charter for health promotion. Ottawa, Canada: World Health Organization. 


\section{Appendix A}

\section{Text of Email to Public Health Advocates}

Dear

I am completing my PhD in Health Promotion and Behavioral Sciences in the School of Public and Information Sciences at the University of Louisville under the direction of Dr. Richard Wilson, the chairman of my dissertation committee. I have completed my course work and am currently performing research for my dissertation. As a former health department health educator in western Kentucky, I have retained my interest in the work of local health departments and the work they do in communities. Because of this and a current interest in health policy, I have chosen to study public health advocacy.

The topic of my study is barriers and enabling factors related to public health advocacy. I plan to interview local health department directors about their advocacy activities. First, I would like to discuss effective health advocacy skills employed by successful health advocates like you.

I would greatly appreciate it if you would participate in my research by agreeing to be interviewed about your work as an advocate. I plan to interview other Kentucky health advocates, also. If you agree, please reply to this email, and I will provide additional information about potential dates and times. Please be assured that this is unrelated to my current employment with the Foundation for a Healthy Kentucky, but is an educational endeavor I have been pursuing.

Gratefully,

Joan Buchar 


\section{Appendix B}

\section{Text of Email to Kentucky Policymakers}

Dear

I am completing my PhD in Health Promotion and Behavioral Sciences in the School of Public and Information Sciences at the University of Louisville. I have completed my course work and am currently performing research for my dissertation. As a former health department health educator in western Kentucky, I have retained my interest in the work of local health departments and the work they do in communities. Because of this, and due to a current interest in health policy, I have chosen to study public health advocacy for my dissertation.

The topic of my study is: barriers and enabling factors related to public health advocacy. I plan to interview local health department directors about their advocacy activities. First, I would like to discuss effective health advocacy skills with a small group of policymakers.

I understand how busy you are at this time of year, but I would greatly appreciate it if you would participate in my research by agreeing to be part of a small focus group of health policymakers. I will follow this email with your assistant at the Legislative Research Commission to receive your response.

If you agree to be part of this focus group, I will provide additional information about potential dates, times and a location. The focus group will last no more than 60 minutes in order to make efficient use of your time. Please feel free to contact me through this email address or by phone: $270-210-9472$.

Gratefully,

Joan Buchar 
Appendix C

\title{
Letter to Policymakers
}

\author{
Joan Buchar \\ 1733 Chichester Avenue \\ Louisville, KY 40205 \\ February 20, 2011
}

Honorable

702 Capitol Avenue 351C

Frankfort, Kentucky 40601

Representative

I am completing my PhD in Health Promotion and Behavioral Sciences in the School of Public and Information Sciences at the University of Louisville. I have completed my course work and am currently performing research for my dissertation. As a former health department health educator in western Kentucky, I have retained my interest in the work of local health departments and the work they do in communities. Because of this, and due to a current interest in health policy, I have chosen to study public health advocacy for my dissertation.

The topic of my study is: barriers and enabling factors related to public health advocacy. I plan to interview local health department directors about their advocacy activities. First, I would like to discuss effective health advocacy skills with a few policymakers familiar with health issues.

I understand how busy you are at this time of year, but I would greatly appreciate it if you would participate in my research by agreeing to a short interview about health advocacy by public health practitioners. I will contact your assistant at the Legislative Research Commission to receive your response.

If you agree to the interview, I will provide additional information about potential dates, times and a location. The interview will last no more than 40 minutes in order to make efficient use of your time. Please feel free to contact me by email: Jmbuchar@gmail.com or by phone: 270-210-9472.

Respectfully,

Joan Buchar 


\section{Appendix D \\ Advocates' Interview Script and Suggested Questions* Joan Buchar}

I am currently collecting data for my dissertation in public health at the University of Louisville. I am also a program officer for the Foundation for a Healthy Kentucky. However, my school work is not related to my work at the Foundation, and no information I gather in this focus group will be attributed to you and shared with the Foundation staff or its boards and committees.

I am interested in understanding the barriers and factors that enable health advocacy as described by local health department directors here in Kentucky. I would like to know how you, based on your experience as advocates, view advocacy. I would also like to know your opinion of which skills are appropriate for local health department practitioners to apply. See the list of skills at the bottom of page.

- Would you tell me how you define health advocacy?

- In your work as an advocate, tell me which of these skills is most effective: Why?

- Tell me about a successful public health advocacy campaign you have worked on and the skills you used to advance it.

- In today's advocacy environment, is there anything you would change if you were designing that campaign today?

- Are there any of these advocacy skills that public health workers should not apply? Why?

- If I would like to assemble a diverse group of policy makers who are familiar with public health issues such as smoke-free workplaces, healthy communities and schools (although not necessarily in favor of these issues), who would you recommend? 


\section{Appendix E}

\section{Policymakers' Script and Interview Questions}

I am currently collecting data for my dissertation in public health at the University of Louisville. I am also a program officer for the Foundation for a Healthy Kentucky. However, my school work is not related to my work at the Foundation, and no information I gather in this focus group will be attributed to you and shared with the Foundation staff or its boards and committees.

I am interested in understanding the barriers and factors that enable health advocacy described by local health department directors here in Kentucky.

- Would you tell me how you define health advocacy?

- In your work as a policy maker, tell me which of these skills used by advocates is most effective: Why?

- Tell me about a successful public health advocacy campaign and the skills the advocates used to advance it.

- Tell me about an unsuccessful public health advocacy campaign and the skills the advocates used. Why did it not succeed?

- Are you often contacted by local health department practitioners regarding a public health issue?

- Are there any of these advocacy skills that public health workers should not apply? Why? 


\section{Appendix F}

\section{Text of Email to Health Department Directors}

Dear

I am completing my $\mathrm{PhD}$ in Health Promotion and Behavioral Sciences in the School of Public Health and Information Sciences at the University of Louisville. I have completed my course work and am currently performing research for my dissertation. As a former health department health educator in western Kentucky, I have retained my interest in the work of local health departments and the work they do in communities. Because of this and a current interest in health policy, I have chosen to study public health advocacy.

The topic of my study is barriers and enabling factors related to public health advocacy. I plan to interview local health department directors about their advocacy activities. The topic of my study is public health advocacy I plan to interview local health department directors about advocacy activities being done as part of the health department's activities.

I would greatly appreciate it if you would participate in my research by granting me an interview. My research will comply with all of the University of Louisville's Institutional Review Board's policies, and your privacy will be protected.

If you agree, please reply to this email, and I will provide additional information about potential dates and times. Please be assured that this is unrelated to my current employment, but is an educational endeavor I have been pursuing. You can reach me my email or phone 270-210-9472.

Gratefully,

Joan Buchar 


\section{Appendix G}

\section{Interviewee's Consent Form \\ Subject Informed Consent Document}

\section{THE BARRIERS AND ENABLING FACTORS TO PUBLIC HEALTH ADVOCACY SKILLS IN KENTUCKY LOCAL HEALTH DEPARTMENTS}

Investigator(s) name \& address: Richard Wilson, $575 \mathrm{E}$. Gray Street, School of Public Health and Information Sciences, Louisville, KY 42002

Site(s) where study is to be conducted: Various, in Kentucky - likely at local health departments.

Phone number for subjects to call for questions: $270-210-9472$

\section{Introduction and Background Information}

You are invited to participate in a research study. The study is being conducted by Richard Wilson, DHSc and Joan Buchar, $\mathrm{PhD}$ (c). The study is sponsored by the University of Louisville, Department of Health Promotion and Behavioral Studies. The study will take place at various locations in Kentucky.

Approximately 35 subjects will be invited to participate.

\section{Purpose}

The purpose of this study is to identify the advocacy activities of local health department directors and what make this advocacy possible and what inhibits this activity.

\section{Procedures}

In this study, you will be asked to agree to be interviewed for approximately 1 hour. The interview questions will be focused on advocacy activities and your experience either as an advocate or as a policymaker. The study should end by May 1,2011 . You may decline to answer any questions that may make you uncomfortable.

Potential Risks

There are no foreseeable risks, although there may be unforeseen risks.

\section{Benefits}

The possible benefits of this study include identifying the barriers to public health advocacy and understanding how public health policy advocacy is enabled. The 
information collected may not benefit you directly. The information learned in this study may be helpful to others.

\section{Confidentiality}

Total privacy cannot be guaranteed. Your privacy will be protected to the extent permitted by law. If the results from this study are published, your name will not be made public. While unlikely, the following may look at the study records:

The University of Louisville Institutional Review Board, Human Subjects Protection Program Office.

Office for Human Research Protections (OHRP),

Office of Civil Rights

The data collected will be kept in a password protected computer and any hard copies will be kept in a locked cabinet in my (Joan Buchar's) office in my private residence. I am the only person who has access to this office.

\section{Conflict of Interest}

This study does not involve a conflict of interest.

\section{Voluntary Participation}

Taking part in this study is voluntary. You may choose not to take part at all. If you decide to be in this study you may stop taking part at any time. If you decide not to be in this study or if you stop taking part at any time, you will not lose any benefits for which you may qualify.

You will be told about any changes that may affect your decision to continue in the study.

\section{Research Subject's Rights, Questions, Concerns, and Complaints}

If you have any concerns or complaints about the study or the study staff, you have three options.

You may contact the principal investigator at 502-852-3443.

If you have any questions about your rights as a study subject, questions, concerns or complaints, you may call the Human Subjects Protection Program Office (HSPPO) (502) 852-5188. You may discuss any questions about your rights as a subject, in secret, with a member of the Institutional Review Board (IRB) or the HSPPO staff. The IRB is an independent committee composed of members of the University 
community, staff of the institutions, as well as lay members of the community not connected with these institutions. The IRB has reviewed this study.

If you want to speak to a person outside the University, you may call 1877-852-1167. You will be given the chance to talk about any questions, concerns or complaints in secret. This is a 24 hour hot line answered by people who do not work at the University of Louisville.

This paper tells you what will happen during the study if you choose to take part. Your signature means that this study has been discussed with you, that your questions have been answered, and that you will take part in the study. This informed consent document is not a contract. You are not giving up any legal rights by signing this informed consent document. You will be given a signed copy of this paper to keep for your records.

Signature of Subject/Legal Representative

Date Signed

Signature of Person Explaining the Consent Form (if other than the Investigator)

Date Signed

Signature of Investigator

Date Signed

LIST OF INVESTIGATORS:

Richard Wilson, DHSc 502-852-3443

Joan Buchar, PhD@ 270-210-9472 


\section{Appendix H}

\section{SCRIPT AND QUESTIONS GUIDING DIRECTORS' INTERVIEWS}

Thank you for agreeing to let me interview you. As you know, I am Joan Buchar, and I am a PhD candidate at University of Louisville in the School of Public Health. My dissertation is investigating health advocacy at local health departments in Kentucky. You may or may not know that I work as a program officer for the Foundation for a Healthy Kentucky in Louisville. It is statewide health philanthropy. I want to make clear that my dissertation in no way is related to the work I do for the Foundation. The Foundation does not direct my research, and I am not pursuing this topic at its request. Also, I want to assure you that your responses during this interview will not be associated with your identity. I will use codes to identify the interviewees so your identity will be protected. Do you have any questions about that?

Well, again, thanks. I understand that much of the public health funding from the Centers for Disease Control and Prevention that is directed at health education and promotion efforts required that health department practitioners work at the policy level, and use advocacy for policy solutions to public health problems. Therefore, I would like to learn how this is being done at the local health department.

- Can you tell me a little about the health department?

- How long have you been the director?

- Can you tell me about the administrative body (fiscal court, Board of Health)?

- Can you tell me what a typical day is like for you?*

- What's the best part of your job? What do you enjoy the most?*

- How do you define health promotion?*

- How much of the health department's work would you describe as health promotion?

- What public health issues are most often promoted?*

- Could you tell me how you define advocacy?* 
- Here is a list of activities that are commonly thought to be advocacy skills.

Tell me how any of these are used during your work as director of the health department?

- Of the skills you employ, tell me why you use these skills.

- Of the skills you employ, tell me HOW you use these skills**.

- Are there any of these skills you do not employ?*

- Can you tell me why you choose not to use these skills?*

- Is there anything else you'd like to add?

- Can I call you if I need anything clarified?

- What are your health department's priorities?**

- What issue would you most like to advance**

Thank you so much. Please feel free to call me if you want to ask anything or if there is something you would like to add.

* Deleted from final script

** Added to final script 


\section{CURRICULUM VITAE}

\section{JOAN BUCHAR, PhD, MPH, CHES}

\section{Summary of Qualifications}

Experienced promoter of public health through educational programming, teaching, grant writing, and consulting. Effective written and oral presenter with an understanding of diverse populations and health conditions. Developed and taught curricula as a college professor and designed a variety of workshops and presentations for conventions, meetings, and community groups. Contributed to health science education, literacy, and health knowledge through professional leadership and community involvement.

Education and Certifications

WESTERN KENTUCKY UNIVERSITY, Bowling Green, KY 2004

Master of Public Health

- Thesis: 'A Comparison of Students', Parents' and School Personnel Perceptions Regarding Bullying Behaviors"

- Relevant Courses: Evaluation of Public Health Programs, Administration of Public Health Programs, Research Methods, Biostatistics, Epidemiology, Health Behavior, Violence Prevention, and Legal and Ethical Issues in Healthcare Management.

SOUTHERN ILLINOIS UNIVERSITY, Carbondale, IL

Master of Science in Education

SOUTHERN ILLINOIS UNIVERSITY, Carbondale, IL

Bachelor of Arts in Biological Sciences

\section{KENTUCKY PUBLIC HEALTH FELLOW}

CERTIFIED HEALTH EDUCATION SPECIALIST - received highest national test score.

Provisional Kentucky teaching certification in reading and biology. 


\section{Professional Experience}

FOUNDATION FOR A HEALTHY KENTUCKY, LOUISVILLE, KY

2006 -

Senior Program Officer

- Administers grant initiatives for advocacy and Coordinated School Health

- Coordinates Foundation's advocacy agenda

- Produces Foundation's e-newsletter

- Collaborates with statewide, regional and local agencies and organizations

PURCHASE AREA HEALTH EDUCATION CTR, Murray State Univ. Murray, KY $1998-2006$

Education Coordinator

- Organized and taught hands-on health education and health science classroom activities, teacher workshops, individual education and academic camps

- Managed grant-writing activities

- Coordinated community diabetes education grant project

- Consulted with local schools on Coordinated School Health programs

- Consulted with local health departments and community based organization on community health surveys, health education and health promotion activities

PURCHASE DISTRICT HEALTH DEPARTMENT, Mayfield, KY

$1992-1998$

Health Education Coordinator

- Promoted community health by managing education and related services for a seven-county public health department.

- Supervised three senior health educators.

- Wrote grants and educational curricula on a variety of health education topics

- Participated in community health survey

- Represented health department on various community based organization boards

THE FINAL DRAFT, Summerville, KY

$1989-1992$

Owner

- Operated a desktop publishing company specializing in the design, development, and production of newsletters, brochures, manuals, and numerous other publications.

CHARLESTON SOUTHERN UNIVERSITY, Charleston, SC

$1980-1992$

Adjunct Professor, Computer Science, 1986-1992

- Taught Computer Literacy, a course covering word processing, file and spreadsheet programs, and BASIC programming for all liberal arts majors. 
Assistant Professor, Foundation Studies, 1980-1986

- Taught Educational Psychology, Human Growth and Development, Children's Literature, Computer Literacy, and Foundation Studies Writing.

- Led a reading and study skills class benefiting high-risk college freshmen.

- Developed a skills laboratory.

- Facilitated grant activities to increase female and minority involvement in natural and physical science programs.

- Provided academic advising.

SOUTHERN ILLINOIS UNIVERSITY, Carbondale, IL

Visiting Instructor, MEDPREP Program, 1978-1979

$1975-1979$

- Taught reading and writing courses for remedial students.

- Designed self-study vocabulary and writing classes.

- Organized a test-taking workshop for the Medical College Admission Test.

- Assisted in writing a grant proposal to increase program funding.

Professional and Community Affiliations

- Kentucky Cancer Program Advisory Board 1993-2005

- Kids Company Too, Family Resource Center 1995-2006

- CDC Preventative Health Block Grant Advisory Committee (Kentucky)

- Lone Oak High School Site-Based Council 1999-2000

- Hendron Lone Oak School Site-Based Council 1993-1994

- American Public Health Association

- Kentucky Public Health Association

- Society of Public Health Educators

\section{Publications}

- Comprehensive School Health, The Advocate - Kentucky School Board Journal, 1996

- Simulated Laparoscopic Surgery in the Middle and High School Classrooms, Surgical Technologist, 2002

- Published numerous articles in the Paducah Sun from 1993 to 1998 on various health topics.

- Published opinion editorials in Louisville Courier Journal and Lexington Herald Leader 2006-2010

\section{Presentations}

- "Healthy, Well, and Wise - Developing and Implementing a Teacher Workshop," given at the National AHEC convention, Baltimore, MD, 2004 
- "Healthy, Well, and Wise," Kentucky Department of Education Teacher's Academy, 2003.

- "Hands-on Activities for Teaching Health," given at the National Area Health Education Center Organization (NAO), Little Rock, AR, 2002.

- "The Health Belief Model in the Time of Bioterrorism," given at the Society for Public Health Educators mid-year conference, Cincinnati, $\mathrm{OH}, 2002$.

- "Hands-on Health," Kentucky AHEC meeting, Bowling Green, KY, 2001.

- "Hands-on-Science" Kentucky Teaching and Learning Conference in Louisville, KY, 1999.

- Citizens and Healthcare: The role of public deliberation in reviewing health care options American Public Health Association Conference, Nov. 2006. Boston, MA.

- KYA Medicaid Monitoring Project kickoff event - 10-05-06

- American Public Health Association's meeting -11-07-06

- Kentucky Health Department Director's meeting - 1-16-2007

- West Kentucky Children's Health Coalition meeting -1-29-2007

- Presented at Sharefest Advocacy Expo - 3-22-2007

- Regional Coordinator's meeting for Partnership for a Fit Kentucky 608-07

References will be provided on request. 